IS- T -469

\title{
ELECTRON TRANSFER REACTIONS OF FERROCENE
}

Ph. D. Thesis Submitted to Iowa State University, August 1971

John R. Pladziewicz

Ames Laboratory, USAEC

Iowa State University

Ames, Iowa 50010

Date Transmitted: September 1971

PREPARED FOR THE U. S. ATOMIC ENERGY COMMISSION DIVISION OF RESEARCH UNDER CONTRACT NO. W-7405-eng-82

This report was prepared as an account of work sponsored by the United States Government. Neither the United States nor the United States Atomic Energy Commission, nor any of their employees, nor any of their contractors, subcontractors, or their employees, makes any warranty, express or implied, or assumes any legal liability or responsibility for the accuracy, completeness or usefulness of any information, apparatus, product or process disclosed, or represents that its use would not infringe privately owned rights. 


\section{DISCLAIMER}

This report was prepared as an account of work sponsored by an agency of the United States Government. Neither the United States Government nor any agency Thereof, nor any of their employees, makes any warranty, express or implied, or assumes any legal liability or responsibility for the accuracy, completeness, or usefulness of any information, apparatus, product, or process disclosed, or represents that its use would not infringe privately owned rights. Reference herein to any specific commercial product, process, or service by trade name, trademark, manufacturer, or otherwise does not necessarily constitute or imply its endorsement, recommendation, or favoring by the United States Government or any agency thereof. The views and opinions of authors expressed herein do not necessarily state or reflect those of the United States Government or any agency thereof. 


\section{DISCLAIMER}

Portions of this document may be illegible in electronic image products. Images are produced from the best available original document. 
IS-T -469

\section{NOTICE}

This report was prepared as an account of work sponsored by the United States Government. Neither the United States nor the United States Atomic Energy Commission, nor any of their empluyees, rivi any of their contractors, subcontractors, or their employees, makes any warranty, express or implied, or assumes any legal liability or responsibillty for the accuracy, completeness or usefulness of any information, apparatus, product or process disclosed, or represents that its use would not infringe privately owned rights.

Available from: National Technical Information Service Department $A$

Springfield, VA 22151

Price: Mịcrofiche $\$ 0.95$ 
Electron transfer reactions of ferrocene

by

John R. Pladziewicz

A Dissertation Submitted to the

Graduate Faculty in Partial Fulfillment of

The Requirements for the Degree of

DOCTOR OF PHILOSOPHY

Major Subject: Inorganic Chemistry

Approved:

$\frac{\text { Sames A. Sepereph }}{\text { to Charge of Major Work }}$

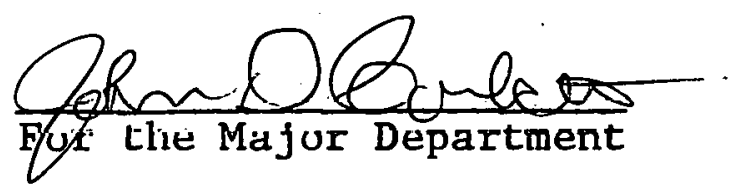

$\frac{\text { Chollt it E Rodunck }}{\text { For the Graduate College }}$

Iowa State University

Ames, Iowa

August 1971 
TABLE OF CONTENTS

INTRODUCTION

$\begin{array}{ll}\text { EXPERIMENTAL SECTION } & 8\end{array}$

Reagents $\quad$ r

Equipment 20

Methods, Procedures, and Data Treatment̀ 22

RESULTS 36

Formal Electrode Potential Measurements 36

Iron(III)-Ferrocene Reactions $\quad 42$

Ferrocene-Ferricenium Electron Transfer 48

Reactions

Chromium(VI)-Ferrocene Reaction 49

INTERPRETATION AND DISCUSSION 64

Ferrocene-Ferricenium Ion Reactions $\quad 64$

Iron(III)-Ferrocene Reactions 75

Ferrocene-Chromium(VI) Reaction . 81

APPENDIX $\quad 83$

Exchange Rate Solution to the Marcus Equation 83

$\begin{array}{lll}\text { BIBLIOGRAPHY } & 88\end{array}$

ACKNOWLEDGMENI $\quad 91$ 
Electron transfer reactions of ferrocene

John R. Pladziewicz

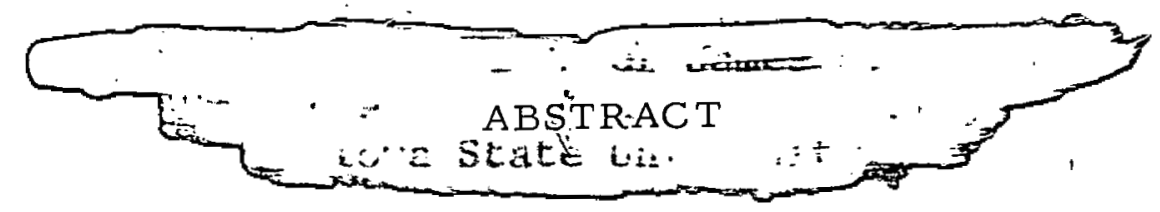

Kinetic studies have been carried out on electrontransfer reactions of eight substituted ferrocenes. The reactions are of three types:

(a) electron transfer between different ferrocenes, as $\mathrm{Fe}\left(\mathrm{C}_{5} \mathrm{H}_{4} \mathrm{R}\right)_{2}+\mathrm{Fe}\left(\mathrm{C}_{5} \mathrm{H}_{5}\right)_{2}^{+}=\mathrm{Fe}\left(\mathrm{C}_{5} \mathrm{H}_{4} \mathrm{R}\right)_{2}^{+}+\mathrm{Fe}\left(\mathrm{C}_{5} \mathrm{H}_{5}\right)_{2}$

(b) oxidation of ferrocenes by iron(III), as $\mathrm{Fe}^{3+}+\mathrm{Fe}\left(\mathrm{C}_{5} \mathrm{H}_{4} \mathrm{R}\right)_{2} \rightarrow \mathrm{Fe}^{2+}+\mathrm{Fe}\left(\mathrm{C}_{5} \mathrm{H}_{4} \mathrm{R}\right)_{2}^{+}$

(c) chromium(VI) oxidation of ferrocene, as $\mathrm{HCrO}_{4}^{-}+7 \mathrm{H}^{+}+3 \mathrm{Fe}\left(\mathrm{C}_{5} \mathrm{H}_{5}\right)_{2} \rightarrow 3 \mathrm{Fe}\left(\mathrm{C}_{5} \mathrm{H}_{5}\right)_{2}^{+}+\mathrm{Cr}^{3+}+4 \mathrm{H}_{2} \mathrm{O}$.

In the first group, rate measurements were made on 22 of the possible 28 combinations. The rate law corresponds to the process in (a), with rate constants $4.2-150 \times 10^{6} \mathrm{M}^{-1} \mathrm{sec}^{-1}$ at $25^{\circ}$ in $1: 1 \mathrm{v} / \mathrm{v} \mathrm{H}_{2} \mathrm{O}$-n-propanol $\mu=0.05 \mathrm{M} \mathrm{Ba}\left(\mathrm{C}_{10}\right)_{2}$. These 22

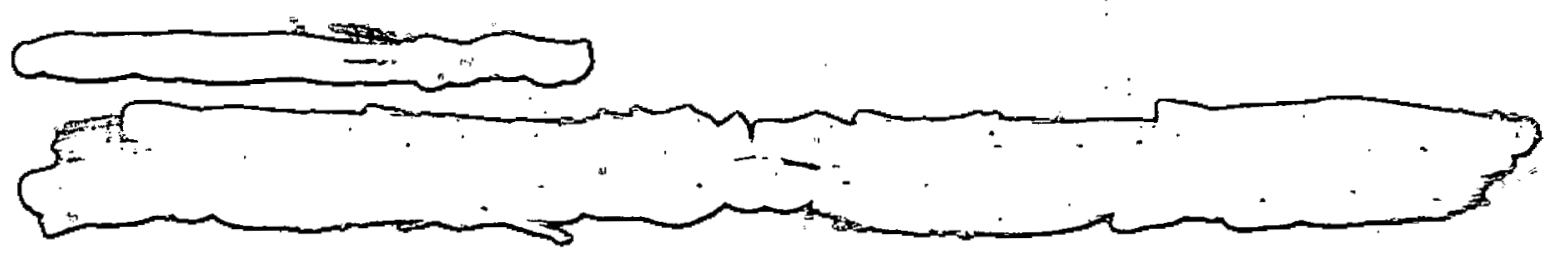




\section{(vi)}

reaction rates were found to correlate quite well with the Marcus equation. From this correlation exchange rates for the ferricenium ion pairs were computed.

The second reaction, which was studied for $\left(\pi-\mathrm{C}_{5} \mathrm{H}_{5}\right)$ $\left(\pi-(3)-1,2-\mathrm{C}_{2} \mathrm{Bg}^{\mathrm{H}} 11\right) \mathrm{Fe}(\mathrm{II})^{-}$as well as for the ferrocenes, has the rate 1 aw $\mathrm{d}\left[\mathrm{Fe}^{2+}\right] / \mathrm{dt}=\mathrm{k}\left[\mathrm{Fe}^{3+}\right]\left[\mathrm{FeCp}_{2}\right]$, with $\mathrm{k}$ between 5.5 . $\times 10^{2}$ and $4.9 \times 10^{6} \mathrm{M}^{-1} \mathrm{sec}^{-1}$ in $1: 1 \mathrm{v} / \mathrm{v} \mathrm{H}_{2} 0$-tetrahydrofuran, $\mu=1.00 \underline{M}\left(\mathrm{LiClO}_{4}\right)$ at $25^{\circ}$. The rates of these reactions were also interpreted in terms of the Marcus equation. For these reactions observed rates were substantially lower than rates calculated from the Marcus equation.

For the third reaction only the oxidation of ferrocene was studied and has the rate $1 \mathrm{aw}-\mathrm{d}[\mathrm{Cr}(\mathrm{VI})] / \mathrm{dt}=\mathrm{k}\left[\mathrm{FeCp}_{2}\right]$ $\left[\mathrm{HCrO}_{4}^{-}\right]\left[\mathrm{H}^{+}\right]$. The value of $\mathrm{k}$ at $25^{\circ} \mathrm{C}$ in $1: 1 \mathrm{v} / \mathrm{v} \mathrm{H}_{2} \mathrm{O}$-acetone $\mu=1.00 \mathrm{M}\left(\mathrm{LiC1O}_{4}\right)$ is $1.01 \pm .04 \times 10^{4} \mathrm{M}^{-2} \mathrm{sec}^{-1}$. A mechanism with three one electron transfer steps is proposed with the first step being rate determining. 


\section{INTRODUCTION}

Attempts to measure electron transfer rates between various ferrocenes and ferricenium ions have been limited to studies of the ferrocene-ferricenium exchange ${ }^{1}$ rate $(1,2 ; 3)$ Eq. 1 .

$$
\stackrel{*}{\mathrm{Fe}}\left(\mathrm{C}_{5} \mathrm{H}_{5}\right)_{2}^{+}+\mathrm{Fe}\left(\mathrm{C}_{5} \mathrm{H}_{5}\right)_{2} \rightleftharpoons \stackrel{*}{\mathrm{Fe}}\left(\mathrm{C}_{5} \mathrm{H}_{5}\right)_{2}+\mathrm{Fe}\left(\mathrm{C}_{5} \mathrm{H}_{5}\right)_{2}^{+}
$$

The methods used in earlier studies have included isotopic exchange $(1,3)$ and nuclear magnetic resonance techniques (2). Only the study by Stranks (3), utilizing isotopic exchange combined with rapid mixing and quenching techniques at very low temperature in methanol, was successful.

of interest to this study is the measurement of the rates of a family of related electron transfer reactions ${ }^{2}$, Eq. 2:

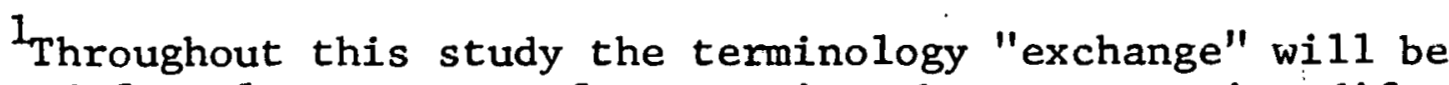
reserved for electron transfer reactions between species differing only by oxidation state, a process which results in no net observable chemical change.

2 The convention will be adopted that all of the reactions are written in the thermodynamically favored direction, in addition rate constants and equilibrium constants will be expressed in $k_{i j}$ and $K_{i j}$ notation respectively, where $i, j$ refer to the numbers $1-8$ assigned the ferrocenes in Table 1 . 


$$
\begin{aligned}
& \left(\mathrm{C}_{5} \mathrm{H}_{4} \mathrm{X}\right) \mathrm{Fe}\left(\mathrm{C}_{5} \mathrm{H}_{4} \mathrm{X}^{\prime}\right)+\left(\mathrm{C}_{5} \mathrm{H}_{4} \mathrm{Y}\right) \mathrm{Fe}\left(\mathrm{C}_{5} \mathrm{H}_{4} \mathrm{Y}^{\prime}\right)+\stackrel{\mathrm{k}_{i j} j}{\rightleftharpoons} \\
& \left(\mathrm{C}_{5} \mathrm{H}_{4} \mathrm{X}\right) \mathrm{Fe}\left(\mathrm{C}_{5} \mathrm{H}_{4} \mathrm{X}^{\prime}\right)^{+}+\left(\mathrm{C}_{5} \mathrm{H}_{4} \mathrm{Y}\right) \mathrm{Fe}\left(\mathrm{C}_{5} \mathrm{H}_{4} \mathrm{Y}^{\prime}\right)
\end{aligned}
$$

and calculations concerning the rates of the corresponding exchange reactions, Eq. 3 .

$$
\begin{array}{r}
\left(\mathrm{C}_{5} \mathrm{H}_{4} \mathrm{X}\right) \stackrel{*}{\mathrm{Fe}}\left(\mathrm{C}_{5} \mathrm{H}_{4} \mathrm{X}^{\prime}\right)^{+}+\left(\mathrm{C}_{5} \mathrm{H}_{4} \mathrm{X}\right) \mathrm{Fe}\left(\mathrm{C}_{5} \mathrm{H}_{4} \mathrm{X}^{\prime}\right) \stackrel{\mathrm{k}_{\mathrm{i} i}}{\rightleftharpoons} \\
\left(\mathrm{C}_{5} \mathrm{H}_{4} \mathrm{X}\right) \stackrel{*}{\mathrm{Fe}}\left(\mathrm{C}_{5} \mathrm{H}_{4} \mathrm{X}^{\prime}\right)+\left(\mathrm{C}_{5} \mathrm{H}_{4} \mathrm{X}\right) \mathrm{Fe}\left(\mathrm{C}_{5} \mathrm{H}_{4} \mathrm{X}^{\prime}\right)^{+}
\end{array}
$$

The electron transfer reactions (Eq. 2), unlike the exchange reactions (Eqs. 1 and 3), lead to net chemical reaction. Consequently, the kinetics can be evaluated by analysis using uv-visible spectrophotometry, for example, without resorting to the rapid quenching and efficient separation techniques required in isotopic exchange studies of these very rapid reactions .

In addition to this group of reactions, two additional kinetic studies have been carried out: (1) a study of the oxidation of ferrocene and certain of its derivatives by iron(III) ions as in Eq. 4, and (2) the oxidation of ferrocene by chromium(VI) as in Eq. 5 .

$$
\begin{aligned}
& \mathrm{Fe}^{3+}+\left(\mathrm{C}_{5} \mathrm{H}_{4} \mathrm{X}\right) \mathrm{Fe}\left(\mathrm{C}_{5} \mathrm{H}_{4} \mathrm{X}^{\prime}\right) \stackrel{\mathrm{k}_{i}}{\rightarrow} \mathrm{Fe}^{2+}+\left(\mathrm{C}_{5} \mathrm{H}_{4} \mathrm{X}\right) \mathrm{Fe}\left(\mathrm{C}_{5} \mathrm{H}_{4} \mathrm{X}^{\prime}\right)^{+} \\
& \mathrm{HCrO}_{4}^{-}+{ }^{+} \mathrm{H}^{+}+3 \mathrm{Fe}\left(\mathrm{C}_{5} \mathrm{H}_{5}\right)_{2} \stackrel{\mathrm{k}}{\rightarrow} \mathrm{Cr}^{3+}+4 \mathrm{H}_{2} \mathrm{O}+3 \mathrm{Fe}\left(\mathrm{C}_{5} \mathrm{H}_{5}\right)_{2}^{+}
\end{aligned}
$$


Except for the one study by Stranks on Eq. 1, no data are in the literature concerning the rates or mechanisms of any of these three classes of reaction. With reference to the work by Stranks a second-order rate for exchange was found with a rate constant of $1.7 \pm 0.4 \times 10^{6} \mathrm{M}^{-1} \mathrm{sec}^{-1}$ at $-70^{\circ} \mathrm{C}$ in methanol. The very high rate of reaction made the measurement quite difficult; the mean half-time for exchange was $2 \pm 0.5 \mathrm{msec}$ at $-70^{\circ} \mathrm{C}$ at $1 \times 10^{-4} \mathrm{M}$ reactant concentrations, while the most rapid mixing and quenching time attainable was $3 \mathrm{msec}$. The present work has been carried out in mixed aqueous-organic solvents, and in every case appropriate stability tests for the reagents have been performed.

The rate constant for reaction 1 ought to be measurable. by proton nmr line-broadening measurements. However, in attempts to do so it was found (2) that the transverse relaxation time of the paramagnetic ferricenium ion was much greater than the average lifetime of ferricenium ion with respect to electron transfer. Hence line broadening was controlled by the transverse relaxation process and only a lower limit could be placed on the specific rate for exchange of $\geq 1 \times 10^{5} \underline{M}^{-1} \sec ^{-1}$.

The motivations and goals of this work can be summarized 
as follows:

(a) To study the oxidation-reduction kinetics of ferrocene, which has been quite neglected. Aside from the exchange study referred to above, only the oxidation of ferrocene by iodine (4), and the reduction of ferricenium ion by $\mathrm{Sn}$ (II) $(5,6)$ have been examined kinetically. It is possible that the paucity of data for the ferrocene-ferricenium ion reactions results from the instability of the ferricenium ions in solution (2), and the difficulty involved with studying reactions that are so rapid (3). However, with judicious choice of compounds and conditions some of these studies can be made (these choices are discussed in the experimental section of this thesis).

(b) In recent years several theoretical models have been developed for electron transfer reactions in homogeneous solution (7). Of these the most often applied model has been that developed by Marcus (8) for outer-sphere electron transfer reactions. In this development Marcus has shown that many. of the quantities which are difficult to estimate for an "a priori" calculation of rate constants cancel when comparing a series of related reactions. As a result Eq. 6 is obtained, 


$$
\begin{aligned}
k_{i j} & =\left(k_{i i} \cdot k_{j j} \cdot k_{i j} \cdot f_{i j}\right)^{\frac{1}{2}} \\
\text { with } \operatorname{lnf} f_{i j} & =\left(\ln k_{i j}\right)^{2} / 4 \ln \left(k_{i i} \cdot k_{j j} / z^{2}\right)
\end{aligned}
$$

where $k_{i j}$ is the rate constant for electron transfer, $k_{i i}$ and $k_{j j}$ are the corresponding electron exchange rate constants, and $Z$ is the collision frequency of two uncharged molecules $\left(10^{11} \mathrm{M}^{-1} \mathrm{sec}^{-1}\right)$. A number of electron transfer reactions have been shown (9-12) to satisfy Eq. 6. These studies have included a series of oxidation-reduction reactions involving iron complexes such as $\mathrm{Fe}\left(\mathrm{OH}_{2}\right)_{6}^{2+}, 3+, \mathrm{Fe}(\mathrm{CN})_{6}^{4-, 3-}, \mathrm{Fe}(\mathrm{phen})-$ $(\mathrm{CN})_{4}^{2-, 1-}, \mathrm{Fe}$ (phen) $2^{(\mathrm{CN})}{ }_{2}^{0,1+}, \mathrm{Fe}(\mathrm{dipy})_{3}^{2+, 3+}, \mathrm{Fe}$ (dipy) ${ }_{2}(\mathrm{CN})_{2}^{0,1+}$, $\mathrm{Fe}(\mathrm{dipy})(\mathrm{CN}){ }_{4}^{2-, 1-}$, and a series of substituted tris-1,10phenanthroline iron complexes. It was of interest in this study to determine if Eq. 6 was also satisfied by the electron transfer reactions of ferrocene, and to see if Eq. 6 could then be used in a predictive sense to calculate as yet unmeasured rate constants. To provide a fair test of Eq. 6 for a series of related reactions the series should cover the widest range of $k_{i j}$ and $k_{i j}$ values possible.

(c) With the hope of learning about the detailed mechanism(s) for electron transfer in the ferrocene compounds several points were investigated. First, to learn if steric requirements were of importance various size substituents 
were used; methyl, n-butyl, phenyl, etc. Second, to determine what effect the geometry of the cyclopentadiene rings play, two "pseudo-ferrocenes" prepared originally by Hawthorne et a1. (13) were reacted; see Figure 1. Third, since it is known that ferricenium ion associated with anions such as triiodide (14) and chloride (15) in solution, and since it appears that association may stabilize ferricenium ion relative to ferrocene (16), some reactions were studied under conditions of added chloride. Also the possibility of a "bridging" ${ }^{1}$ mechanism was investigated by including studies on iodoferrocene and chloromercuriferrocene.

$\mathbb{I}_{\text {This }}$ is not meant to imply a conventional halide ion inner-sphere type of bridge; but rather the possibility of a weak association between an electronegative substituent like I on one ferrocene with the positive charge associated with the iron atom on another ferricenium ion. 
a

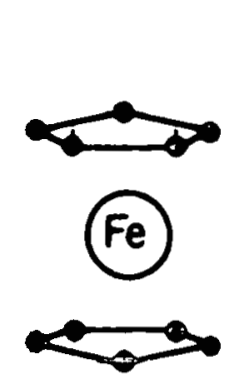

b

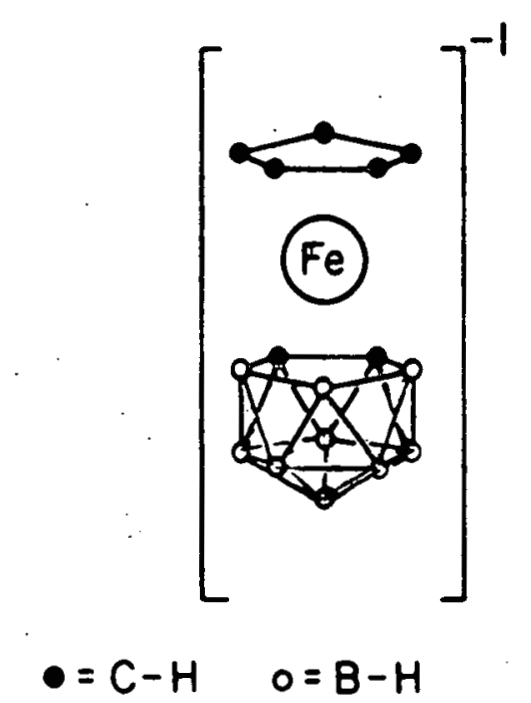

c

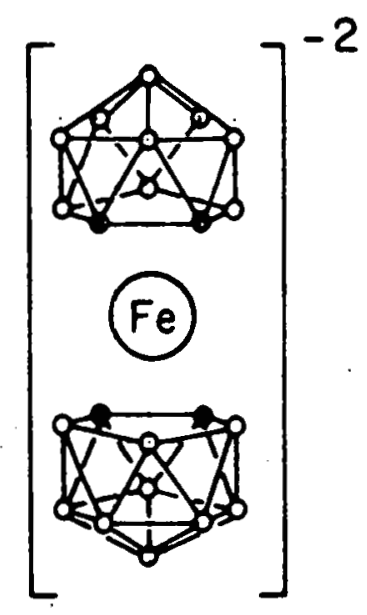

Figure 1. Structures of ferrocene (a) and two "pseudo-ferrocenes" $\pi$-cyclopentadieny 1- $\pi$ - (3)-1,2-dicarbollyliron(II) ion

(b) and bis- $\pi-(3)-1,2-$ dicarbollyliron(II) ion (c) 


\section{EXPERIMENTAL SECTION}

Reagents

\section{Ferrocene derivatives}

A11 the compounds used. in this study were previously known and were either purchased or prepared as described in the literature. 'Ferrocene, $\mathrm{Fe}\left(\mathrm{C}_{5} \mathrm{H}_{5}\right)_{2}$, (Alfa Inorganics) was purified by vacuum sublimation. 1,1'-Dimethylferrocene, $\mathrm{Fe}\left(\mathrm{C}_{5} \mathrm{H}_{4} \mathrm{CH}_{3}\right)_{2}$, (Alfa Inorganics) was recrystallized twice from water-ethanol $(1: 1, v / v)$. 1, 1'-Di-n-butylferrocene, $\mathrm{Fe}\left(\mathrm{C}_{5} \mathrm{H}_{4} \mathrm{C}_{4} \mathrm{H}_{9}\right) 2$, and $\underline{n}$-butylferrocene, Fe $\left(\mathrm{C}_{5} \mathrm{H}_{5}\right)\left(\mathrm{C}_{5} \mathrm{H}_{4} \mathrm{C}_{4} \mathrm{H}_{9}\right)$, (Alfa Inorganics) were used without further purification. Pheny1ferrocene, $\mathrm{Fe}\left(\mathrm{C}_{5} \mathrm{H}_{5}\right)\left(\mathrm{C}_{5} \mathrm{H}_{4} \mathrm{C}_{6} \mathrm{H}_{5}\right)$, was prepared and purified by the method of Weinmayr (17). Iodoferrocene, $\mathrm{Fe}\left(\mathrm{C}_{5} \mathrm{H}_{5}\right)\left(\mathrm{C}_{5} \mathrm{H}_{4} \mathrm{I}\right)$, was prepared and purified as described in the literature (18a). Chloromercuriferrocene, $\mathrm{Fe}\left(\mathrm{C}_{5} \mathrm{H}_{5}\right)\left(\mathrm{C}_{5} \mathrm{H}_{4} \mathrm{HgCl}\right)$, (Research Organic Chemica1) was recrystallized once from acetone. Hydroxymethylferrocene, $\mathrm{Fe}\left(\mathrm{C}_{5} \mathrm{H}_{5}\right)\left(\mathrm{C}_{5} \mathrm{H}_{4} \mathrm{CH}_{2} \mathrm{OH}\right)$, (Research Organic Chemical) was recrystallized twice from "Ske1ly B". Characterization of ferrocene derivatives

The identity and purity of the ferrocene compounds were established by melting point (solids), or refractive index (1iquids), and by visible-uv spectrophotometry in comparison 
with literature values $(17-27)$. In a few cases elemental analyses were also obtained. These results are summarized in Table 1. The MMR spectrum of each compound was also determined and in each case was in agreement with the assumed identity.

The uv-visible spectra of all of the ferrocene derivatives (28a), have been obtained and appear in Table 2; a complete spectrum is given for ferrocene in Figure 2. In addition each ferrocene derivative can be oxidized by iron(III) perchlorate to give the corresponding ferricenium ion (Eq. 4), whose spectrum can then be determined.

The uv-visible spectrum of each ferricenium ion derivative (28b) is also given in Table 3 ; a complete spectrum of ferricenium ion is shown in Figure 2.

All of the ferrocene derivatives, with the exception of iodoferrocene, are quantitatively oxidized by iron(III) in aqueous $\underline{n}$-propanol and dilute perchloric acid (ca. $1 \times 10^{-3} \mathrm{M}$ ). Hence, each ferrocene derivative can be analyzed by a spectrophotometric titration using a standard iron(III) solution at the appropriate wavelength in the $600-700 \mathrm{~nm}$ region. In this region on1y the ferricenium ions absorb; ferrocene, iron(III), and iron(II) have negligible absorbance. In every case the 
Table 1. Characterization of ferrocene derivatives

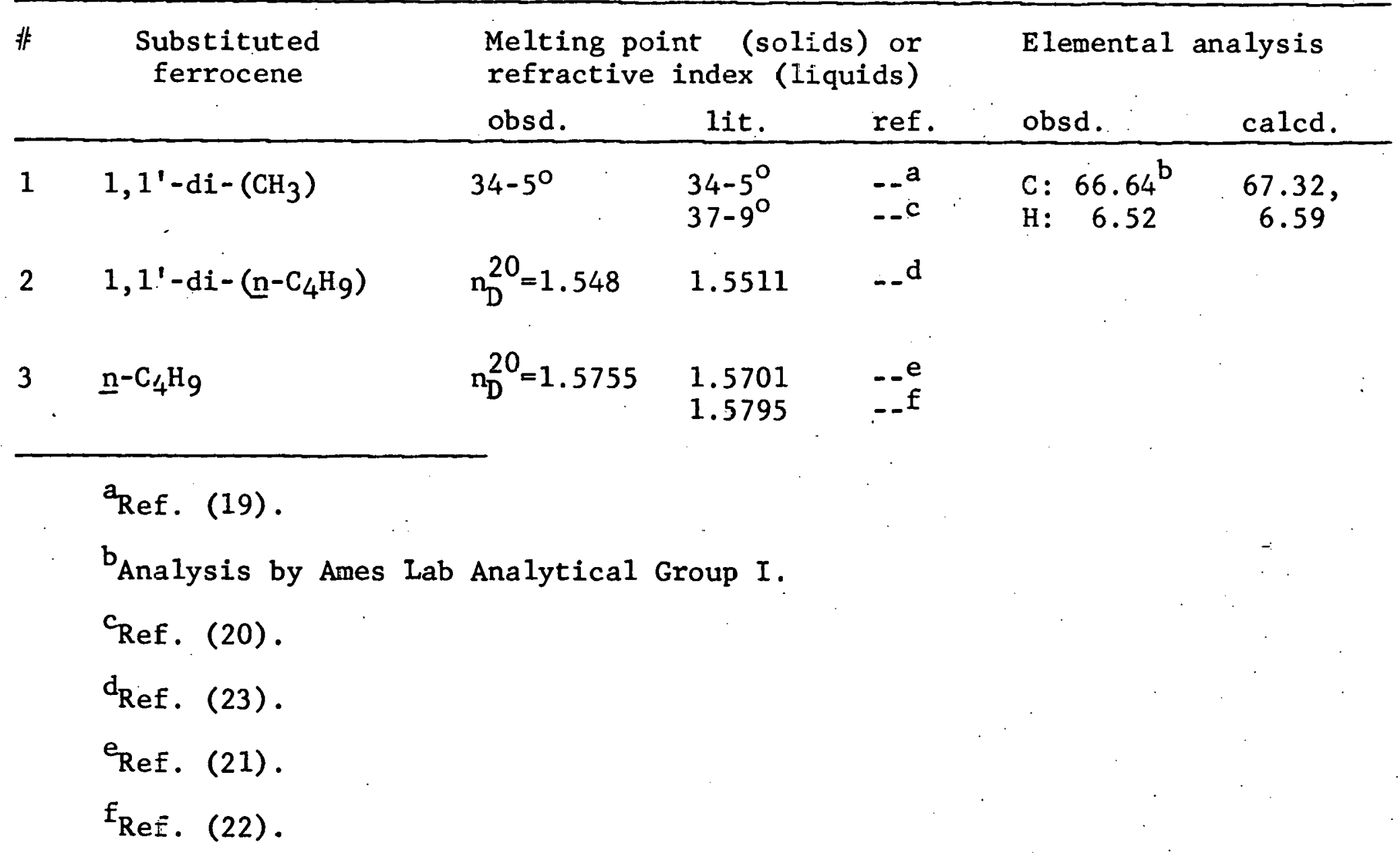


Table 1. (Continued)

\begin{tabular}{|c|c|c|c|c|c|c|}
\hline \multirow[t]{2}{*}{ 非 } & \multirow[t]{2}{*}{$\begin{array}{l}\text { Substituted } \\
\text { ferrocene }\end{array}$} & \multicolumn{3}{|c|}{$\begin{array}{l}\text { Melting point (solids) or } \\
\text { refractive index (liquids) }\end{array}$} & \multicolumn{2}{|c|}{ Elemental analysis } \\
\hline & & obsd. & lit. & ref. & obsd. & calcd. \\
\hline 4 & Ferrocene & $173-4^{\circ}$ & $174^{\circ}$ & --8 & $\begin{array}{l}\mathrm{C}: \quad 64.22^{\mathrm{h}} \\
\mathrm{H}: \quad 5.38\end{array}$ & $\begin{array}{r}64.56 \\
5.42\end{array}$ \\
\hline 5 & $\mathrm{HgCl}$ & $194-6^{\circ}$ & $194-6^{\circ}$ & $--^{i}$ & & \\
\hline 6 & $\mathrm{CH}_{2} \mathrm{OH}$ & $79-80^{\circ}$ & $81-2^{\circ}$ & $\ldots j$ & $\begin{array}{l}\mathrm{C}: \quad 60.95^{\mathrm{h}} \\
\mathrm{H}: \quad 5.52\end{array}$ & $\begin{array}{l}61.15 \\
5.60\end{array}$ \\
\hline 7 & $\mathrm{C}_{6} \mathrm{H}_{5}$ & $110-111^{\circ}$ & $\begin{array}{l}109-110^{\circ} \\
110-111^{\circ}\end{array}$ & $\begin{array}{l}-k \\
--1\end{array}$ & $\begin{array}{l}\mathrm{C}: 73.29^{\mathrm{h}} \\
\mathrm{H}: \quad 5.46\end{array}$ & $\begin{array}{l}73: 31 \\
5.38\end{array}$ \\
\hline 8 & $I$ & $43-4^{\circ}$ & $44-5^{\circ}$ & $--^{m}$ & & \\
\hline
\end{tabular}

$\mathrm{g}_{\text {Ref. (18b). }}$

${ }^{h}$ Averages of results from Chemalytics, Inc., Tempe, Arizona and Ames Lab Analytical Group I, Iowa State University.

$i_{\text {Ref. (24). }}$.

$j_{\text {Ref. (25). }}$.

$k_{\text {Ref. (26). }}$.

$1_{\text {Ref. (17). }}$.

mef. (27). 
Table 2. U.V.-visible spectra of the ferrocene derivatives

\begin{tabular}{|c|c|c|c|}
\hline 非 & & $\lambda_{\max } \mathrm{nm}\left(\varepsilon, \underline{\mathrm{M}}^{-1} \mathrm{~cm}^{-1}\right)$ & Ref. \\
\hline 1 & $1,1^{\prime}-\mathrm{di}-\left(\mathrm{CH}_{3}\right)$ & $\begin{array}{l}240(4140) \mathrm{sh}^{\mathrm{a}} \\
325(80) \\
435(104)\end{array}$ & $--b$ \\
\hline 2 & $1,1^{\prime}-\mathrm{di}-\left(\underline{\mathrm{n}}-\mathrm{C}_{4} \mathrm{H}_{9}\right)$ & $\begin{array}{l}240(4,400) \mathrm{sh}^{\mathrm{a}} \\
325(89) \\
435(112)\end{array}$ &.$- b$ \\
\hline 3 & $\underline{n}-C_{4} H_{9}$ & $\begin{array}{ll}240(3,600) \mathrm{sh}^{\mathrm{a}} \\
325(58) \\
450(100)\end{array}$ & $--b$ \\
\hline 4 & Ferrocene & $\begin{array}{l}240(3,280) \mathrm{sh}^{\mathrm{a}} \\
325(52) \\
440(96)\end{array}$ & $-\mathrm{b}$ \\
\hline 5 & $\mathrm{HgCl}$ & $\begin{array}{l}240(6,840) \mathrm{sh}^{\mathrm{c}} \\
448(160)\end{array}$ & $--\mathrm{b}$ \\
\hline 6 & $\mathrm{CH}_{2} \mathrm{OH}$ & $\begin{array}{l}240(4,940) \mathrm{sh}^{\mathrm{c}} \\
325(100) \mathrm{sh} \\
435(100) \therefore\end{array}$ & $--^{b}$ \\
\hline 7 & $\mathrm{c}_{6^{-}} \mathrm{H}_{5}$ & $\begin{array}{l}238(16,300) \mathrm{sh}^{\mathrm{c}} \\
2.78(10,400) \\
433(344)\end{array}$ & $--b$ \\
\hline & & $\begin{array}{l}237(16,100) \\
277(9,900) \\
447(322) \cdots\end{array}$ & $--d$ \\
\hline
\end{tabular}

${ }^{a}$ Spectrum taken in $1: 1 \mathrm{v} / \mathrm{v}$ water-ethano1.

$\mathrm{b}_{\text {This work. }}$

${ }^{\mathrm{c}}$ Spectrum taken in 1:1 v/v water-n-propanol. $d_{\text {Ref. (17). }}$. 
Table 2. (Continued)

\begin{tabular}{|c|c|c|c|}
\hline 非 & $\begin{array}{l}\text { Substituted } \\
\text { ferrocene }\end{array}$ & $\lambda_{\max } \mathrm{nm}\left(\epsilon, \underline{M}^{-1} \mathrm{~cm}^{-1}\right)$ & Ref. \\
\hline 7 & $\mathrm{C}_{6} \mathrm{H}_{5}$ & $\begin{array}{ll}238 & (17,600) \\
278 & (10,600) \\
310 & \mathrm{sh} \\
447 & (330)\end{array}$ & $\ldots e$ \\
\hline 8 & I & $\begin{array}{l}240(5,200) \mathrm{sh}^{\mathrm{c}} \\
280(2,300) \mathrm{sh} \\
430(188)\end{array}$ & $-{ }^{b}$ \\
\hline
\end{tabular}

e $_{\text {Ref. (28a). }}$ 
Table 3. U.V.-visible spectra of the ferricenium ion derivatives

\begin{tabular}{|c|c|c|c|}
\hline 非 & $\begin{array}{l}\text { Substituted } \\
\text { ferricenium ion }\end{array}$ & $\lambda_{\max } \mathrm{nm}\left(\epsilon, \underline{M}^{-1} \mathrm{~cm}^{-1}\right)$ & Ref. \\
\hline 1 & $1,1^{\prime}-\mathrm{di}-\mathrm{CH}_{3}$ & $\begin{array}{l}257(15,200)^{a} \\
285(10,600) \mathrm{sh} \\
650(332)\end{array}$ & $--b$ \\
\hline 2 & $1,1^{\prime}-\mathrm{di}-\underline{n}-\mathrm{C}_{4} \mathrm{H}_{9}$ & $\begin{array}{l}258(15,400)^{a} \\
285(11,200) \cdot s h \\
650(380)\end{array}$ & $--b$ \\
\hline 3 & $\underline{n}-C_{4} H_{9}$ & $\begin{array}{l}255(15,400)^{\mathrm{a}} \\
280(10,600) \mathrm{sh} \\
625(352)\end{array}$ & $\ldots b$ \\
\hline 4 & Ferricenium ion & $\begin{array}{l}254(16,500)^{\mathrm{a}} \\
280(10,000) \mathrm{sh} \\
380(325) \mathrm{sh} \\
618(450) \\
255((17,000) \\
617(420)\end{array}$ & $--c$ \\
\hline 5 & $\mathrm{HgCl}$ & $\begin{array}{l}254(15,900)^{\mathrm{d}} \\
280(10,700) \mathrm{sh} \\
623(504)\end{array}$ & $--b$ \\
\hline 6 & $\mathrm{CH}_{2} \mathrm{OH}$ & $\begin{array}{l}255(15,200)^{d} \\
285(9,800) \mathrm{sh} \\
627(400)\end{array}$ & $--b$ \\
\hline
\end{tabular}

${ }^{a}$ Spectra taken in $1: 1 \mathrm{v} / \mathrm{v}$ water-ethanol.

$b_{\text {This work. }}$

$c_{\text {Ref. (28b). }}$.

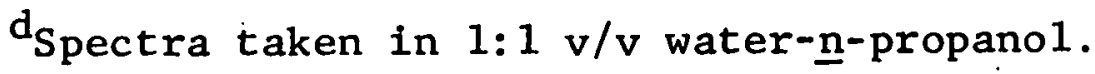


Table 3. (Continued)

\begin{tabular}{llll}
\hline \# & $\begin{array}{c}\text { Substituted } \\
\text { ferricenium ion }\end{array}$ & $\lambda_{\max } \mathrm{nm}\left(\varepsilon, \underline{\mathrm{M}}^{-1} \mathrm{~cm}^{-1}\right)$ & Ref. \\
\hline 7 & $\mathrm{C}_{6} \mathrm{H}_{5}$ & $235(15,500) \mathrm{d}$ & $\ldots \mathrm{b}$ \\
& $250(14,200) \mathrm{sh}$ & \\
& $293(11,400)$ & \\
& $750(521)$ & \\
& & $244(10,250) \mathrm{d}$ & $\mathrm{b}$ \\
& & $255(11,400)$ & \\
& $\mathrm{I}$ & $280(9,000) \mathrm{sh}$ & \\
& & $700(?)$ & \\
& &
\end{tabular}




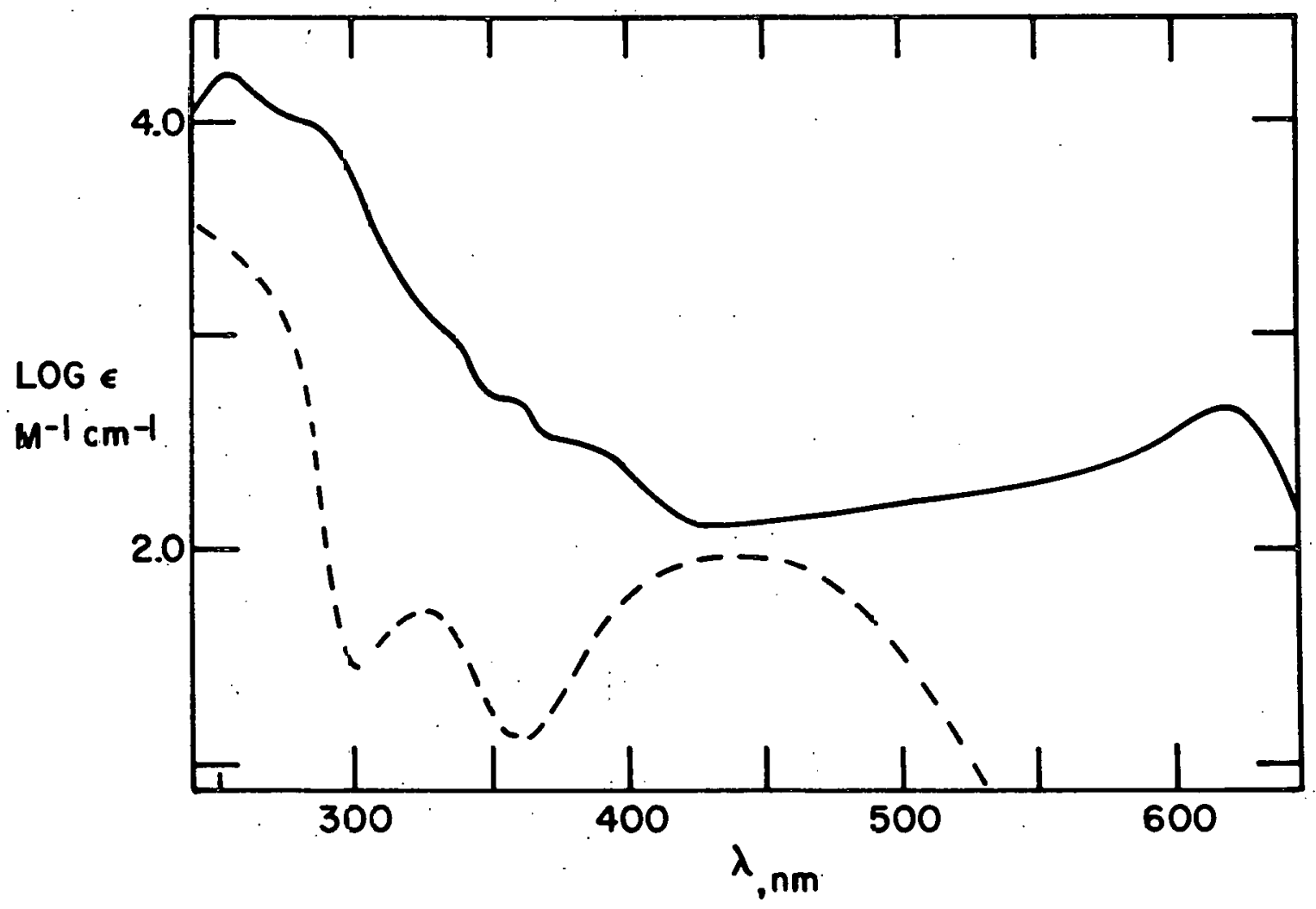

Figure 2. Spectrum for ferrocene (broken 1ine) and ferricenium ion (solid line) in 1:1 v/v water-ethanol 
spectrophotometric titration for ferrocene agreed within $1 \%$ of the weighed amount.

Stability of ferrocene and ferricenium solutions

Stock solutions of the ferrocene derivatives were prepared in several solvents (n-propanol, acetone, $95 \%$ ethanol) and in each case the solution was stable towards oxidation or decomposition over extended periods of time (up to 6 months). This is not a general property of ferrocene compounds, however, and is dependent on the derivative and solvent.

Ferricenium ion derivative solutions are generally much less stable than the corresponding ferrocene compound $(2,18 \mathrm{~b})$. In water-n-propano1; $(1: 1, v / v), \mu=0.050$ (maintained with barium perchlorate), however, all of the ferricenium ion derivatives studied here were stable (i.e., u.v.-visible spectra did not change by more than $3-5 \%$ ) for at least 30 min. This is sufficient time to carry out any of the studies done here. Except for phenylferricenium and iodoferricenium ions, the ferricenium ion derivatives were stable for even longer periods of time. It was generally found that as the oxidation potential of the ferrocene derivative became more negative the stability of the ferricenium ion derivative decreased. Hence, 1,1' dimethylferricenium and ferricenium ions were found to be 
more stable than phenylferricenium and iodoferricenium ion solutions. Many ferrocene derivatives (methylferrocenoate, $\mathrm{Fe}\left(\mathrm{C}_{5} \mathrm{H}_{5}\right)\left(\mathrm{C}_{5} \mathrm{H}_{4} \mathrm{COOCH}_{3}\right)$, ferrocenecarboxylic acid $\left(\mathrm{Fe}\left(\mathrm{C}_{5} \mathrm{H}_{5}\right)\right.$ $\left(\mathrm{C}_{5} \mathrm{H}_{4} \mathrm{COOH}\right)^{\prime}$, ferrocenyl acetic acid, $\mathrm{Fe}\left(\mathrm{C}_{5} \mathrm{H}_{5}\right)\left(\mathrm{C}_{5} \mathrm{H}_{4} \mathrm{CH}_{2} \mathrm{COOH}\right)$, 1,1'-di-iodoferrocene, $\mathrm{Fe}\left(\mathrm{C}_{5} \mathrm{H}_{4} \mathrm{I}\right)_{2}, \mathrm{~N}, \mathrm{~N}$-dimethy laminomethy 1 ferrocene, $\mathrm{Fe}\left(\mathrm{C}_{5} \mathrm{H}_{5}\right)\left(\mathrm{C}_{5} \mathrm{H}_{4} \mathrm{CH}_{2} \mathrm{~N}\left(\mathrm{CH}_{3}\right)_{2}\right)$, benzolyferrocene, $\mathrm{Fe}\left(\mathrm{C}_{5} \mathrm{H}_{5}\right)\left(\mathrm{C}_{5} \mathrm{H}_{4} \mathrm{COC}_{6} \mathrm{H}_{5}\right)$, and ferrocenecarboxaldehyde, $\mathrm{Fe}\left(\mathrm{C}_{5} \mathrm{H}_{5}\right)$ $\left(\mathrm{C}_{5} \mathrm{H}_{4} \mathrm{CHO}\right)$ ) were also found to be oxidized by iron(III) to the blue ferricenium ion derivatives. In each case the blue ferricenium ion solution then decomposed rapidly $(3-300 \mathrm{sec}$ for the compounds cited) making it unsuitable for the studies. of interest here. All of the compounds having ferricenium ion solutions too unstable to study have oxidation potentials near or higher than iodoferrocene $(29,30)$. $\pi$-(3)-1,2-Dicarbollyliron(III) and iron(II) derivatives (31) Bis- $-(3)-1,2-d i c a r b o 11 y l i r o n(I I I)$ and bis- $-(3)-1,2-$ dicarbollyliron(II) were prepared as their tetramethylammonium salts: $\quad\left[\left(\mathrm{CH}_{3}\right)_{4} \mathrm{~N}\right]\left[\pi-(3)-1,2-\mathrm{B}_{9} \mathrm{C}_{2} \mathrm{H}_{11}\right]_{2} \mathrm{Fe}$ and $\left[\left(\mathrm{CH}_{3}\right)_{4} \mathrm{~N}\right]_{2}[\pi-(3)-1$, $2-\mathrm{B}_{9} \mathrm{C}_{2} \mathrm{H}_{11} \mathrm{~J}_{2} \mathrm{Fe}$, and characterized by their uv-visible spectra as given by Hawthorne and co-workers (13). Solvents

Water used in all rate studies, reagent purifications, 
and stock solutions was the product of a double redistillation of laboratory distilled water from alkaline permanganate in a tin-lined Barnstead still. Specific conductance of the water was $\leq 1 \times 10^{-6} \mathrm{ohm}^{-1} \mathrm{~cm}^{-1}$. Baker analyzed reagent grade n-propanol and acetone were used without further purification. Baker analyzed reagent grade tetrahydrofuran (THF) was freshly distilled from a Na-THF mixture which had refluxed for 6-12 hours. THF thus purified was collected and stored under an atmosphere of dry nitrogen, and was used within 6 hours of distillation. Other reagents

Hydrated iron(III) perchlorate was prepared by fuming solutions of the chloride in perchloric acid. The chloridefree iron(III) perchlorate was then recrystallized twice from perchloric acid solution. The iron(III) perchlorate solutions were analyzed by reduction with stannous chloride followed by titration of the iron(II) produced with a standard cerium(IV) solution (32).

Solutions of iron(II) perchlorate were prepared by oxidation of electrolytic iron by perchloric acid under a nitrogen atmosphere.

Nitrogen gas was purified by passage through a series of 
five gas-washing bottles. The first two bottles contained $\mathrm{Cr}^{2+}$ over amalgamated zinc, followed by one bottle containing dilute sodium hydroxide, one bottle containing distilled water, and one empty bottle. Where necessary, this nitrogen was dried by scrubbing with concentrated sulfuric acid followed by a calcium sulfate drying tube.

Hydrated lithium and barlum perchlorate salts were crystallized from solutions prepared by dissolving the carbonate in perchloric acid. The products, twice recrystallized from water, were used to prepare stock solutions which were analyzed by a cation exchange method using Dowex 50W-X8 resin (50-100 mesh) in the hydrogen ion form.

Potassium dichromate, perchloric acid, and sodium chloride were obtained commercially and used without further purification.

\section{Equipment}

Kinetic measurements

Kinetic measurements were carried out using a DurrumGibson D-100 stopped-flow spectrophotometer equipped with a Kel-F mixing system. The output signal of the photomultiplier tube of the spectrophotometer was connected to a Tektronix storage oscilloscope. An oscilloscope trace was electron- 
ically triggered by the spectrophotometer when freshly mixed solutions were in the observation cuvette. The oscilloscope trace was then photographed with a Polaroid camera. The experimental concentrations and wavelengths were adjusted so that the absorbance changes were less than 0.10 absorbance units (more typically 0.02-0.05 absorbance units). When the change in absorbance, $D$, is $\leq 0.10$ absorbance units the absorbance and transmittance are related by the expression, $T \cong 1-2.303$ D. This expression is differentiated with respect to concentration, giving $\partial \mathrm{T} / \partial \mathrm{C} \approx-2.303 \mathrm{\partial D} / \partial \mathrm{C}$. Hence, the change in transmittance with respect to concentration is directly proportional to the change in absorbance with respect to concentration. Consequently the voltage display on the vertical axis of the oscilloscope screen is proportional to absorbance in this limit, and thus to concentration. Formal electrode potential $\left(\mathrm{E}^{\mathrm{O}^{\prime}}\right)$ measurements $\mathrm{E}^{\mathrm{O}^{\prime}}$ measurements were made by potentiometric titration versus a saturated calomel electrode (SCE) using a Leeds and Northrup K-2 potentiometer and galvanometer.

Spectra1 measurements

UV-visible spectral measurements were made with a Cary 14 recording spectrophotometer. NMR measurements were made with a. Perkin-E1mer R-20B spectrometer. 
Methods, Procedures, and Data Treatment

Reaction media

Different solvents and electrolytes were used for each of the three main categories of reactions. Except as otherwise noted in the text, the following conditions apply to all measurements in the different systems:

Ferrocene-ferricenium ion electron transfer reactions: water-n-propanol $\left(1: 1 \mathrm{v} / \mathrm{v} ; \mathrm{z}_{\mathrm{PrOH}}=0.194\right), 0.05 \underline{\mathrm{M}}$ ionic strength provided by barium perchlorate.

Ferrocene-iron(III) reactions: water-tetrahydrofuran $\left(1: 1 \mathrm{v} / \mathrm{v} ; Z_{\mathrm{THF}}=0.180\right), 1.00 \underline{\mathrm{M}}$ ionic strength maintained with lithium perchlorate-perchloric acid, $\left[\mathrm{H}^{+}\right] \geq 0 . \underline{1}$.

Ferrocene-chromium(VI) reaction: water-acetone $(1: 1 \mathrm{v} / \mathrm{v}$; $\left.\mathrm{Z}_{\text {Acetone }}=0.195\right), 1.00 \mathrm{M}$ ionic strength maintained with lithium perchlorate-perchloric acid, $\left[\mathrm{H}^{+}\right] \geq 0.01 \mathrm{M}$. Formal electrode potential measurement

Several methods have been used in previous studies to determine the $\mathrm{E}^{\mathrm{O}^{\prime}}$ values of the ferrocene derivatives $(29,30$, 33,34). Potentiometric titration was one of these methods (33) and was used here.

A typical $\mathrm{E}^{\mathrm{U}^{\prime}}$ titration was done as follows. A ferrocene solution in the desired medium, typically $6 \times 10^{-4} \underline{M}$ in ferro- 
cene, was placed in the titration cell which was then equilibrated at the desired temperature. A standard iron(III) solution was then titrated into the ce11, and the EMF measured potentiometrically.

The Nernst equation is

$$
\mathrm{E}=\mathrm{E}_{\mathrm{FeCp}}^{\mathrm{O}_{2}^{\prime}} / \mathrm{FeCp}_{2}+\mathrm{RT} / \mathrm{nF} \ln \frac{\left[\mathrm{FeCp}_{2}^{+}\right]}{\left[\mathrm{FeCp}_{2}\right]}
$$

where $\mathrm{E}$. is the measured electrode potential vs. $\mathrm{SCE}$ and $\mathrm{FeC}_{2}$ and $\mathrm{FeC}_{\mathrm{p}}^{+}$represent ferrocene and ferricenium ion respectively, for which $n=1$. The following equation is obtained from it:

$$
E=E^{\prime}{ }_{F e C p}^{+} / \mathrm{FeCp}_{2}+R T / F \ln \left[\frac{V_{t} \times N_{t}}{V \times N-v_{t} \times N_{t}}\right]
$$

where $v_{t}$ and $N_{t}$ are volume and normality of titrant respectively and $\mathrm{V}$ and $\mathrm{N}$ are the initial volume and concentration of ferrocene placed in the titration ce11." A plot of E vs. $\ln \left[V_{t} \times N_{t} / V \times N-V_{t} \times N_{t}\right]$ is linear with a slope $R T / F$ and has a value of $\mathrm{E}^{\mathrm{O}^{\prime}} \mathrm{FeCp}_{2}^{+} / \mathrm{FeCP}_{2}$ vs. SCE at the half equivalence point (i.e. when $\left.\left[\mathrm{FeCp}_{2}^{+}\right]=\left[\mathrm{FeCp}_{2}\right]\right) . \quad \mathrm{E}^{\circ}$ titration data was treated in this manner.

For titrations of air sensitive compounds and for all titrations in THF-water mixtures, the side of the titration cell containing the ferrocene solution was purged with nitrogen 
throughout the titration. In addition the titrant was purged with nitrogen and added with a syringe rather than with a buret.

Iodoferrocene has a potential too close to that of iron (III) to allow a potentiometric titration as above. To obtain $\mathrm{E}^{\mathrm{O}^{\prime}}$ for iodoferrocene a solution of iodoferricenium ion was prepared by oxidizing with cerium(IV) perchlorate a small amount of a concentrated $(0.010$ M) solution of iodoferrocene in $3 \mathrm{M}$ perchloric acid. This solution was then diluted and added in known increments to an iodoferrocene solution.

Ferrocene-ferricenium ion rate studies

The Durrum-Gibson stopped flow spectrophotometer was used to follow these reactions. The reaction rates were very high and consequent ly measured under second-order conditions. The rates of reaction were studied at wavelengths between 240 and $300 \mathrm{~nm}$ where the ferricenium species have large molar absorbtivities. The reaction is more conveniently studied at wavelengths slightly away from the wavelength maximum (for example at $240 \mathrm{~nm}$ for the ferricenium ion-1,1'dimethylferrocene reaction rather than $254 \mathrm{~nm}$ or $257 \mathrm{~nm}$ ) since the spectrum of both species are changing more rapidly there than at the 
peak. By doing this one observes a larger absorbance change and a smaller background absorbance. In all cases where more than one wavelength was used to study a reaction the reaction rate was independent of wavelength. Ferrocene-iron(III) rate studies

These reactions were studied in water-THF rather than water-n-propanol to avoid formation of n-propanol complexes of iron(III) (35). To avoid formation of significant amounts of hydrolytic polymers of iron(III), all experiments were at hydrogen ion concentrations greater than $0.1 \underline{\mathrm{M}}$.

A typical iron(III)-ferrocene oxidation-reduction reaction experiment was done as follows. Solutions of ferrocene and of iron(III) of the desired composition were prepared under nitrogen from freshly prepared THF. The perchloric acid was usually added to the iron(III) reactant solution, with the exception of experiments at high hydrogen ion concentration where perchloric acid was initially added to both solutions. The ferrocene and iron(III) reactant solutions were then transferred under nitrogen, using glass syringes with Teflon needles, to the Durrum-Gibson stopped flow spectrophotometer. Since the peroxide formed in THF in the presence of oxygen was shown to react with ferrocene in acidic solution, oxygen was 
excluded from a11 phases of the experiment and only freshly distilled solvent was used.

The iron(III)-ferrocene reactions were observed in the region $600-700 \mathrm{~nm}$ where only the various ferricenium ions absorb $\left(\varepsilon_{\max }=300-600\right)$. Experiments with lower reactant concentrations were observed in the region $300-340 \mathrm{~mm}$ where the molar absorbtivities of the ferricentum species formed are much larger. In all cases the reaction rate was independent of wavelength.

The rate studies were carried out under pseudo-firstorder conditions both with ferrocene in excess and with iron (III) in excess.

Ferrocene-chromium(VI) rate studies

The reaction of $\mathrm{Fe}\left(\mathrm{C}_{5} \mathrm{H}_{5}\right)_{2}$ and $\mathrm{Cr}(\mathrm{VI})(\mathrm{Eq}$. 5) does not occur in the absence of added $\mathrm{H}^{+}$. The kinetic studies were carried out using the stopped-flow method. In all the experiments reported here, a solution containing both $\mathrm{HCrO}_{4}^{-}$and $\mathrm{Fe}\left(\mathrm{C}_{5} \mathrm{H}_{5}\right)_{2}$ was mixed with a solution of perchloric acid. In this manner, (a) the oxidation of acetone by $\mathrm{HCrO}_{4}^{-}$was rendered unimportant and (b) the slow decomposition of $\mathrm{Fe}\left(\mathrm{C}_{5} \mathrm{H}_{5}\right)_{2}$ in acidic acetone solution is avoided.

A11 experiments were done under pseudo-first-order 
excesses of $\mathrm{Fe}\left(\mathrm{C}_{5} \mathrm{H}_{5}\right)_{2}$. The experiments were done at four wavelengths; the molar absorptivities were determined at these wavelengths and appear in Table 4. No rate dependence on wavelength was found.

Table 4. Wavelengths and molar absorptivities of reactants and products in the ferrocene-chromium(VI) reaction

\begin{tabular}{lrrrr}
\hline & \multicolumn{4}{c}{ Molar absorptivities, $\mathrm{cm}^{-1} \underline{M}^{-1}$} \\
$\lambda, \mathrm{nm}$ & $\mathrm{FeCp}_{2}$ & $\mathrm{FeCp}_{2}^{+}$ & $\mathrm{HCrO}_{4}^{-}$ & $\mathrm{Cr}^{3+}$ \\
\hline 618 & 0 & 450 & 0 & $\sim 10$ \\
330 & 53 & 1280 & 1170 & $\sim 8$ \\
350 & 19 & 588 & 1600 & $\sim 10$ \\
370 & 17 & 380 & 1260 & $\sim 12$ \\
\hline
\end{tabular}

\section{Kinetic data}

The pseudo-first-order kinetic data in terms of absorbance, D, for the $\mathrm{Fe}$ (III) oxidations, Eq. 4, were treated by the equation:

$$
\ln \left(D_{\infty}-D_{t}\right)=\ln \left(D_{\infty}-D_{0}\right)-k_{i}[x]_{a v e}
$$

where $k_{i}$ is the second-order rate constant corresponds to the kinetic expression,

$$
-d[\text { ferrocene }] / d \underline{t}=k_{i}[F e(I I I)][\text { ferrocene }]
$$

$[\mathrm{X}]_{\text {ave }}$ is the average concentration of the reactant in excess, either $\mathrm{Fe}(\mathrm{III})$ or ferrocene, for that particular run, and the 
subscripts refer to time. Plots of $\log \left(D_{\infty}-D_{t}\right)$ vs. time were linear, and from their slopes values of $k$ were computed using the average concentration of $\mathrm{x}$ in each run.

A similar treatment of the kinetic data was applied to the reaction of $\mathrm{Fe}\left(\mathrm{C}_{5} \mathrm{H}_{5}\right)_{2}$ by $\mathrm{Cr}(\mathrm{VI})$, for which a third-order rate constant is defined by the following rate equation:

$-\mathrm{d}[\mathrm{Cr}(\mathrm{VI})] / \underline{\mathrm{t}}=-\frac{\mathrm{I}}{3} \mathrm{~d}\left[\mathrm{Fe}\left(\mathrm{C}_{5} \mathrm{H}_{5}\right)_{2}\right] / \mathrm{dt}=\mathrm{k}^{\prime}\left[\mathrm{Fe}\left(\mathrm{C}_{5} \mathrm{H}_{5}\right)_{2}\right][\mathrm{Cr}(\mathrm{VI})]\left[\mathrm{H}^{+}\right]$

In this case the slope of the plot of $\ln \left(D_{t}-D_{\infty}\right)$ vs. $t$ is $k^{\prime}\left[\mathrm{Fe}\left(\mathrm{C}_{5} \mathrm{H}_{5}\right)_{2}\right]$ ave ${ }^{\left[\mathrm{H}^{+}\right]}$ave permitting the calculation of $k^{\prime}$.

The reactions between ferrocenes and ferricenium ions follow the kinetic pattern:

$$
\begin{gathered}
A+B^{+} \underset{k^{\prime}}{\underset{k}{k}} A^{+}+B ; K=k / k^{\prime} \\
-d[A] / d t=k[A]\left[B^{+}\right]-k^{\prime} \cdot\left[A^{+}\right][B]
\end{gathered}
$$

the integrated rate expression for which has been derived by Frost and Pearson (36). The form of the equation used depended upon the conditions:

(a) with $\left[\mathrm{B}^{+}\right]_{\mathrm{O}} \neq[\mathrm{A}]_{0}$ and $\mathrm{A}^{+}$and $\mathrm{B}$ initially absent, the following expression applies

$$
\left[\left(1-K^{-1}\right) Q\right]^{-1} \ln \left[\frac{X_{e}\left(A-A_{e}+Q\right)}{\left(A-A_{e}\right)\left(X_{e}+Q\right)}\right]=k \underline{t}
$$


where the subscript e refers to equilibrium, $A=A_{0}-X, X_{e}=$ $A_{o}-A_{e}$, and $X=X_{e}\left(D_{o}-D_{t}\right) /\left(D_{o}-D_{e}\right)$. The equilibrium concentration of $\mathrm{A}$ is given by

$$
A_{e}=\frac{-b+\left(b^{2}-4 a c\right)^{\frac{3}{2}}}{2 a}
$$

with $a=K-1, b=2 A_{O}+K B_{0}^{+}-K A_{O}$, and $c=-A_{O}^{2}$. $Q$ is given by Eq. 16.

$$
Q=[1 /(K-1)]\left[K^{2}\left(B_{O}^{+}-A_{O}\right)^{2}+4 A_{O} B_{O}^{+} K\right]^{\frac{3}{2}}
$$

(b) with $[\mathrm{A}]_{\mathrm{O}}=\left[\mathrm{B}^{+}\right]_{\mathrm{O}},\left[\mathrm{A}^{+}\right]_{\mathrm{O}}=[\mathrm{B}]_{\mathrm{O}}=0, \mathrm{Eq} \cdot 14$ simplifies to

$$
\left[\frac{(K)^{\frac{1}{2}}}{2 A_{O}}\right] \ln \left[\frac{X\left(A_{o}-2 X_{e}\right)+A_{o} \cdot X_{e}}{A_{o}\left(X_{e}-X\right)}\right]=k t
$$

where $A_{e}$ under these conditions is calculated from the exprexsion $A_{e}=A_{0} /(\sqrt{K}+1)$ and $X$ and $X_{e}$ have the same definition as above.

The fit of the individual kinetic data to the appropriate integrated rate expression, Eq. 14 or 17, was carried out using a CPS computer program.

The experiments on these reactions were of one of these two forms. In addition, the equilibrium in Eq. 12 may be approached from either side with the same result. Hence, similar equations can be written for experiments starting with 
mixtures of $\mathrm{A}^{+}$and $\mathrm{B}$, and no initial $\mathrm{A}$ and $\mathrm{B}^{+}$. For $\left[\mathrm{A}^{+}\right]_{\mathrm{O}} \neq$ $[\mathrm{B}]_{\mathrm{O}} \mathrm{Eq} \cdot 18$ results; for $\left[\mathrm{A}^{+}\right]_{\mathrm{O}}=[\mathrm{B}]_{\mathrm{O}} \mathrm{Eq} \cdot 19$ is derived.

$$
\left[Q\left(K^{-1}-1\right)\right]^{-1} \cdot \ln \left[\frac{X_{e}\left(A^{+}-A_{e}^{+}+Q\right)}{\left(A^{+}-A_{e}^{+}\right)\left(X_{e}+Q\right)}\right]=k t
$$

where $\mathrm{Q}=\left[\left(\mathrm{K}^{-1}-1\right)^{-1}\left[\left(\mathrm{~K}^{-1}\right)^{2}\left(\mathrm{~B}_{\mathrm{O}}-\mathrm{A}_{\mathrm{O}}^{+}\right)^{2}+4 \mathrm{~A}_{\mathrm{O}}^{+} \mathrm{B}_{\mathrm{O}} \mathrm{K}^{-1}\right]^{\frac{1}{2}}\right]$,

$A^{+}=A_{o}^{+}-X, X_{e}=A_{o}^{+}-A_{e}^{+}, x=x_{e}\left(D_{o}-D_{t}\right) /\left(D_{0}-D_{e}\right)$, and

$A_{e}^{+}=\left(-b+\left(b^{2}-4 a c\right)^{\frac{1}{2}} / 2 a\right)$ with $a=K^{-1}-1, b=2 A_{O}^{+}+K^{-1} B_{O}-$ $\mathrm{K}^{-1} \mathrm{~A}_{\mathrm{O}}^{+}$, and $\mathrm{C}=-\left(\mathrm{A}_{\mathrm{O}}^{+}\right)^{2}$.

$$
\left[\frac{(K)^{\frac{1}{2}}}{2 A_{o}^{+}}\right] \ln \left[\frac{X\left(A_{o}^{+}-2 X_{e}\right)+A_{o}^{+} X_{e}}{A_{o}^{+}\left(X_{e}-X\right)}\right]=k t
$$

where $X_{e}, X$ are as defined for Eq. 18 and $A_{e}^{+}=A_{O}^{+}\left[K^{-\frac{1}{2}}+1\right]^{-1}$.

A sample oscillogram for a typical ferrocene-ferricenium ion reaction, Eq. 2, is shown in Figure $3 \mathrm{~A}$, and for a typical iron(III)-ferrocene reaction, Eq. 4, in Figure 3B. To 11lustrate the treatment of these data, the data from Figure $3 \mathrm{~A}$ have been treated in accord with the integrated equation for reversible second-order kinetics given by Eq. 17 and are shown on Figure 4. The data from Figure 3B have been treated in accord with Eq. 9, and are shown in Figure 5. 
Figure 3. Typica1 stopped flow oscillograms

A. $\mathrm{Fe}\left(\mathrm{C}_{5} \mathrm{H}_{5}\right)\left(\mathrm{C}_{5} \mathrm{H}_{4} \mathrm{C}_{6} \mathrm{H}_{5}\right)^{+}, 4 \times 10^{-6}, \mathrm{Me}\left(\mathrm{C}_{5} \mathrm{H}_{5}\right)$ $\left(\mathrm{C}_{5} \mathrm{H}_{4} \mathrm{CH}_{2} \mathrm{OH}\right), 4 \times 10^{-6} \underline{\mathrm{M}}$, in $\mathrm{H}_{2} \mathrm{O}-\underline{n}$-propanol $(1: 1 \mathrm{v} / \mathrm{v}), \mu=0.05$ maintained with $\mathrm{Ba}\left(\mathrm{ClO}_{4}\right)_{2}$ at $25^{\circ} \mathrm{C}, \lambda=278 \mathrm{~nm}$

B. $\mathrm{Fe}^{3+}, 3 \times 10^{-5} \underline{\mathrm{M}}, \mathrm{Fe}\left(\mathrm{C}_{5} \mathrm{H}_{5}\right)\left(\mathrm{C}_{5} \mathrm{H}_{4} \mathrm{C}_{4} \mathrm{H}_{9}\right), 3 \times 10^{-4}$ $\underline{M}$, in $\mathrm{H}_{2} \mathrm{O}-\mathrm{THF}(1: 1 \mathrm{v} / \mathrm{v}),\left[\mathrm{H}^{+}\right]=0.50 \mathrm{M}, \mu=$ 1.00 maintained with $\mathrm{LiC}_{4}$ at $25^{\circ} \mathrm{C}, \lambda=$ $620 \mathrm{~nm}$ 
$31 b$

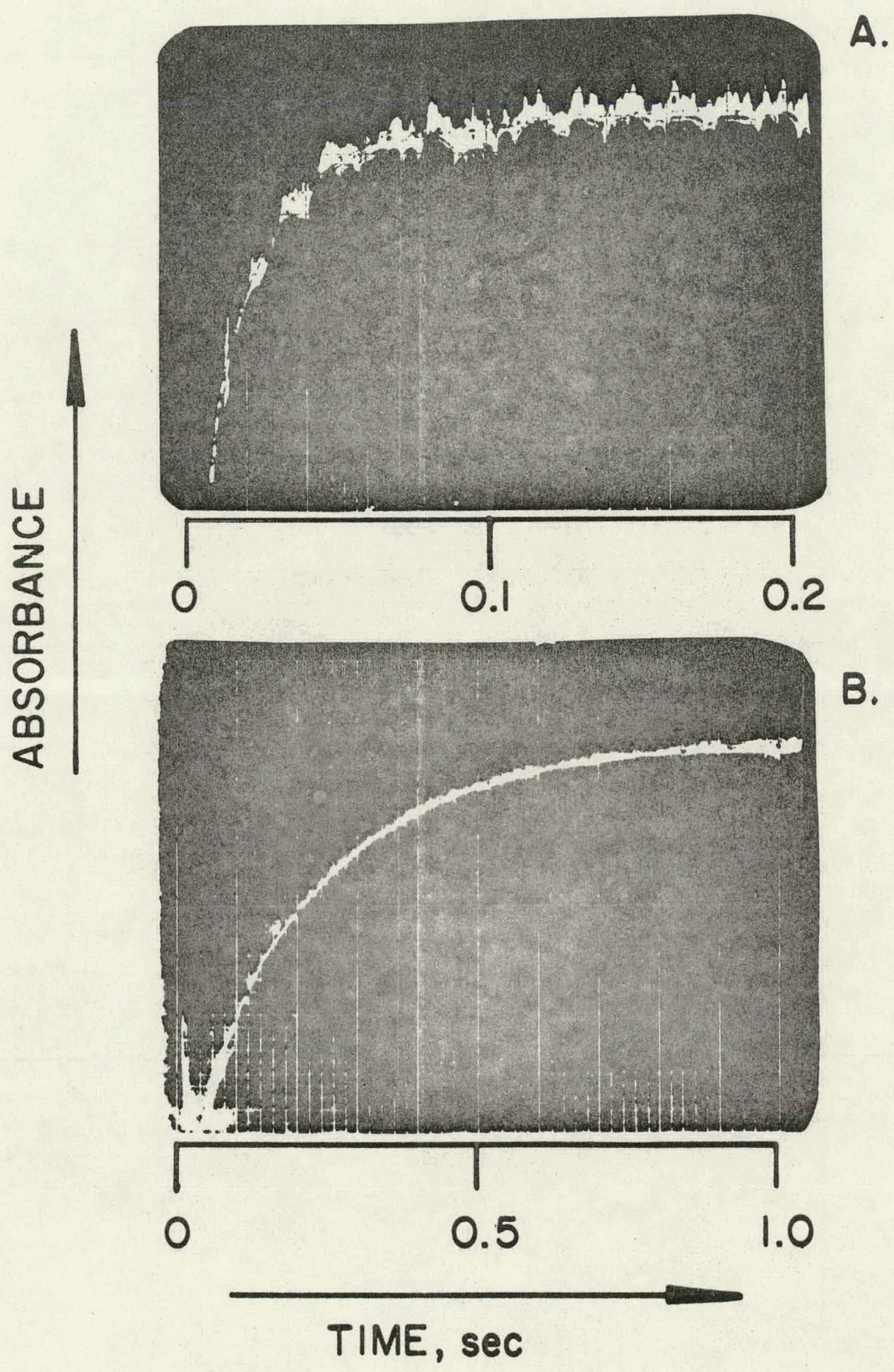




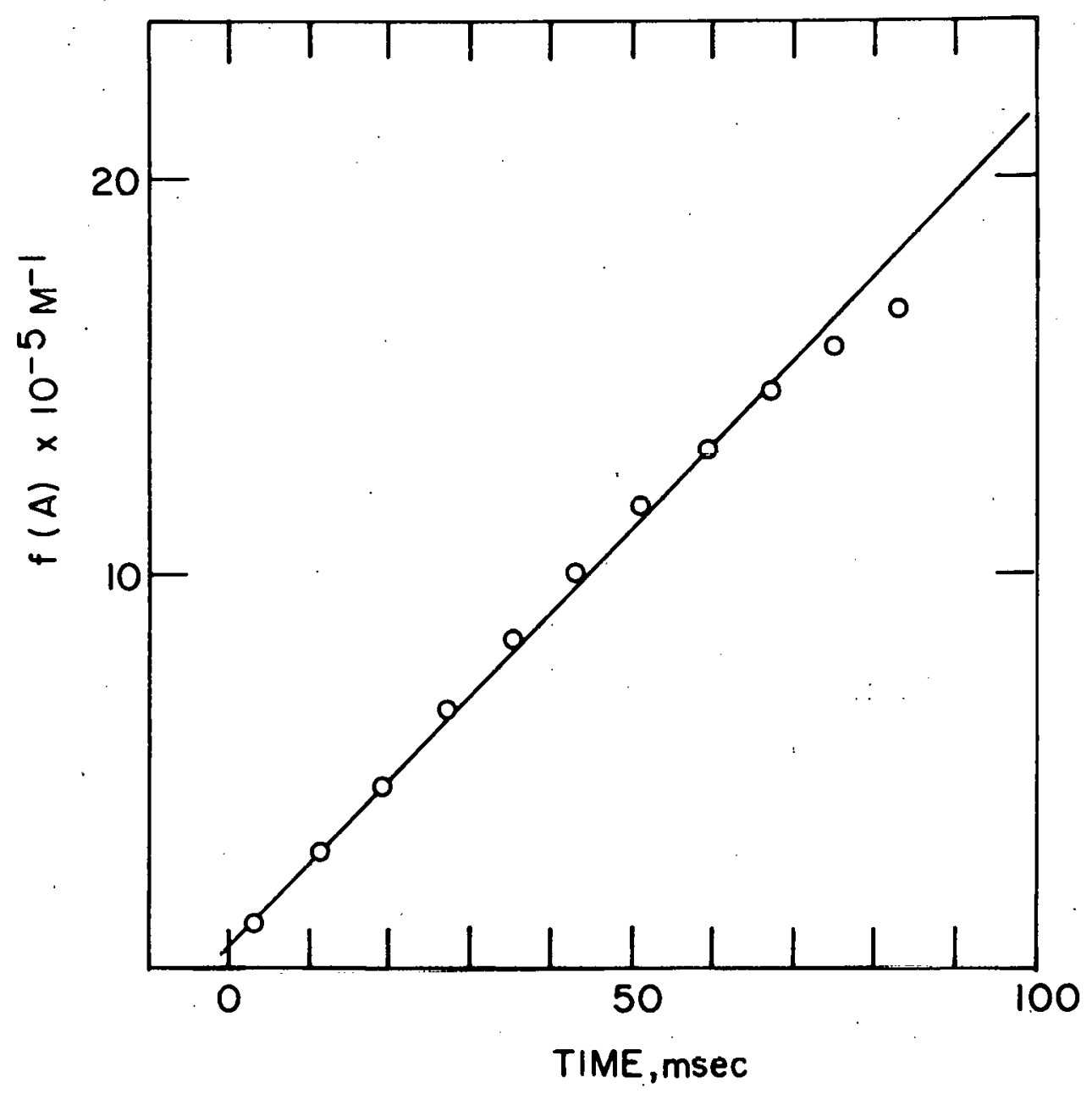

Figure 4. A plot of the left-hand side of Eq. 17, here designated $f(A)$, vs time for oscillogram $A$ in Figure 3 
33

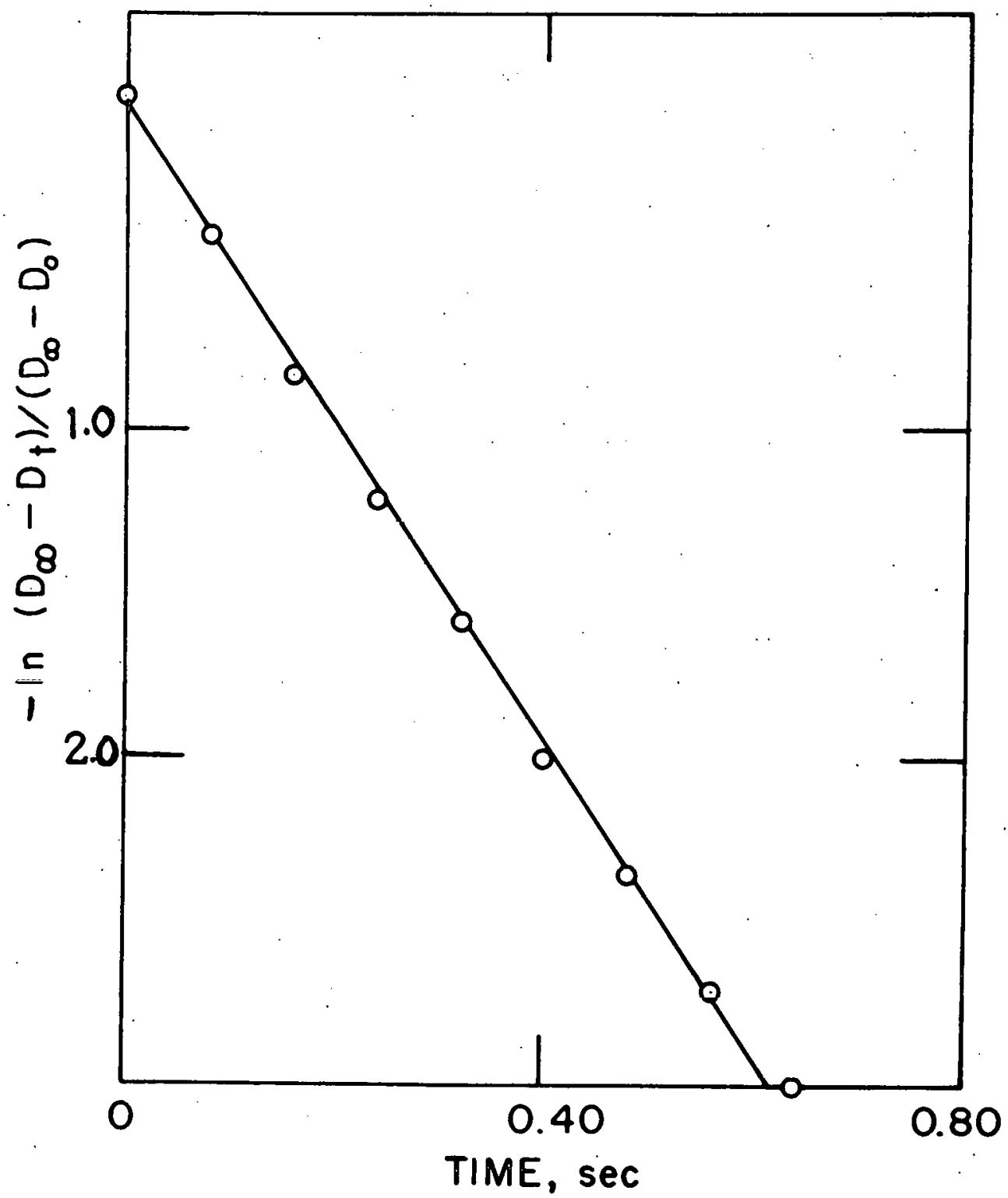

Figure 5. A plot of $-\ln \left(D_{\infty}-D_{t}\right) /\left(D_{\infty}-D_{0}\right)$ vs time for oscillogram $B$ in Figure 3 


\section{Stoichiometry studies}

Ferricenium ion was determined to be the only product resulting from iron(III) oxidation of ferrocene by its characteristic uv-visible spectrum. The 1:1 stoichiometry of this oxidation was established by spectrophotometric titration of ferrocene with iron(III) at a wavelength where only ferricenium ion absorbs. In this titration the absorbance increased linearly as iron(III) was added until the equivalence point (determined by weighed amount of ferrocene and the analytical concentration of iron(III)). Iron(III) added in excess of the equivalent amount resulted in no further absorbance changes at this wavelength. This established that one mole of iron(III) reacts with one mole of ferrocene to produce one mole of ferricenium ion and that ferricenium ion does not react further with excess iron(III).

The stoichiometry of the chromium(VI)-ferrocene reaction was determined via a spectrophotometric titration (at $\lambda=618$ $\mathrm{nm}$ ) of ferrocene by chromium(VI) in a manner similar to that used for the iron(III)-ferrocene reaction. This titration, however, was carried out in $1: 1 \mathrm{v} / \mathrm{v}$ water-acetone and the order of addition of reactants to each sample was: ferrocene followed by chromium(VI) followed by perchloric acid, with 
vigorous stirring during the perchloric acid addition. Ferricenium ion was also established as being the only ferrocene product resulting from this reaction as long as ferrocene was present in three-fold molar excess over chromium(VI). However, when greater than $1 / 3$ mole of chromium(VI) per mole of ferrocene was present the ferricenium ions produced by the initial oxidation were subsequently destroyed by a further slow reaction with chromium(VI). During the titration and up to the equivalence point of three moles of ferrocene to one mole of chromium(VI) the reaction does proceed with quantitative production of ferricenium ion. All kinetic studies were performed under conditions of excess ferrocene where this second slow reaction is not important. No kinetic or stoichiometric studies were carried out on the second slow reaction:between chromium(VI) and ferricenium ion. 


\section{RESULTS}

Formal Electrode Potential Measurements

Formal electrode potentials of the compounds used in this study were determined by potentiometric titration. The results, given in Table 5 , were obtained under the same conditions as the kinetic studies. By combining the appropriate electrode potentials from Table 5, the equilibrium constants for the electron transfer reactions, Eq. 2, and the $\mathrm{Fe}$ (III) oxidation reactions, Eq. 4, were calculated. To check the equilibrium constants obtained in this manner, spectral studies for several ferrocene-ferricenium ion systems, Eq. 2, were carried out. Using the known molar absorptivities of the reactants and products, the equilibrium constant as determined above, and mass balance of the ferrocene and ferricenium ion reactants and products, spectra of the mixed ferrocene-ferricenium ion systems, Eq. 2, were calculated. The calculated spectra are within $2 \%$ of the observed spectra of the equilibrated solutions. For example, in the reaction described by Eq. 20,

$$
\begin{aligned}
\mathrm{Fe}\left(\mathrm{C}_{5} \mathrm{H}_{5}\right)_{2}^{+}+ & \mathrm{Fe}\left(\mathrm{C}_{5} \mathrm{H}_{5}\right)\left(\mathrm{C}_{5} \mathrm{H}_{4} \underline{\mathrm{n}}-\mathrm{C}_{4} \mathrm{H}_{9}\right) \rightleftarrows \\
& \mathrm{Fe}\left(\mathrm{C}_{5} \mathrm{H}_{5}\right)_{2}+\mathrm{Fe}\left(\mathrm{C}_{5} \mathrm{H}_{5}\right)\left(\mathrm{C}_{5} \mathrm{H}_{4} \mathrm{n}-\mathrm{C}_{4} \mathrm{H}_{9}\right)+
\end{aligned}
$$


Table 5. Formal electrode potentials ${ }^{a}$ of iron compounds studied

\begin{tabular}{|c|c|c|c|c|}
\hline & & (a25 & $\mathrm{CO}^{\circ}$ & (225 \\
\hline 例 & Compound & $E^{O^{\prime}}, V^{b}$ & $\mathrm{E}^{\mathrm{o}^{\prime}}, \mathrm{V}^{\mathrm{b}}$ & $E^{O^{\prime}}, V^{C}$ \\
\hline
\end{tabular}

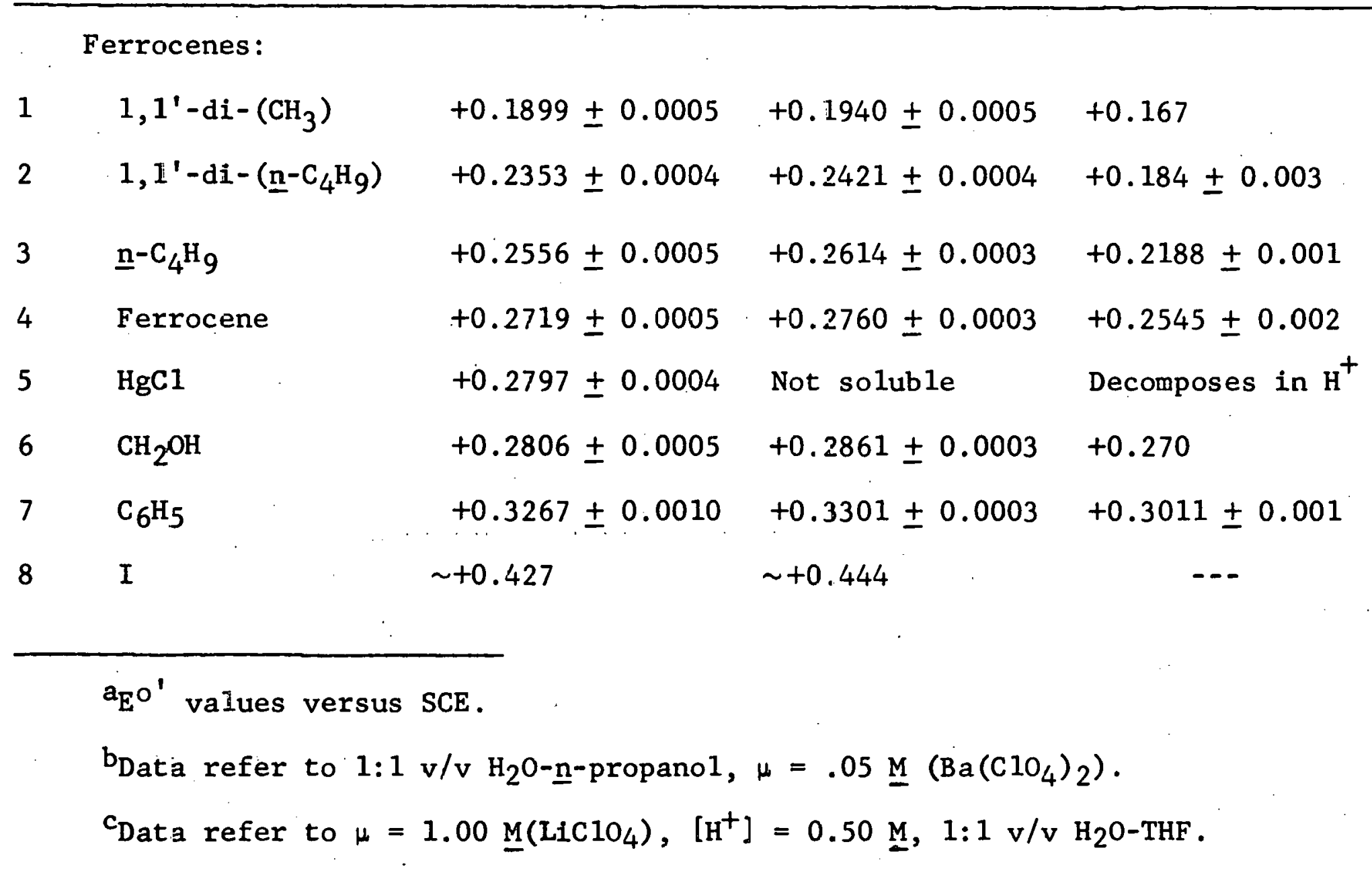


Table 5. (Continued)

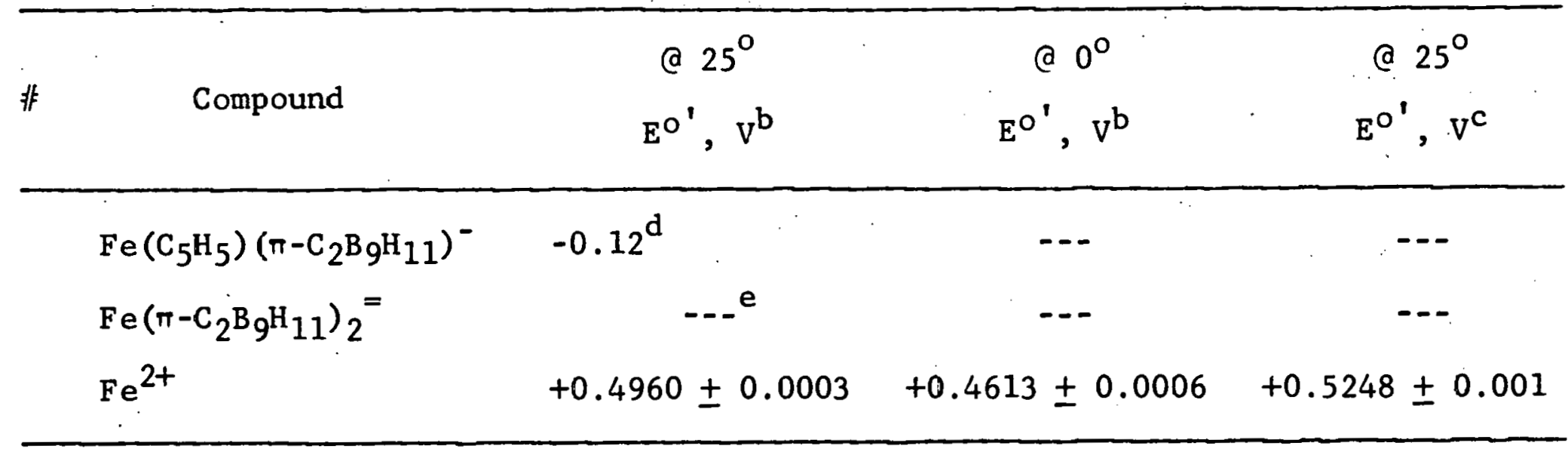

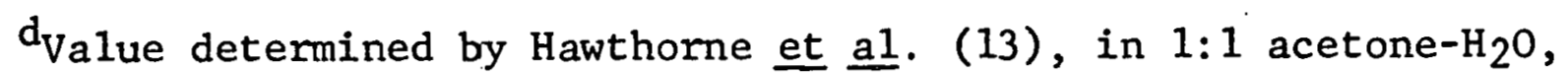
$0.1 \mathrm{~N}(\mathrm{Et})_{4} \mathrm{NClO}_{4}$ is $-0.08 \mathrm{~V}$.

EValue determined by Hawthorne et a1. (13), in 1:1 acetone- $\mathrm{H}_{2} \mathrm{O}$, $0.1 \mathrm{~N}(\mathrm{Et})_{4} \mathrm{NC} 10_{4}$ is $-0.425 \mathrm{~V}$. 
the equilibrium constant determined from data in Table 5 is 1.89 and in the region $600 \mathrm{~nm}$ to $700 \mathrm{~nm}$ only the $\mathrm{Fe}\left(\mathrm{C}_{5} \mathrm{H}_{5}\right)_{2}^{+}$ and $\mathrm{Fe}\left(\mathrm{C}_{5} \mathrm{H}_{5}\right)\left(\mathrm{C}_{5} \mathrm{H}_{4} \underline{\mathrm{n}}-\mathrm{C}_{4} \mathrm{H}_{9}\right)^{+}$species absorb.

Based on the spectra of the two absorbing species $\left(\mathrm{Fe}\left(\mathrm{C}_{5} \mathrm{H}_{5}\right)_{2}^{+}\right.$and $\left.\mathrm{Fe}\left(\mathrm{C}_{5} \mathrm{H}_{5}\right)\left(\mathrm{C}_{5} \mathrm{H}_{4} \text { n- } \mathrm{C}_{4} \mathrm{H}_{9}\right)^{+}\right)$, Figure 6 , the spectrum of the reaction mixture, Eq. 20, was calculated. The observed and calculated spectra of this solution are given in Figure 7 . The agreement between the observed and calculated spectra is not a strong confirmation of the value of $\mathrm{K}$ because the spectra are not a sensitive function of equilibrium constant. Consequent1y spectrophotometric determinations of the equilibrium constant are not reliable and were not attempted.

Data in Table 5 at $0^{\circ} \mathrm{C}$ and $25^{\circ} \mathrm{C}$ are combined to calculate equilibrium constants at other temperatures. In principle $\Delta S^{\circ}$. and $\Delta \mathrm{H}^{\circ}$ for the electron transfer reactions, Eq. 2, also can be calculated from the data at $0^{\circ} \mathrm{C}$ and $25^{\circ} \mathrm{C}$, however, this calculation is based on data for only two temperatures and a temperature range of on $1 \mathrm{y} 25^{\circ} \mathrm{C}$ over which the measured $\mathrm{E}^{\mathrm{O}^{\prime}}$ values do not change very much. Hence, $\Delta \mathrm{S}^{\circ}$ and $\Delta \mathrm{H}^{\circ}$ values calculated in this manner must be regarded as estimates.

The potentials in Table 5 are formal electrods potentials $\left(E^{\circ}\right)$ rather than standard electrode potentials $\left(E^{\circ}\right)$, since 


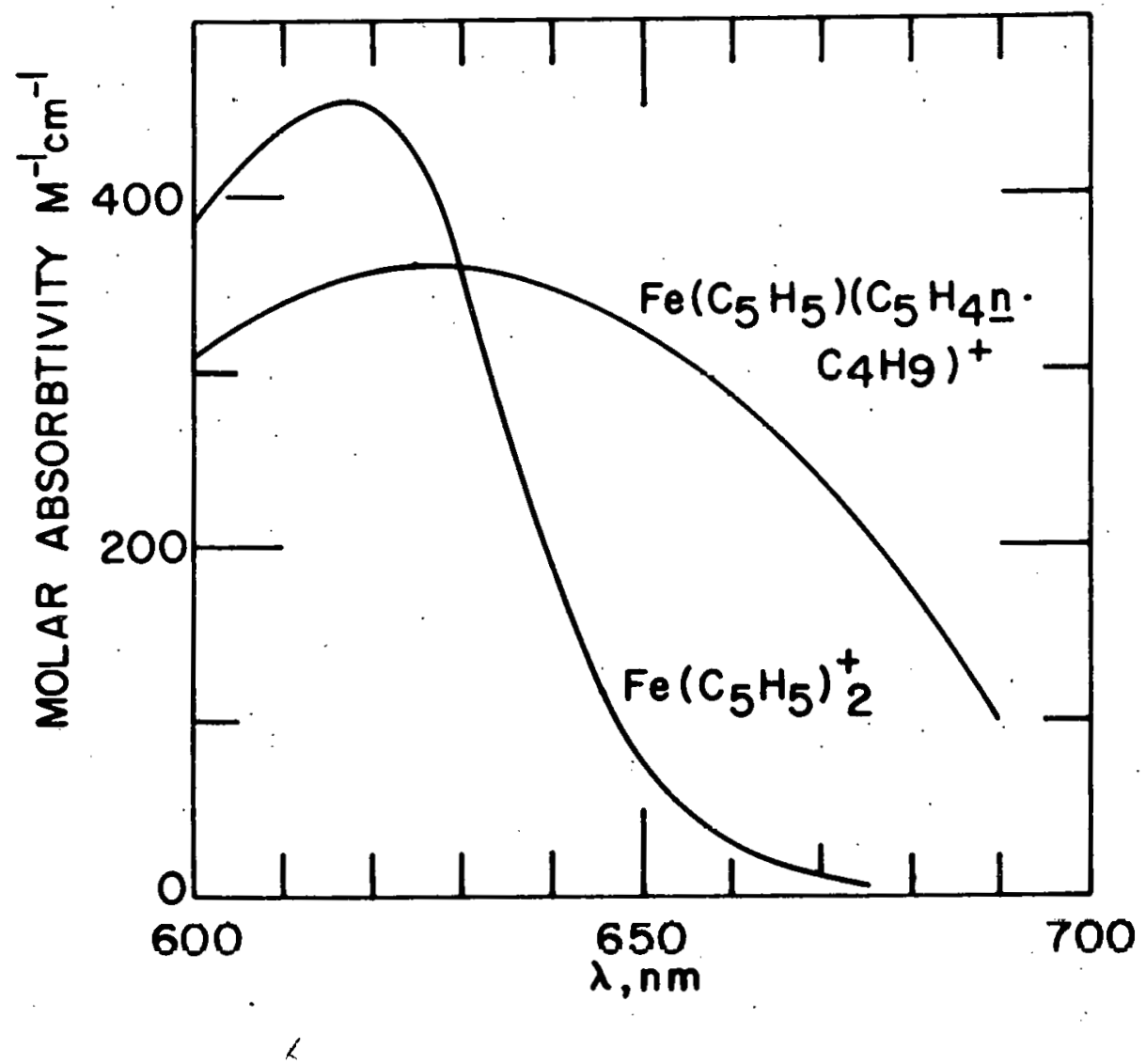

Figure 6. Spectrum of ferricenium ion and n-butylferricenium ion in $1: 1 \mathrm{v} / \mathrm{v} \mathrm{H} 20$-n-propanol, $\mu=0.05 \mathrm{Ba}\left(\mathrm{ClO}_{4}\right)_{2}$ at $25^{\circ} \mathrm{C}$ 


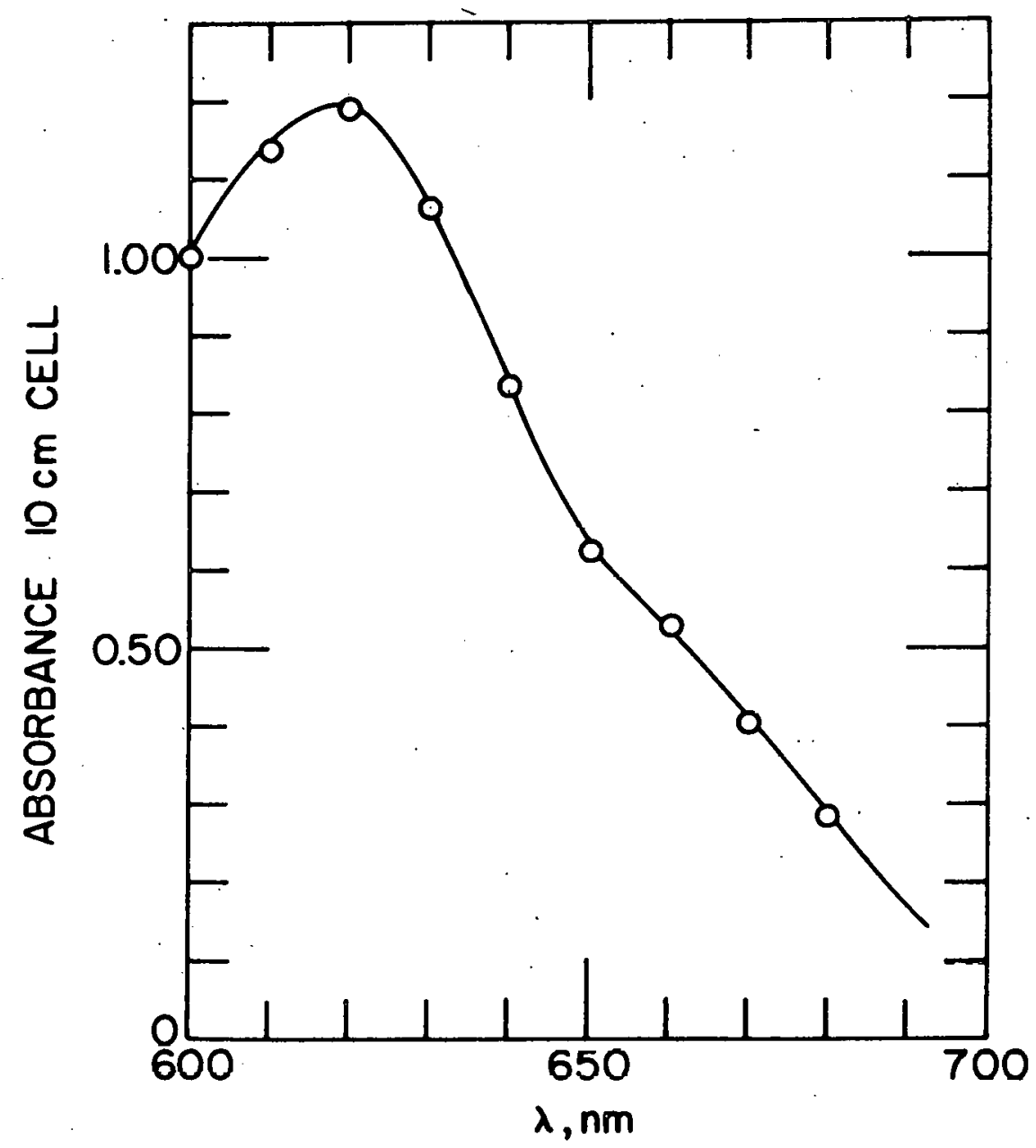

Figure 7. Observed spectrum (solid line) and calculated spectrum (dots) for a mixture of ferrocene, ferricenium ion, n-butylferrocene, and n-butylferricenium ion, $\vec{E}_{q}$. 20. Calculated concentrations are $1.43 \times 10^{-4}, 1.3 \times 10^{-4}, 1.0 .3 \times 10^{-4}$ and $1.70 \times 10^{-4 \mathrm{M}}$ respectively. $\quad 1: 1 \mathrm{v} / \mathrm{v} \mathrm{H}_{2} \mathrm{O}-\underline{n}$-propanol, $\mu=0.05 \mathrm{M}$ maintained with $\mathrm{Ba}\left(\mathrm{C}_{4}\right)_{2}$ at $25^{\circ} \mathrm{C}$ 
attempts were not made to extrapolate data to infinite dilution or to correct for junction potential. However, since all the ferrocene potentials were measured with the same experimental method and apparatus and by titration with the same titrant $(\mathrm{Fe}(\mathrm{III}))$ it is assumed that junction potentials and activity effects are identical for each of the ferroceneferricenium ion couples, which is especially so considering that each couple involves the same charge types and similar structures. Any differences between the experimental $\mathrm{E}^{\mathrm{O}^{\prime \prime}} \mathrm{s}$ and the trie $\mathrm{E}^{\mathrm{O}^{\prime}} \mathrm{s}$ would then cancel in the combination of a pair of $E^{\mathrm{O}} \mathrm{s}$ to compute an equilibrium constant.

\section{Iron(III)-Ferrocene Reactions}

Kinetic studies were carried out on iron(III) oxidations of substituted ferrocenes, Eq. 4. The rate law, Eq. 10, was established by following the reactions under pseudo-first order excesses of either iron(III) or the ferrocene derivative. The second-order rate constants obtained were independent of the reagent in excess and were constant over a wide range of reactant concentration. The second-order rate constants were also independent of hydrogen ion concentration from 0.10 to $1.00 \mathrm{M}$.

The results of these experiments are given in Table 6 . 
Table 6. Rate data for the iron(III)-ferrocene reactions ${ }^{a}$

$$
\mathrm{Fe}^{3+}+\mathrm{Fe}\left(\mathrm{C}_{5} \mathrm{H}_{5}\right)_{2} \stackrel{\mathrm{k}_{1}}{\rightarrow} \mathrm{Fe}^{2+}+\mathrm{Fe}\left(\mathrm{C}_{5} \mathrm{H}_{5}\right) \frac{1}{2}
$$

\begin{tabular}{|c|c|c|c|c|}
\hline $\begin{array}{l}\text { Substituted } \\
\text { ferrocene }\end{array}$ & $\begin{array}{l}{\left[\mathrm{Fe}^{3+}\right]} \\
\mathrm{M} \times 10^{3}\end{array}$ & $\begin{array}{l}\text { [Ferro- } \\
\text { cene] } \\
\mathrm{M} \times 10^{3}\end{array}$ & $\begin{array}{l}{\left[\mathrm{H}^{+}\right]} \\
M\end{array}$ & $k_{i}, M^{-1} \sec ^{-1} \times 10^{-4^{b}}$ \\
\hline \multirow[t]{6}{*}{ Ferrocene } & $\begin{array}{l}0.05 \\
1.00 \\
0.01 \\
0.10\end{array}$ & $\begin{array}{l}1.00 \\
0.05 \\
0.10 \\
0.01\end{array}$ & $\begin{array}{l}0.50 \\
0.50 \\
0.10 \\
1.00\end{array}$ & $\begin{array}{l}1.00 \pm 0.03 \\
1.03 \pm 0.03 \\
1.07 \pm 0.05 \\
1.11 \pm 0.05\end{array}$ \\
\hline & & & & Ave. $1.05 \pm 0.04$ \\
\hline & $\begin{array}{l}0.02 \\
0.30\end{array}$ & $\begin{array}{l}0.20 \\
0.02\end{array}$ & $\begin{array}{l}0.50 \\
0.50\end{array}$ & $\begin{array}{l}2.57 \pm 0.13^{c} \\
2.56 \pm 0.12 c\end{array}$ \\
\hline & & & & Ave. $2 . \overline{56} \pm 0.13^{c}$ \\
\hline & $\begin{array}{l}0.10 \\
5.00\end{array}$ & $\begin{array}{l}2.00 \\
0.10\end{array}$ & $\begin{array}{l}0.50 \\
0.50\end{array}$ & $\begin{array}{l}0.41 \pm 0.01 \\
0.43 \pm 0.01 \\
d\end{array}$ \\
\hline & & & & Ave. $0.42 \pm 0.01^{d}$ \\
\hline \multirow[t]{2}{*}{$1,1^{\prime}-d i-\mathrm{CH}_{3}$} & $\begin{array}{l}0.05 \\
3.00 \\
0.03\end{array}$ & $\begin{array}{l}0.50 \\
0.10 \\
0.003\end{array}$ & $\begin{array}{l}0.50 \\
0.50 \\
0.50\end{array}$ & $\begin{array}{l}3.1 \pm 0.15 \\
3.4 \pm 0.10 \\
3.1 \pm 0.15\end{array}$ \\
\hline & & & & Ave. $3.2 \pm 0.15$ \\
\hline
\end{tabular}

${ }^{a_{\text {Except }}}$ where noted all data pertain to $1: 1 \mathrm{v} / \mathrm{v} \mathrm{II}_{2} \mathrm{O}-\mathrm{THF}$, $\mu=1.00 \mathrm{LiC}_{10}, 25^{\circ} \mathrm{C}$.

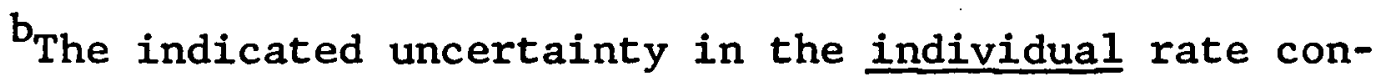
stants represents the average deviation from the mean in three or four repetitive determinations using the same set of reagents. The uncertainty cited for the average rate constants is the average deviation from the unweighted mean of the individual values.

${ }^{C}$ Data obtained at $40^{\circ} \mathrm{C}$.

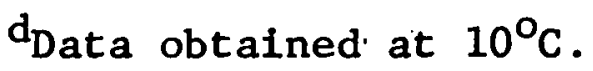


Table 6. (Continued)

\begin{tabular}{|c|c|c|c|c|}
\hline $\begin{array}{l}\text { Substituted } \\
\text { ferrocene }\end{array}$ & $\begin{array}{l}{\left[\mathrm{Fe}^{3+}\right]} \\
\mathrm{Mx} 10^{3}\end{array}$ & $\begin{array}{l}\text { [Ferro- } \\
\text { cene] } \\
\mathrm{M} \times 10^{3}\end{array}$ & $\begin{array}{c}{\left[\mathrm{H}^{+}\right]} \\
\underline{M}\end{array}$ & $k_{i}, \underline{M}^{-1} \sec ^{-1} \times 10^{-4^{t}}$ \\
\hline $\mathrm{C}_{6} \mathrm{H}_{5}$ & $\begin{array}{l}0.05 \\
2.00 \\
0.10 \\
0.50 \\
0.80\end{array}$ & $\begin{array}{l}0.50 \\
0.10 \\
0.01 \\
1.00 \\
0.08\end{array}$ & $\begin{array}{l}0.50 \\
0.50 \\
0.50 \\
0.50 \\
0.25\end{array}$ & $\begin{array}{c}0.52 \pm 0.02 \\
0.48 \pm 0.01 \\
0.49 \pm 0.01 \\
0.47 \pm 0.02 \\
0.54 \pm 0.02 \\
\text { Ave. } 0.50 \pm 0.02\end{array}$ \\
\hline $\mathrm{CH}_{2} \mathrm{OH}$ & $\begin{array}{l}0.089 \\
3.00 \\
0.10 \\
0.05\end{array}$ & $\begin{array}{l}1.00 \\
0.10 \\
0.01 \\
0.50\end{array}$ & $\begin{array}{l}0.50 \\
0.50 \\
0.50 \\
0.20\end{array}$ & $\begin{array}{c}1.80 \pm 0.07 \\
1.77 \pm 0.05 \\
1.85 \pm 0.05 \\
1.73 \pm 0.10 \\
\text { Ave. } 1.79 \pm 0.07\end{array}$ \\
\hline $1,1^{\prime}-\mathrm{di}-\underline{n}-\mathrm{C}_{4} \mathrm{H}_{9}$ & $\begin{array}{l}0.08 \\
0.03 \\
3.00 \\
0.10\end{array}$ & $\begin{array}{l}1.00 \\
0.30 \\
0.10 \\
0.01\end{array}$ & $\begin{array}{l}0.50 \\
0.50 \\
0.50 \\
0.50\end{array}$ & $\begin{array}{c}1.39 \pm 0.05 \\
1.31 \pm 0.05 \\
1.43 \pm 0.05 \\
1.59 \pm 0.05 \\
\text { Ave. } 1.43 \pm 0.10\end{array}$ \\
\hline$\underline{n}-\mathrm{C}_{4} \mathrm{H}_{9}$ & $\begin{array}{l}0.30 \\
0.03 \\
0.10 \\
3.00\end{array}$ & $\begin{array}{l}0.03 \\
0.30 \\
1.00 \\
0.10\end{array}$ & $\begin{array}{l}0.50 \\
0.50 \\
0.50 \\
0.50\end{array}$ & $\begin{array}{c}1.50 \pm 0.04 \\
1.47 \pm 0.04 \\
1.55 \pm 0.06 \\
1.49 \pm 0.04 \\
\text { Ave. } 1.50 \pm 0.05\end{array}$ \\
\hline $\mathrm{Fe}\left(\mathrm{C}_{5} \mathrm{H}_{5}\right)\left(\mathrm{C}_{2} \mathrm{~B}_{9} \mathrm{H}_{11}\right)^{-}$ & $\begin{array}{l}0.0025 \\
0.025 \\
0.010\end{array}$ & $\begin{array}{l}0.025 \\
0.0025 \\
0.0015\end{array}$ & $\begin{array}{l}0.50 \\
0.50 \\
0.50\end{array}$ & $\begin{array}{c}480 \pm 30 \\
460 \pm 30 \\
530 \pm 30\end{array}$ \\
\hline $\mathrm{Fe}\left(\mathrm{C}_{2} \mathrm{~B}_{9} \mathrm{H}_{11}\right)_{2}^{2-}$ & 0.003 & 0.003 & 0.001 & $>1 \times 10^{4}$ \\
\hline
\end{tabular}


The oxidation of ferrocene by $\mathrm{Fe}^{3+}$ is the only member of the series for which rate constants were evaluated at temperatures other than $25^{\circ}$. From the experiments at $10^{\circ}, 25^{\circ}$, and $40^{\circ} \mathrm{C}$ for the iron(III)-ferrocene reaction $\Delta S^{\ddagger}$ and $\Delta \mathrm{H}^{\ddagger}$ are found to be $-6.5 \pm 0.7$ eu and $10.0 \pm 0.2 \mathrm{kcal}$ mole $\mathrm{e}^{-1}$ respectively.

Data for the iron(III)-iodoferrocene reaction, Eq. 21, are not included in Table 6 .

$\mathrm{Fe}\left(\mathrm{C}_{5} \mathrm{H}_{5}\right) \cdot\left(\mathrm{C}_{5} \mathrm{H}_{4} \mathrm{I}\right)+\mathrm{Fe}^{3+} \underset{\mathrm{k}_{8}^{+}}{\mathrm{k}} \mathrm{Fe}\left(\mathrm{C}_{5} \mathrm{H}_{5}\right)\left(\mathrm{C}_{5} \mathrm{H}_{4} \mathrm{I}\right)^{+}+\mathrm{Fe}^{2+} ; \mathrm{K}$

The oxidation potential for iodoferrocene is too close to that of $\mathrm{Fe}$ (III) for the oxidation of iodoferrocene by $\mathrm{Fe}$ (III) to be complete, hence Eq. 9 and 10 do not apply to this system. The rate law for the reaction described by Eq. 21 is given by Eq. 22 .

$$
\begin{aligned}
\frac{d\left[\mathrm{Fe}\left(\mathrm{C}_{5} \mathrm{H}_{5}\right)\left(\mathrm{C}_{5} \mathrm{H}_{4} \mathrm{I}^{+}\right)\right]}{\mathrm{dt}}= & \mathrm{k}_{8}\left[\mathrm{Fe}^{3+}\right]\left[\mathrm{Fe}\left(\mathrm{C}_{5} \mathrm{H}_{5}\right)\left(\mathrm{C}_{5} \mathrm{H}_{4} \mathrm{I}\right)\right]- \\
& \mathrm{k}_{8}^{\prime}\left[\mathrm{Fe}^{2+}\right]\left[\mathrm{Fe}\left(\mathrm{C}_{5} \mathrm{H}_{5}\right)\left(\mathrm{C}_{5} \mathrm{H}_{4}^{+} \mathrm{I}\right)\right]
\end{aligned}
$$

With pseudo-first-order excesses of $\mathrm{Fe}(\mathrm{III})$ and $\mathrm{Fe}$ (II), Eq. 21 and 22 lead to a pseudo-first-order observed rate constant given by $\mathrm{Eq} \cdot 23$.

$k_{\text {obs }}=d \ln \left[\mathrm{Fe}\left(\mathrm{C}_{5} \mathrm{H}_{5}\right)\left(\mathrm{C}_{5} \mathrm{H}_{4} \mathrm{I}\right)^{+}\right] / \mathrm{dt}=\mathrm{k}_{8}\left[\mathrm{Fe}^{3+}\right] \mathrm{ave}^{+} \mathrm{k}_{8}^{\prime}\left[\mathrm{Fe}^{2+}\right]$ ave 
A plot of $\mathrm{k}_{\mathrm{obs}} /\left[\mathrm{Fe}^{3+}\right]$ ave versus $\left[\mathrm{Fe}^{2+}\right]$ ave $/\left[\mathrm{Fe}^{3+}\right]$ ave gives a straight line having an intercept, $k_{8}$ of $5.5 \times 10^{2}$ $\mathrm{M}^{-1} \mathrm{sec}^{-1}$ and a slope, $\mathrm{k}_{8}^{\prime}$, of $19 \mathrm{M}^{-1} \mathrm{sec}^{-1}$, Figure 8. A11 experiments for this system are given in Table 7. From $\mathrm{k}_{8}$ and $k_{8}^{\prime}$ an equilibrium constant of 29 is obtained.

Table 7. Rate data for iron(III)-iodoferrocene system ${ }^{a}$

\begin{tabular}{rrrr}
$\begin{array}{c}{\left[\mathrm{Fe}^{2+}\right],} \\
\mathrm{M} \times 10^{3}\end{array}$ & $\begin{array}{c}{\left[\mathrm{Fe}^{3+}\right],} \\
\mathrm{M} \times 10^{3}\end{array}$ & $\begin{array}{c}{\left[\mathrm{Fe}\left(\mathrm{C}_{5} \mathrm{H}_{5}\right)\left(\mathrm{C}_{5} \mathrm{H}_{4} \mathrm{I}\right)\right]} \\
\mathrm{M} \times 10^{3}\end{array}$ & $\mathrm{k}_{\mathrm{obs}}, \mathrm{sec}^{-1}$ \\
\hline 1.00 & 1.00 & 0.10 & $0.55 \pm .015$ \\
0.50 & 10.00 & 0.05 & $5.61 \pm .15$ \\
10.00 & 0.05 & 0.05 & $0.44 \pm .03$ \\
10.00 & 1.00 & 0.10 & $0.64 \pm .01$ \\
50.00 & 0.50 & 0.05 & $1.31 \pm .02$ \\
0.00 & 0.50 & 0.50 &. \pm .5 \\
0.00 & 1.50 & 0.50 & $1.42 \pm .05$ \\
50.00 & 1.00 & 0.05 & $-\mathrm{b}$ \\
\hline
\end{tabular}
at $25^{\circ} \mathrm{C}$.

$\mathrm{a}_{\mathrm{All}}$ data at $1: 1 \mathrm{v} / \mathrm{v} \mathrm{H}_{2} \mathrm{O}-\mathrm{THF}, \mu=1.00 \mathrm{LiClO}_{4}, \mathrm{H}^{+}=0.50 \underline{\mathrm{M}}$

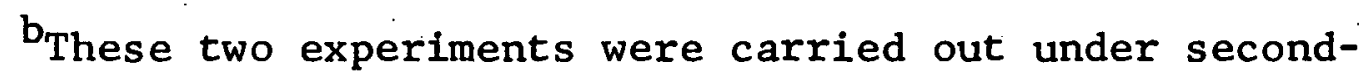
order conditions and were treated in the same manner as the ferrocene-ferricenium electron transfer reactions as described in the experimental section of this thesis. Hence, the rate constants are second order rate constants, the values being $510 \pm 30$ and $540 \pm 20 \mathrm{M}^{-1} \mathrm{sec}^{-1}$ for these two experiments respectively. These correspond to a determination of $k_{8}$, which is also the intercept on Figure 8 . 


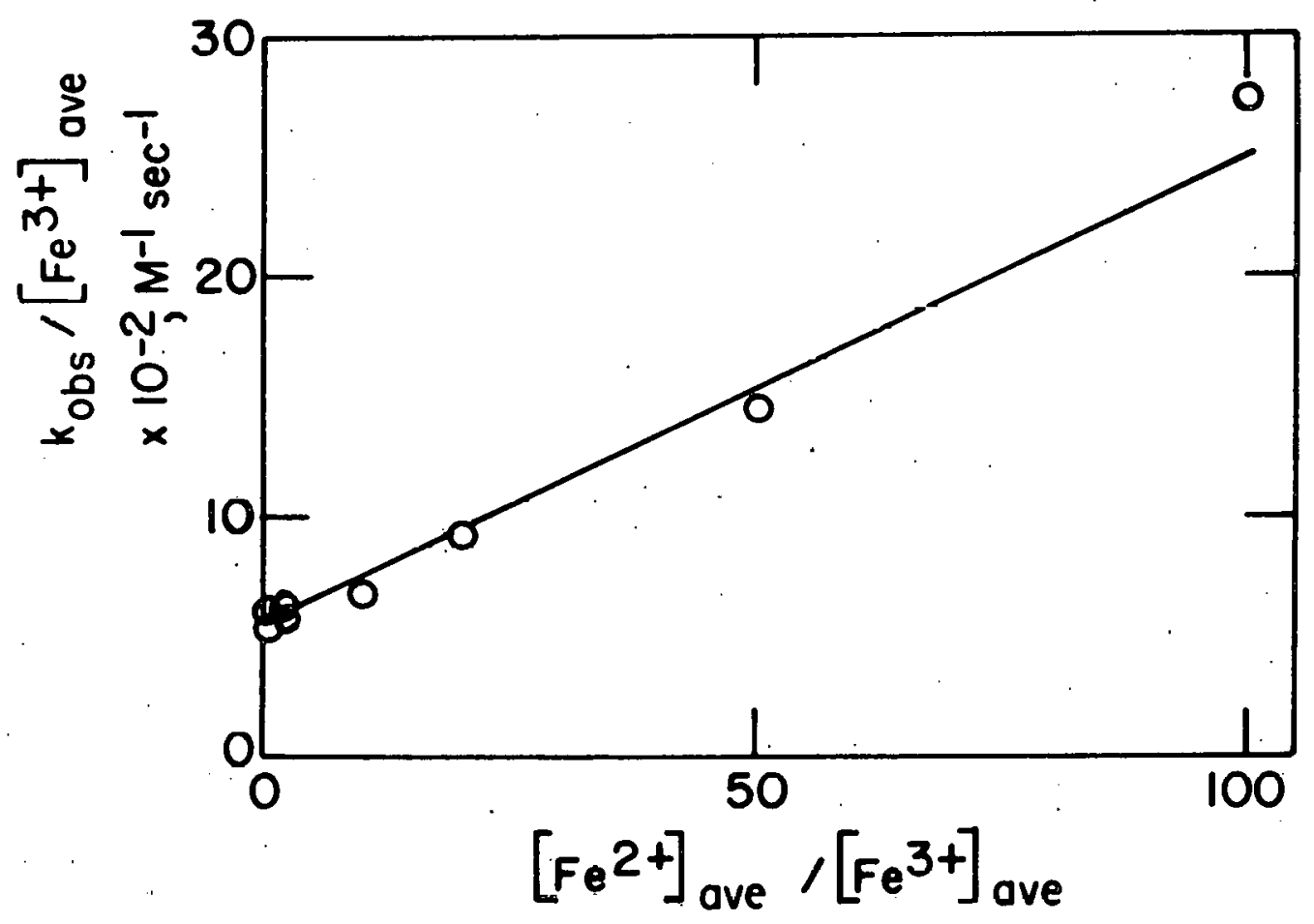

Figure 8. A plot of kinetic data as suggested by Eq. 23 for the iron(III)-iodoferrocene reaction 
Ferrocene-Ferricenium Electron Transfer Reactions

The ferrocene-ferricenium electron transfer reactions, Eq. 2, are much too fast to be followed under pseudo-firstorder conditions. However, the reactions can be studied under reversible second-order conditions. The assumed rate law, Eq. 13, has several integrated forms, Eq. 14, 17, 18, 19, the form applicable depending on the concentration conditions of the experiment.

Kinetic studies have been carried out under conditions pertaining to each of the different forms of the integrated rate equation and over a range of concentrations within these limits. The constraints on which were based the lower and upper limits of concentrations studied for a given reaction were (a) the minimum amount of reactants necessary to produce a measurable absorbance change (about 0.01 absorbance unit) and (b) the maximum concentration of reactants that could be used without rendering the reaction immeasurably fast. For some reactions these limits were so restrictive that only a narrow range of concentration could be covered (e.g. ferroceneiodoferricenium ion reaction).

All data obtained. for these systems are in agreement with the assumed rate law, Eq. 13, and its related integrated 
forms. The conditions and results of these experiments appear in Table 8 .

The reactions between ferricenium ion and 1,1'-dimethy1ferrocene and between phenylferricenium ion and ferrocene have also been studied as a function of temperature. The activation parameters for these two reactions are given in Table 9 .

Several experiments were done under different salt and solvent conditions and are presented as the last seven entries in Table 8.

\section{Chromium(VI)-Ferrocene Reaction}

The oxidation of ferrocene by chromium(VI), Eq. 5, was found to obey the rate law given by Eq. 11 under conditions of pseudo-first-order excesses of ferrocene and hydrogen ion. Under these conditions the observed pseudo-first-order rate constant is given by Eq. 24 .

$$
k_{\mathrm{obs}}=-\mathrm{d} \ln [\mathrm{Cr}(\mathrm{VI})] / \mathrm{dt}=\mathrm{k}^{\prime}\left[\mathrm{H}^{+}\right]_{\mathrm{ave}}\left[\mathrm{Fe}\left(\mathrm{C}_{5} \mathrm{H}_{5}\right)_{2}\right]_{\mathrm{ave}}
$$

The results of kinetic experiments are given in Table 10 and also in Figure 9. The data in Table 10 indicate a slight but systematic decrease in $k^{\prime}$ with increasing $\left[\mathrm{H}^{+}\right]$. This effect might be related to the following equilibrium: 
Table 8. Rate and equilibrium data for the ferrocene-ferricenium electron transfer reactions ${ }^{a}$

$$
A+B^{+} \underset{k_{i j}}{\vec{i}} \underset{i j}{\vec{k}} A^{+}+B ; \quad k_{i j}=k_{i j} / k_{i j}^{\prime}
$$

\begin{tabular}{|c|c|c|c|c|c|c|c|}
\hline$\underset{i j}{\text { Reaction }}$ & $\begin{array}{c}\text { Substituted ferr } \\
\text { A }\end{array}$ & $\begin{array}{l}\text { ene system } \\
\text { B }\end{array}$ & $\begin{array}{l}\text { Init } \\
\text { [A] }\end{array}$ & $\begin{array}{l}a 1 \text { cor } \\
{\left[\begin{array}{c}x \\
B^{+}\end{array}\right]}\end{array}$ & $\begin{array}{l}\mathrm{M} \text { entrat } \\
{\left[\mathrm{A}^{+}\right]}\end{array}$ & [B] & $k_{i j} \times 10^{-6} \underline{M}^{-1} \mathrm{sec}^{-1}$ \\
\hline \multirow[t]{2}{*}{24} & $\begin{array}{r}1,1^{\prime}-\mathrm{di}-\underline{\mathrm{n}}-\mathrm{C}_{4} \mathrm{H}_{9} \\
(\mathrm{~K}=4.17)\end{array}$ & Ferrocene & $\begin{array}{l}6.0 \\
1.0 \\
8.0 \\
3.0 \\
4.0 \\
6.0 \\
0.0 \\
0.0\end{array}$ & $\begin{array}{l}6.0 \\
1.0 \\
8.0 \\
3.0 \\
8.0 \\
4.0 \\
0.0 \\
0.0\end{array}$ & $\begin{array}{l}0.0 \\
0.0 \\
0.0 \\
0.0 \\
0.0 \\
0.0 \\
6.0 \\
9.0\end{array}$ & $\begin{array}{l}0.0 \\
0.0 \\
0.0 \\
0.0 \\
0.0 \\
0.0 \\
6.0 \\
9.0\end{array}$ & $\begin{array}{l}15 . \pm 1 . \\
16 . \pm 2 . \\
15 . \pm 2 . \\
11.3 \pm 2 . \\
13.8 \pm 1 . \\
11.8 \pm 1.3 \\
13 . \pm \pm 1.2 \\
11.5 \pm 1 .\end{array}$ \\
\hline & & & & & & & Ave. $12.8 \pm 1.4$ \\
\hline \multirow[t]{2}{*}{34} & $\begin{array}{l}\underline{\mathrm{n}}-\mathrm{C}_{4} \mathrm{H}_{9} \\
\quad \\
\quad(\mathrm{~K}=1.89)\end{array}$ & Ferrocene & $\begin{array}{l}6.0 \\
3.0 \\
8.0 \\
4.5 \\
0.0 \\
0.0 \\
0.0\end{array}$ & $\begin{array}{l}6.0 \\
3.0 \\
3.0 \\
3.0 \\
0.0 \\
0.0 \\
0.0\end{array}$ & $\begin{array}{l}0.0 \\
0.0 \\
0.0 \\
0.0 \\
6.0 \\
8.0 \\
8.0\end{array}$ & $\begin{array}{l}0.0 \\
0.0 \\
0.0 \\
0.0 \\
6.0 \\
8.0 \\
4.5\end{array}$ & $\begin{array}{l}7.1 \pm 0.8 \\
6.5 \pm 0.4 \\
8.0 \pm 0.5 \\
7.9 \pm 0.6 \\
7.8 \pm 0.5 \\
6.7 \pm 0.6 \\
7.1 \pm 0.6\end{array}$ \\
\hline & & & & & & & Ave. $7.3 \pm 0.5$ \\
\hline
\end{tabular}

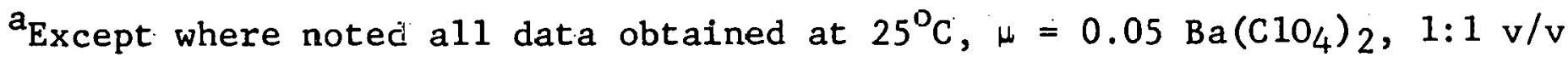
$\mathrm{H}_{2} \mathrm{O}-\underline{n}$-propanol, also see note $\mathrm{b}$ in Table 6 . 
Table 8. (Continued)

\begin{tabular}{|c|c|c|c|c|c|c|c|}
\hline $\begin{array}{l}\text { Reaction } \\
\quad i j\end{array}$ & $\begin{array}{l}\text { Substituted ferr } \\
\text { A }\end{array}$ & $\begin{array}{c}\text { cene system } \\
\text { B }\end{array}$ & $\begin{array}{l}\text { Init } \\
\text { [A] }\end{array}$ & $\begin{array}{c}1 \text { cor } \\
\times \\
{\left[B^{+}\right]}\end{array}$ & $\begin{array}{l}\text { centrat } \\
{ }^{6} \underline{M} \\
{\left[\mathrm{~A}^{+}\right]}\end{array}$ & $\begin{array}{l}\text { [ons } \\
\text { [B] }\end{array}$ & $k_{i j} \times 10^{-6} \underline{M}^{-1} \sec ^{-1}$ \\
\hline \multirow[t]{4}{*}{14} & $\begin{array}{l}1,1^{\prime}-\mathrm{di}-\mathrm{CH}_{3} \\
\quad(\mathrm{~K}=24.5) \\
\because \quad\end{array}$ & \multirow[t]{4}{*}{ Ferrocene } & $\begin{array}{l}6.0 \\
3.0 \\
1.5 \\
4.5 \\
5.0 \\
4.0 \\
6.0 \\
0.0 \\
0.0\end{array}$ & $\begin{array}{l}5.0 \\
3.0 \\
1.5 \\
4.5 \\
5.0 \\
7.0 \\
6.0 \\
0.0 \\
0.0\end{array}$ & $\begin{array}{r}0.0 \\
0.0 \\
0.0 \\
0.0 \\
0.0 \\
0.0 \\
0.0 \\
12.0 \\
6.0\end{array}$ & $\begin{array}{r}0.0 \\
0.0 \\
0.0 \\
0.0 \\
0.0 \\
0.0 \\
0.0 \\
12.0 \\
6.0\end{array}$ & $\begin{array}{l}23 . \pm 3 . \\
27 . \pm \pm 3 . \\
17.5 \pm 3 . \\
28.3 \pm 3 . \\
27 . \pm \pm 3 . b \\
24 . \pm \pm 5 . \\
20 . \pm 2 . \\
20 . \pm 1.5 \\
20 . \pm 1.5\end{array}$ \\
\hline & $(\mathrm{K}=21.0)$ & & $\begin{array}{l}6.0 \\
4.0\end{array}$ & $\begin{array}{l}6.0 \\
4.0\end{array}$ & $\begin{array}{l}0.0 \\
0.0\end{array}$ & $\begin{array}{l}0.0 \\
0.0\end{array}$ & $\begin{array}{l}\text { Ave. } 23 \pm 3 . \\
26.5 \pm 1.5^{c} \\
27 . \pm 1 . c\end{array}$ \\
\hline & $(\mathrm{K}=29.1)$ & & $\begin{array}{l}6.0 \\
4.0\end{array}$ & $\begin{array}{l}6.0 \\
4.0\end{array}$ & $\begin{array}{l}0.0 \\
0.0\end{array}$ & $\begin{array}{l}0.0 \\
0.0\end{array}$ & $\begin{array}{l}\text { Ave. } 27 . \pm 1.5^{\mathrm{c}} \\
\begin{array}{l}15 . \pm 2.5^{\mathrm{d}} \\
14 . \pm 1 . \mathrm{d}\end{array}\end{array}$ \\
\hline & & & & & & & Ave. $14.5 \pm 2.5$ \\
\hline $\begin{array}{r}\mathrm{b}_{\mathrm{Fe}} \\
\mathrm{Fe}(\mathrm{III})\end{array}$ & Lcenium prepared & oxidation & $\mathrm{f}$ & cent & ith & VI) $r$ & ather than \\
\hline
\end{tabular}


Table 8. (Continued)

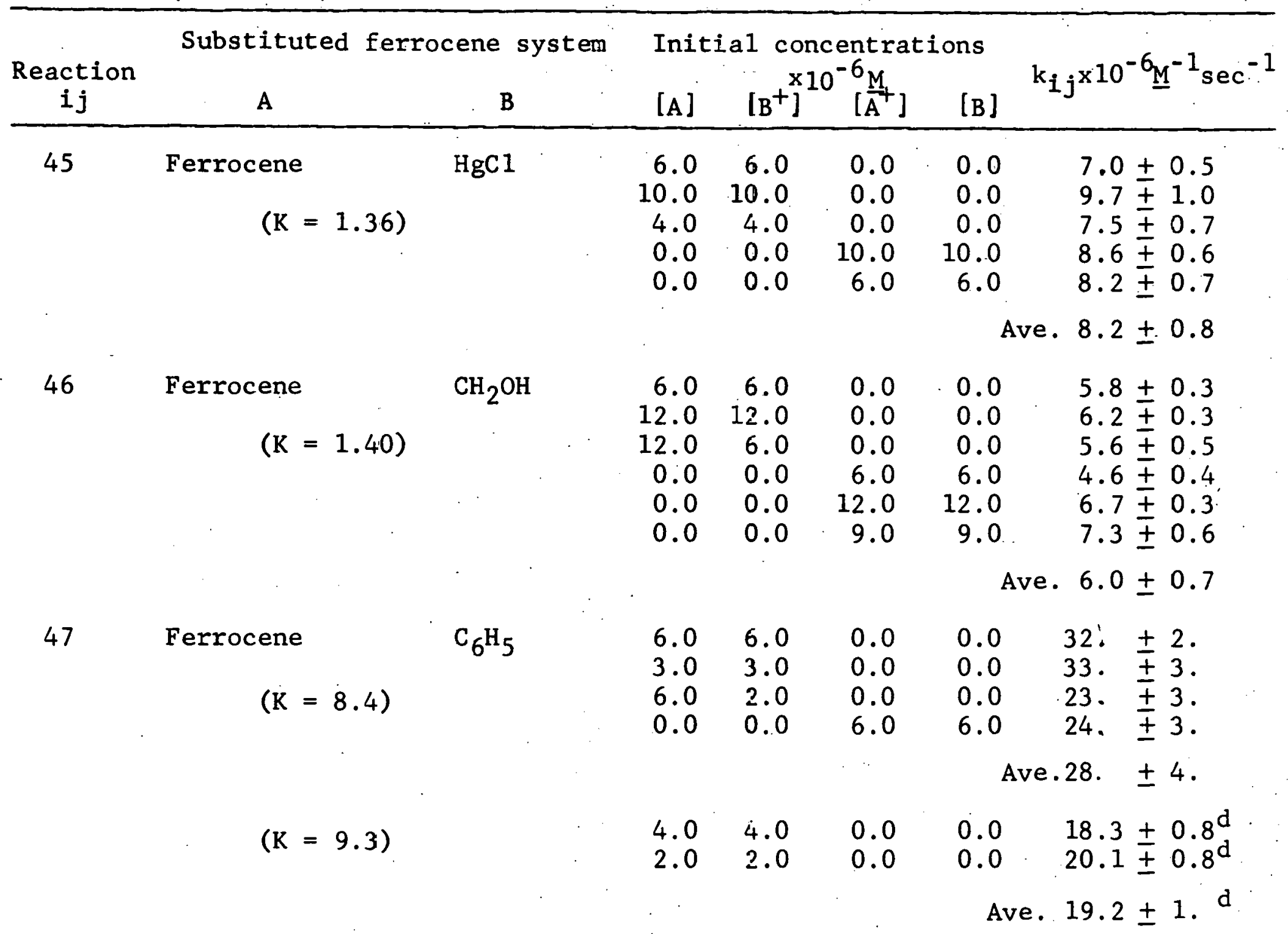


Table 8. (Continued)

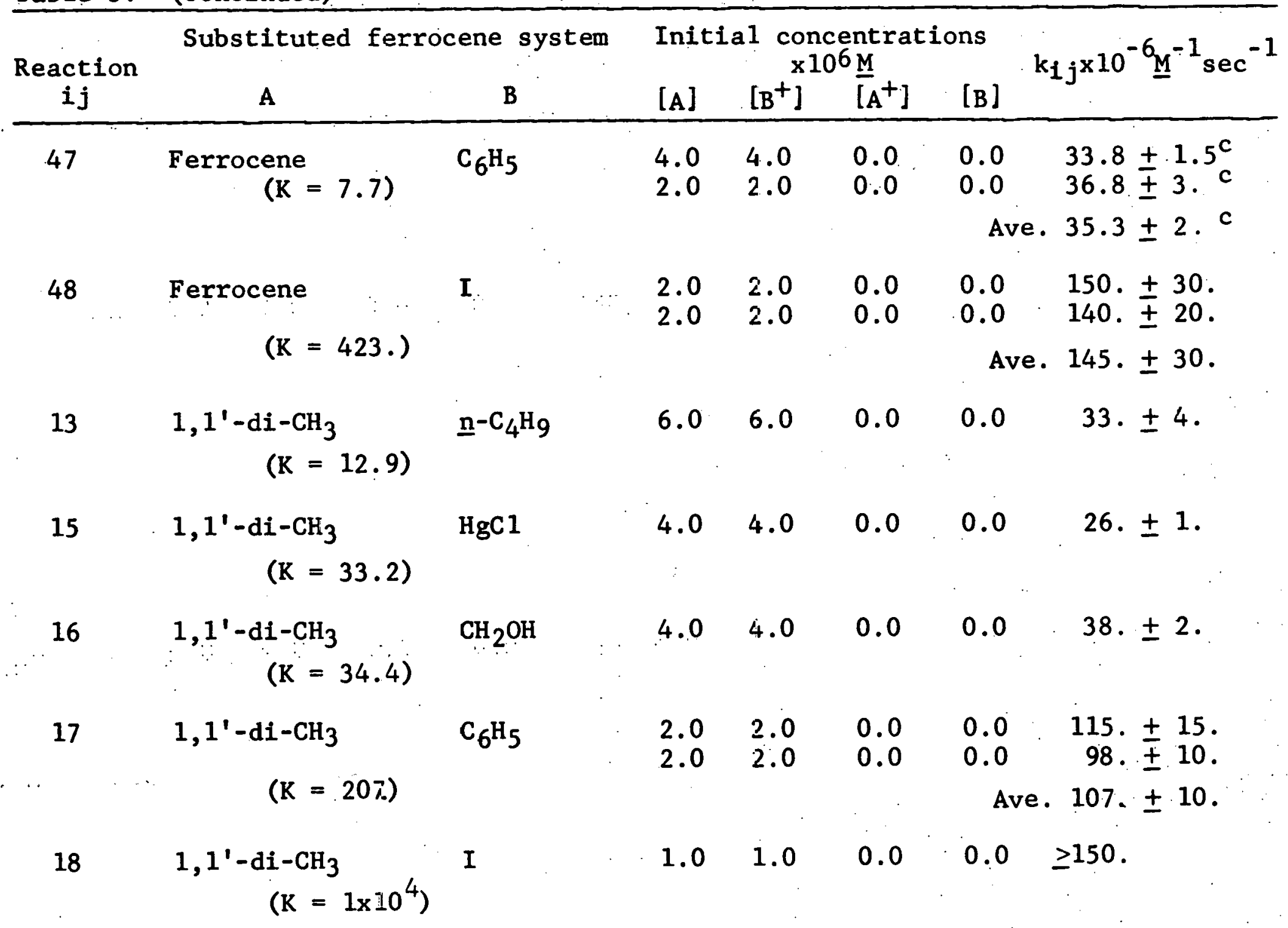


Table 8. (Continued)

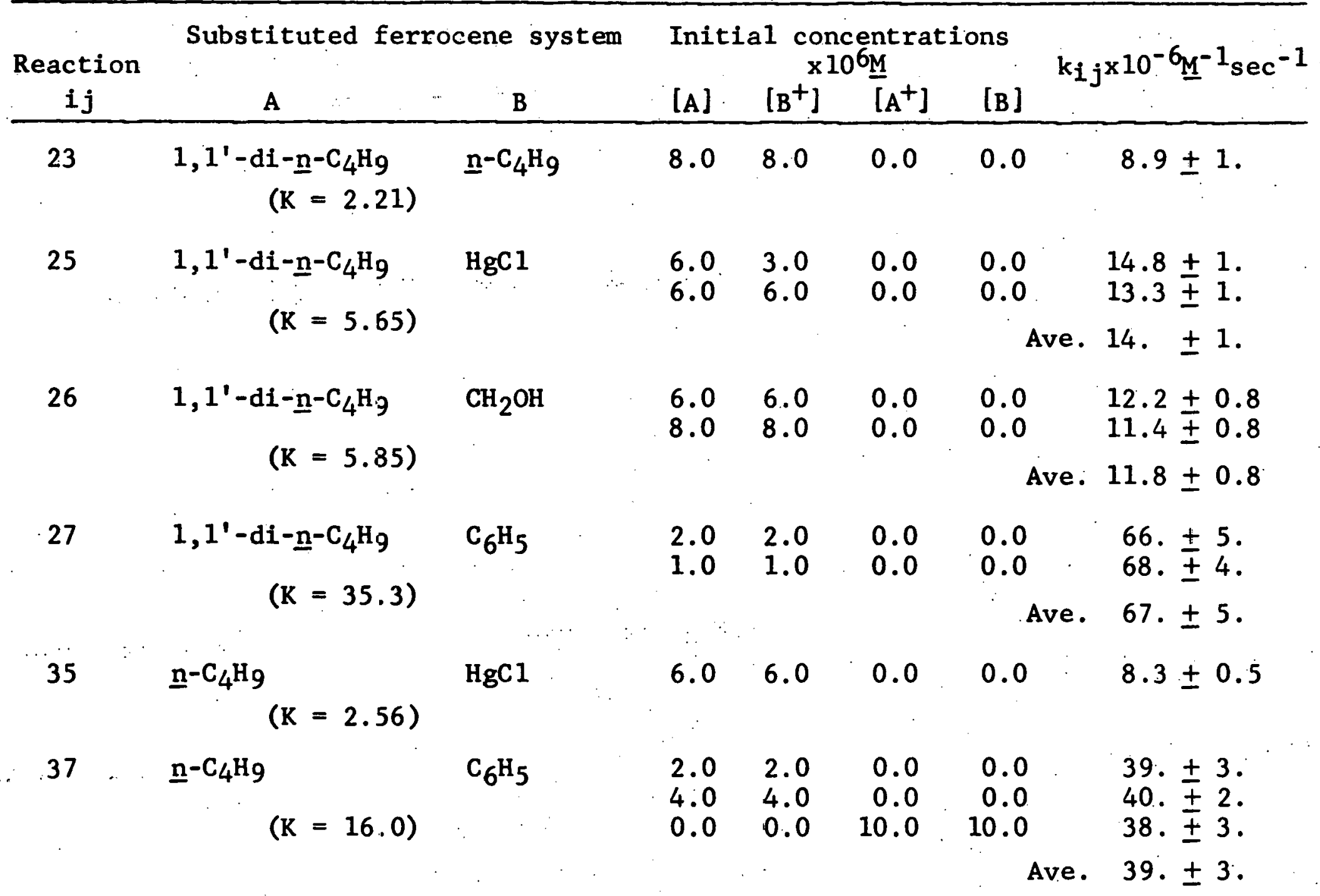


Table 8. (Continued)

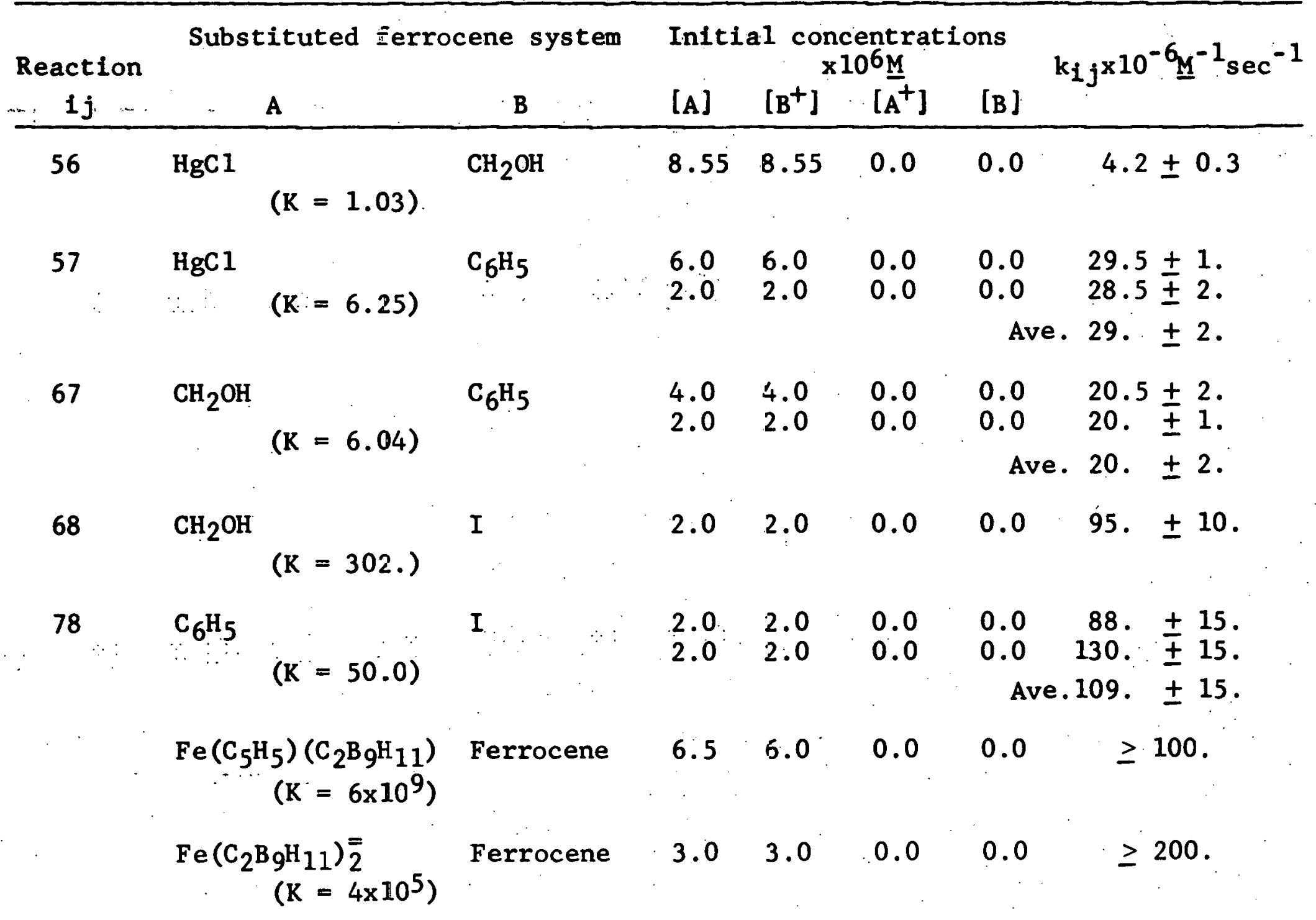


Table 8. (Continued)

\begin{tabular}{|c|c|c|c|c|c|c|c|}
\hline $\begin{array}{l}\text { Reaction } \\
\quad \mathbf{i j} \\
\end{array}$ & \multicolumn{2}{|c|}{ Substituted ferrocene system } & \multicolumn{4}{|c|}{$\begin{array}{c}\text { Initial concentrations } \\
\times 10^{6} \underline{\mathrm{M}}\end{array}$} & $k_{i j} \times 10^{-6} \underline{M}^{-1} \sec ^{-1}$ \\
\hline & $\begin{array}{c}\mathrm{Fe}\left(\mathrm{C}_{2} \mathrm{~B}_{9} \mathrm{H}_{11}\right)_{2}= \\
(\mathrm{K}=7 \times 1\end{array}$ & $\begin{array}{l}\mathrm{Fe}\left(\mathrm{C}_{5} \mathrm{H}_{5}\right) \\
\left(\mathrm{C}_{2} \mathrm{~B}_{9} \mathrm{H}_{11}\right)^{-}\end{array}$ & 2.0 & 2.0 & 0.0 & 0.0 & $\geq 200$ \\
\hline 14 & $1,1^{\prime}-\mathrm{di}-\mathrm{CH}_{3}$ & Ferrocene & $\begin{array}{l}6.0 \\
6.0\end{array}$ & $\begin{array}{l}6.0 \\
6.0\end{array}$ & $\begin{array}{l}0.0 \\
0.0\end{array}$ & $\begin{array}{l}0.0 \\
0.0\end{array}$ & $\begin{array}{l}21.6 \pm 1 . \\
16 . \pm 2 .\end{array}$ \\
\hline 34 & $1,1^{\prime}-d i-\underline{n}-C_{4} H_{9}$ & Ferrocene & $\begin{array}{l}6.0 \\
6.0 \\
6.0\end{array}$ & $\begin{array}{l}6.0 \\
6.0 \\
6.0\end{array}$ & $\begin{array}{l}0.0 \\
0.0 \\
0.0\end{array}$ & $\begin{array}{l}0.0 \\
0.0 \\
0.0\end{array}$ & $\begin{array}{l}7.4 \pm 0.5^{g} \\
21 . \pm \pm 1 . h \\
3.85 \pm 0.2^{i}\end{array}$ \\
\hline
\end{tabular}

${ }^{\mathrm{e}} \mathrm{Ch}$ loride ion as $\mathrm{NaCl}$ added at $0.01 \mathrm{M}$.

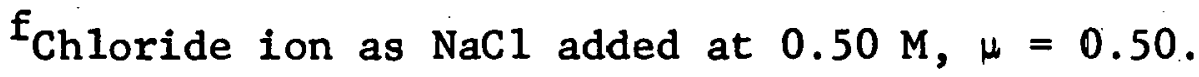

$\mathrm{g}_{\mathrm{No}}$ salt added to maintain ionic strength; $\mu \cong 0.0007$ from $\mathrm{HC}_{10}, \mathrm{Fe}^{2+}$, and ferricenium ion.

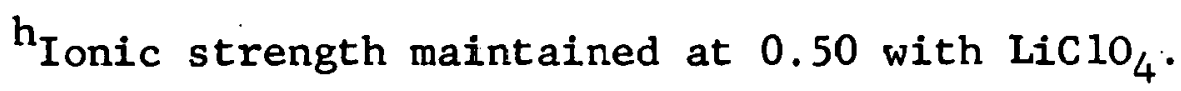

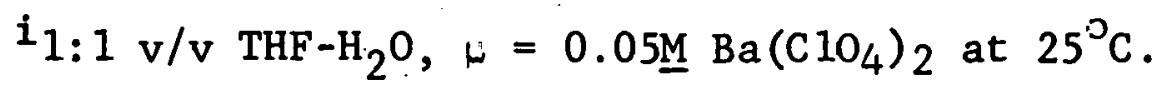


Table 8. (Continued)

\begin{tabular}{|c|c|c|c|c|c|c|c|}
\hline \multirow{2}{*}{$\begin{array}{c}\text { Reaction } \\
\text { ij } \\
\end{array}$} & \multirow{2}{*}{$\begin{array}{c}\text { Substituted } \\
\text { A }\end{array}$} & \multirow{2}{*}{$\begin{array}{c}\text { इerrocene system } \\
\therefore \quad \cdots\end{array}$} & \multicolumn{4}{|c|}{$\begin{array}{c}\text { Initial concentrations } \\
\times 10^{6} \underline{M}\end{array}$} & \multirow{2}{*}{$\mathrm{k}_{\mathrm{i} j} \times 10^{-6} \underline{\mathrm{M}}^{-1} \mathrm{sec}^{-1}$} \\
\hline & & & [A] & {$\left[\mathrm{B}^{+}\right]$} & $\left.\left[\mathrm{A}^{+}\right]\right]$ & {$[\mathrm{B}]$} & \\
\hline 34 & . &.. & $\begin{array}{l}6.0 \\
6.0\end{array}$ & $\begin{array}{l}6.0 \\
6.0\end{array}$ & $\begin{array}{l}0.0 \\
0.0\end{array}$ & $\begin{array}{l}0.0 \\
0.0\end{array}$ & $\begin{array}{l}\text { 10. } \pm 1 \cdot j \\
24 \cdot \pm 2 \cdot k\end{array}$ \\
\hline 14 & $1,1^{\prime}-\mathrm{d} \mathbf{i}-\mathrm{CH}_{3}$ & Ferrocene & 4.0 & 4.0 & 0.0 & 0.0 & $120 . \pm 10 .^{\ell}$ \\
\hline
\end{tabular}

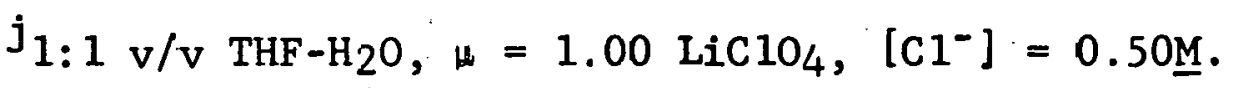

$\mathrm{k}_{1: 1} \mathrm{v} / \mathrm{v} \mathrm{THF}-\mathrm{H}_{2} \mathrm{O} \quad \mu=1.00 \mathrm{LiClO}_{4},\left[\mathrm{H}^{+}\right]=0.50 \mathrm{M}$.

${ }^{\ell}$ Neat rethano $1, \mathrm{HC}_{10} \cong 1 \times 10^{-3} \underline{\mathrm{M}}$, no added salt; $\mu \cong 1 \times 10^{-3}$ from $\mathrm{HC}_{4}$. 
Table 9. Activation and thermodynamic parameters for ferrocene-ferricenium ion electron transfer reactions

$$
\mathrm{A}+\mathrm{B}^{+} \rightleftharpoons \mathrm{A}^{+}+\mathrm{B}
$$

\begin{tabular}{lccccccc}
\hline $\begin{array}{l}\text { Reac- } \\
\text { tion }\end{array}$ & $\begin{array}{c}\text { Substituted ferrocene } \\
\mathrm{A}\end{array}$ & $\mathrm{B}$ & $\begin{array}{c}\Delta \mathrm{H}^{\ddagger}, \mathrm{kcal} \\
\mathrm{mole}\end{array}$ & $\Delta \mathrm{S}^{\ddagger}$, eu & $\begin{array}{c}\Delta \mathrm{H}^{\circ}, \mathrm{kcal} \\
\mathrm{mole}\end{array}$ & $\Delta \mathrm{S}^{\circ}$, eu \\
\hline 14 & $1,1-\mathrm{di}-\mathrm{CH}_{3}$ & Ferrocene & $+3.0 \pm 1.0$ & $-15.0 \pm 3.0$ & -1.91 & -0.05 \\
47 & Ferrocene & $\mathrm{C}_{6} \mathrm{H}_{5}$ & $+3.0 \pm .64$ & $-14.4 \pm 2.1$ & -1.08 & +0.61 \\
\hline
\end{tabular}


Table 10. Rate data for the oxidation of ferrocene by chromium(VI) a

\begin{tabular}{llccc}
\hline $\begin{array}{c}\text { [Ferrocene], } \\
\times 10^{3}, \underline{M}\end{array}$ & $\begin{array}{c}\text { Cr(VI), } \\
\times 10^{5}, \underline{M}\end{array}$ & $\begin{array}{c}{\left[\mathrm{H}^{+}\right],} \\
\underline{\mathrm{M}}\end{array}$ & $\begin{array}{c}\mathrm{k}_{\mathrm{obs},} \\
\mathrm{sec}^{-1}\end{array}$ & $\begin{array}{c}\mathrm{M}^{-2} \mathrm{sec}^{-1} \\
\times 10^{-4}\end{array}$ \\
\hline 1.01 & 3.34 & 0.050 & $0.47 \pm .01$ & 0.98 \\
2.06 & 3.0 & 0.050 & $0.98 \pm .03$ & 0.97 \\
0.12 & 0.4 & 0.050 & $0.059 \pm .004$ & 1.04 \\
0.60 & 2.0 & 0.050 & $0.28 \pm .01$ & 0.98 \\
1.65 & 2.0 & 0.100 & $1.38 \pm .03$ & 0.85 \\
1.03 & 2.0 & 0.100 & $0.85 \pm .02$ & 0.85 \\
0.206 & 0.686 & 0.100 & $0.168 \pm .01$ & 0.86 \\
0.237 & 0.79 & 0.100 & $0.23 \pm .01^{\mathrm{b}}$ & 1.02 \\
1.85 & 2.0 & 0.300 & $4.28 \pm .10$ & 0.78 \\
0.82 & 2.0 & 0.300 & $1.88 \pm .03$ & 0.79 \\
0.83 & 2.0 & 0.300 & $2.16 \pm .17^{\mathrm{b}}$ & 0.90 \\
1.24 & 2.0 & 0.300 & $2.66 \pm .05$ & 0.73 \\
0.515 & 1.72 & 0.300 & $1.13 \pm .05$ & 0.77 \\
1.24 & 2.0 & 0.300 & $4.19 \pm .1^{\mathrm{c}}$ &. \\
0.82 & 2.0 & 0.300 & $2.13 \pm .06^{\mathrm{d}}$ & \\
& & & & Ave. $0.89 \pm 10 \%$ \\
\hline
\end{tabular}
$25^{\circ} \mathrm{C}$.

${ }^{\mathrm{a}} \mathrm{All}$ work done at $\mu=1.00$ maintained with added $\mathrm{LiClO}_{4}$,

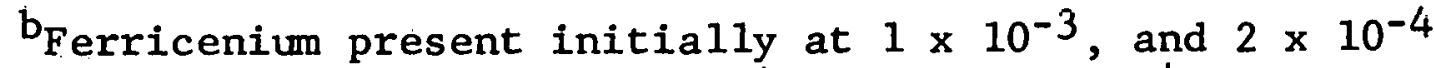
for these experiments at $0.100 \underline{\mathrm{M}}\left[\mathrm{H}^{+}\right]$and $0.300 \underline{\mathrm{M}}\left[\mathrm{H}^{+}\right]$respectively.

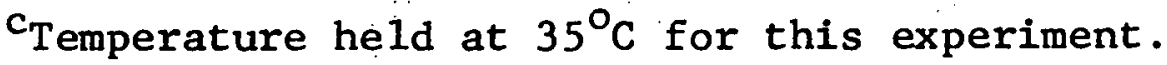

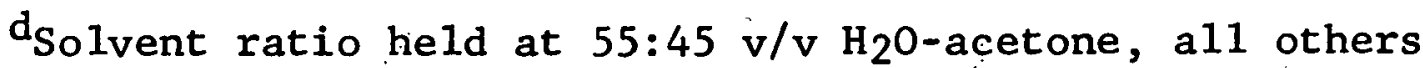
at a solvent ratio of $1: 1 \mathrm{v} / \mathrm{v} \mathrm{H}_{2} \mathrm{O}$-acetone. 


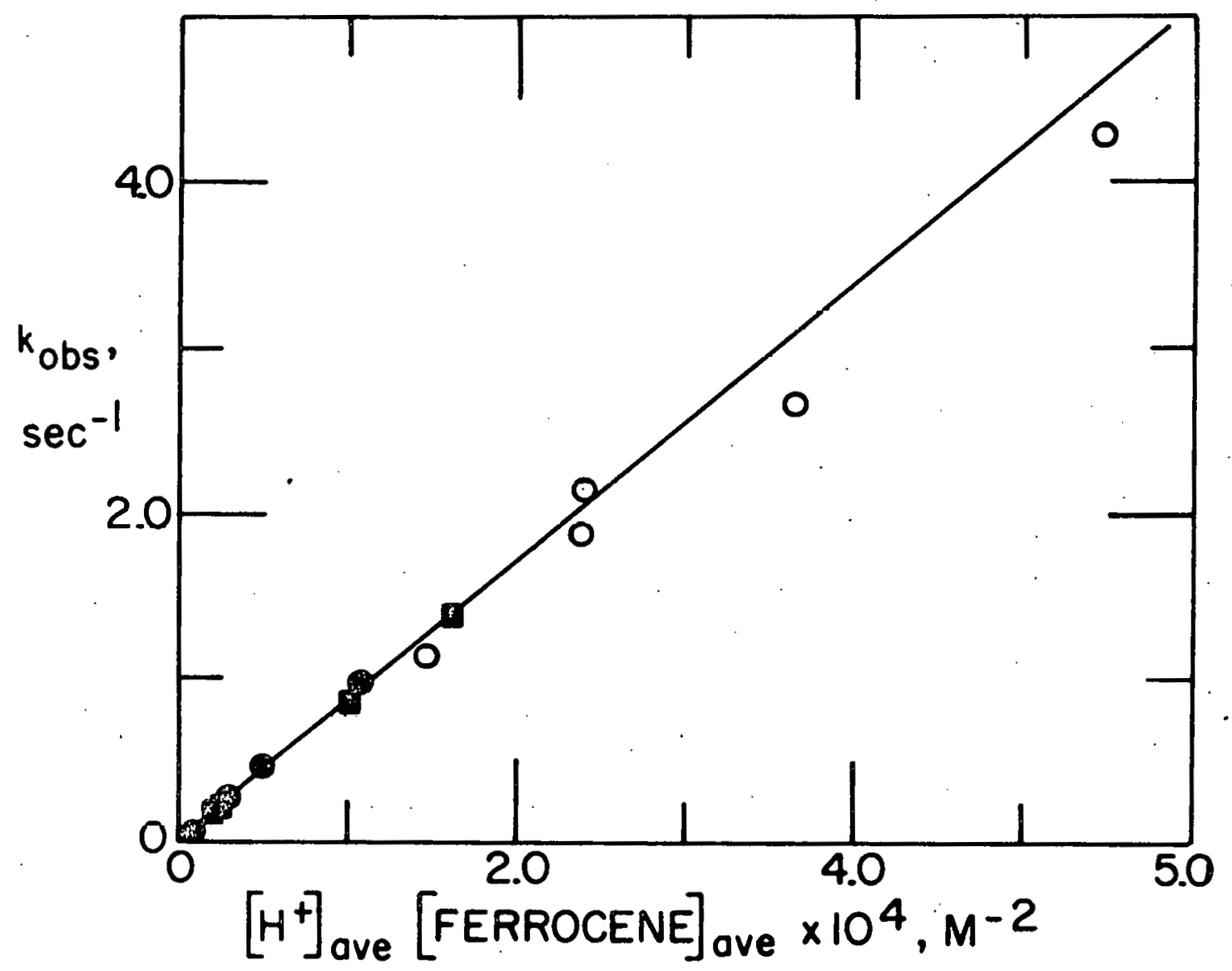

Figure 9. A plot of kinetic data in accord with Eq. 24 for the ferrocene-chromium(VI) reaction. The legend refers to different $\left[\mathrm{H}^{+}\right]: 0.05$ (solid circles), 0.10 (solid squares), and $0.30 \underline{\mathrm{M}}$ (open circles) 


$$
\mathrm{H}_{2} \mathrm{CrO}_{4} \rightleftharpoons \mathrm{HCrO}_{4}^{-}+\mathrm{H}^{+} \quad\left(\mathrm{K}_{\mathrm{a}}\right)
$$

To obtain a rate expression in terms of the predominant species of $\operatorname{Cr}(\mathrm{VI})$, rather than in terms of the total $\mathrm{Cr}$ (VI) concentration as in Eq. 24, the substitution [ $\left.\mathrm{HCrO}_{4}^{-}\right]=$ $[\mathrm{Cr}(\mathrm{VI})] \mathrm{K}_{\mathrm{a}} /\left(\left[\mathrm{H}^{+}\right]+\mathrm{K}_{\mathrm{a}}\right)$ is made, leading to the equation

$$
\frac{-\mathrm{d}[\mathrm{Cr}(\mathrm{VI})]}{\mathrm{dt}}=\mathrm{k}\left[\mathrm{HCrO}_{4}^{-}\right]\left[\mathrm{H}^{+}\right]\left[\mathrm{Fe}\left(\mathrm{C}_{5} \mathrm{H}_{5}\right)_{2}\right]
$$

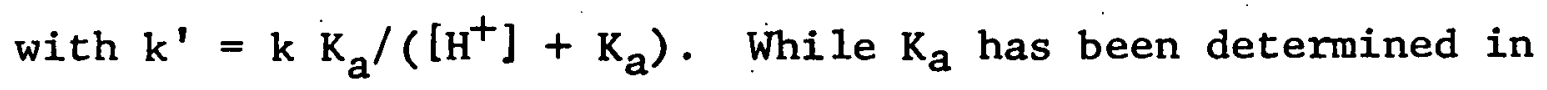
strictly aqueous medium $\left(\mathrm{K}_{\mathrm{a}} \sim 5.0 \mathrm{M}\right.$ at $\left.\mu=1.00 \underline{\mathrm{M}}, 25^{\circ}\right)$ (37), its value is not known in water-acetone. Judging by this value of $\mathrm{K}_{a}$, the correction for reaction 25 is likely to be a relatively small one.

An alternative approach is to fit the data in Table 10 numerica11y, treating both $\mathrm{k}$ and $\mathrm{k}_{\mathrm{a}}$ as unknowns. A least squares calculation gives the result $k=1.01 \pm 0.04 \times 10^{4} \mathrm{M}^{-2}$ $\sec ^{-1}$ and $\mathrm{K}_{\mathrm{a}}=1.06 \pm 0,25 \underline{\mathrm{M}}$. While this cannot be taken as an accurate determination of $\mathrm{K}_{\mathrm{a}}$, it does show that the $\mathrm{K}_{\mathrm{a}}$ necessary to account for the observed trend in ' ${ }^{\prime}$ with hydrogen ion concentration is not an unreasonable one.

To compare the results of the two parameter treatment $\left(\mathrm{K}_{\mathrm{a}}, \mathrm{k}\right)$ to that of the single parameter treatment (where 
formation of $\mathrm{H}_{2} \mathrm{CrO}_{4}$ was ignored), the deviations between the observed and calculated values of $k_{o b s}$ can be cited:

\section{Ave. deviation, $\%$ Max. deviation, $\%$}

2 parameter treatment

4

10

1 parameter treatment

10

18

While it is not surprising that the addition of a parameter improves the fit of the data, it is important to note that this treatment does remove the systematic trend of $k^{\prime}$ with hydrogen ion concentration and does so without invoking an unreasonable $\mathrm{k}_{\mathrm{a}}$. Consequently, it is concluded that over the range of hydrogen ion concentration and reactant concentration studied that only one transition state, $\left(\mathrm{Fe}\left(\mathrm{C}_{5} \mathrm{H}_{5}\right)_{2} \cdot \mathrm{H} \cdot \mathrm{HCrO}_{4}\right)^{\neq}$ is important.

In studies with excess chromium(VI) it was found that the stoichiometry is no longer given by Eq. 5. The ferricenium. ion produced by the initial oxidation step is subsequently destroyed in a slower reaction by excess chromium(VI). In addition, to interpret data with chromium(VI) in excess successfully, the equilibrium constant and relaxation time for the reaction below (38), Fq, 27 , must he known.

$$
2 \mathrm{HCrO}_{4}^{-} \underset{\mathrm{k}^{\prime}}{\stackrel{\mathrm{k}}{\rightleftarrows}} \mathrm{Cr}_{2} \mathrm{O}_{7}=+\mathrm{H}_{2} \mathrm{O} ; \quad \mathrm{K}
$$


Attempts to measure this relaxation, Eq. 27 , in $1: 1 \mathrm{v} / \mathrm{v} \mathrm{H}_{2}{ }^{\mathrm{O}}$ acetone were unsuccessful since the relaxation is complicated. by the attack of chromium(VI) on the solvent at a rate comparable to that of Eq. 27 . 


\section{INTERPRETATION AND DISCUSSION \\ Ferrocene-Ferricenium Ion Reactions}

The 22 electron transfer reactions, as described by Eq. 2, have rate constants which are related to their respective equilibrium constants. Figure 10 shows a plot of $\log k_{i j}$ vs $\log$ $\mathrm{K}_{\mathrm{ij}}$. The plot is approximately linear with the slope of the line shown being 0.55 . The linearity and slope of this line are predicted by the Marcus cross-relation, Eq. 6, provided the exchange rates, $k_{i i}$ and $k_{j j}$, remain approximately constant and provided that $f_{i j}, E q .6$, remains close to unity. Since $f_{i j}$ is a function of $k_{i j}$ one expects some curvature in a plot of this form, the extent of curvature being dependent on how significantly $f_{i j}$ deviates from unity as well as on the assumed equality of all the exchange rates. For the data presented in Figure 10 the experimental error in $k_{i j}$ in addition to these effects could disguise such curvature.

While Figure 10 then appears to be in reasonable agreement with the Marcus cross-relation a more rigorous test is possible, removing the assumption that all the exchange rates are identical. The method can be simply illustrated by considering on 1y three ferrocene compounds. Three cross-reactions are possible between them, the resulting experimental 


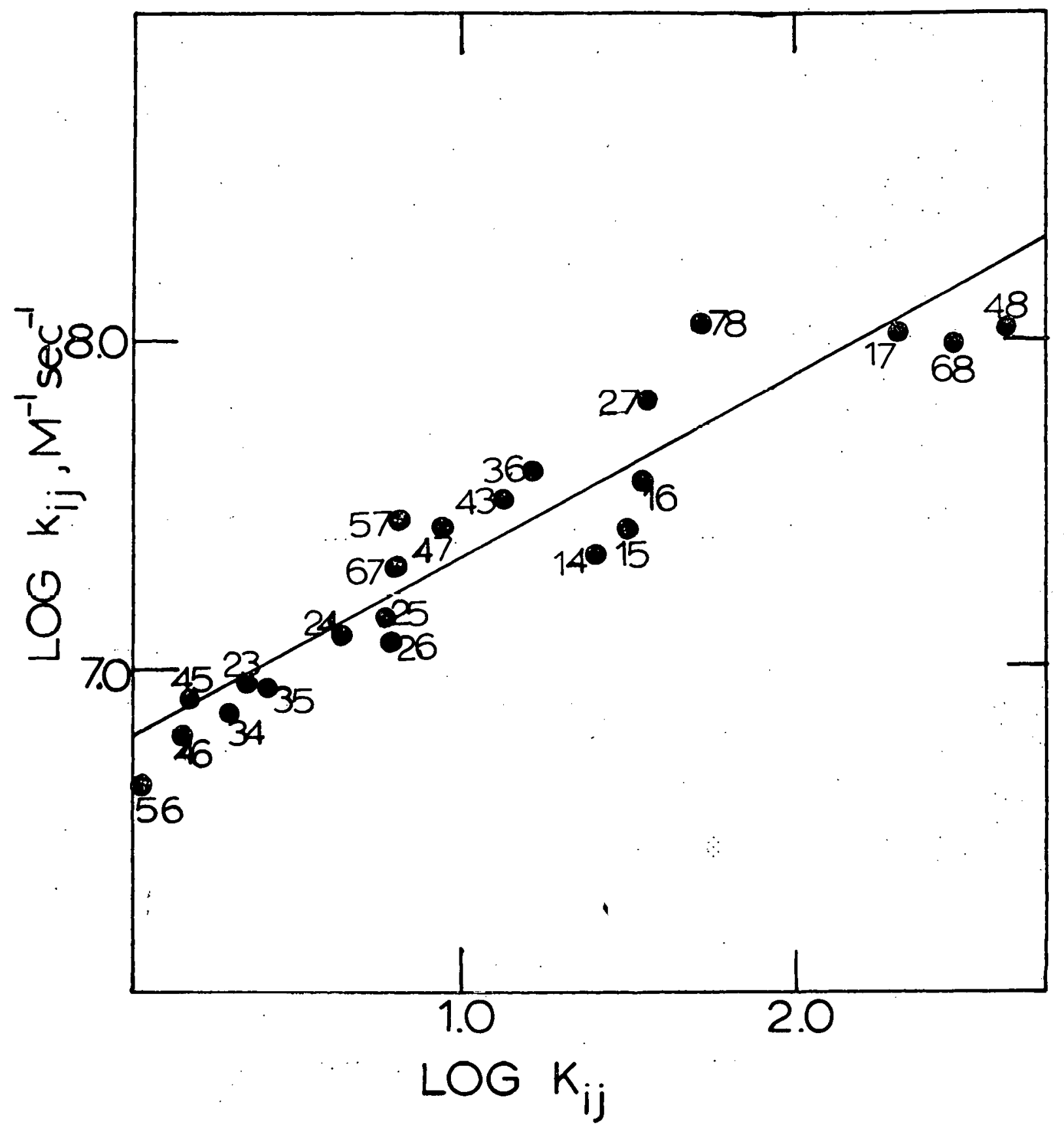

Figure 10. A plot of the $\log$ of the observed rate constant, $k_{i j}$, for the ferrocene-ferricenium ion electron transfer reactions, Eq. 2, vs the $\log$ of the respective equilibrium constants, $K_{i j}$ 
rate constants, say $k_{12} ; k_{13}$, and $k_{23}$ can be expressed in terms of their known equilibrium constants $\mathrm{K}_{12}, \mathrm{~K}_{13}$, and $\mathrm{K}_{23}$ and unknown exchange rates $k_{11}, k_{22}$, and $k_{33}$ as given by $E_{q}$. 6 . The result is three equations and three unknowns. 1

Solving these three equations gives $k_{11}, k_{22}$; and $k_{33}$ under the assumption that the Marcus relation is correct.

To apply this method more generally so as to utilize a11 the data in computing a "best" value for each exchange rate, a general solution for the separation of variables in the Marcus cross-relation was used. The relation is

$$
\ln k_{i i}+\ln k_{j j}=A_{i j}
$$

where $A_{i j}=\left(\ln k_{i j}-\frac{1}{2} \ln k_{i j}+\ln z\right)-\left[\left(\ln z-\ln k_{i j}\right)^{2}+\right.$ $\ln K_{i j}\left(\ln z-\ln k_{i j}\right) j^{\frac{1}{2}}$. Note that $A_{i j}$ is a function only of the collision frequency $\mathrm{Z}\left(\simeq 10^{11} \underline{\mathrm{M}}^{-1} \mathrm{sec}^{-1}\right)$ and of the experimentally determined cross-reaction rate $k_{i j}$ and equilibrium constant $K_{i j}$. With more than three related reactions it becomes useful to fit Eq. 28 for the "best" $k_{i i}, k_{j j}$ values. The 22 cross reactions and hence 22 equations such as Eq. 28 were fit for the best eight exchange rates $k_{11}$ through $k 88$. The results of this compilation are given in Table 11 .

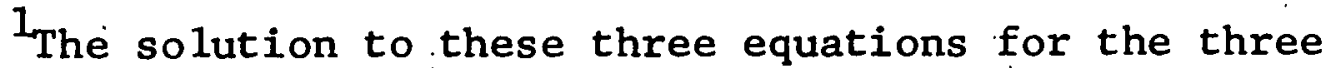
unknown exchange rates is given in the appendix of this thesis. 
Table 11. Calculated exchange rates for the ferroceneferricenium ion reactions

$$
\text { Substituted ferrocene } \quad k_{i i} \times 10^{-6}{ }_{M}{ }^{-1} \sec ^{-1}
$$

\begin{tabular}{llc}
1 & $1,1^{\prime}-\mathrm{di}-\mathrm{CH}_{3}$ & 6.6 \\
2 & $1,1^{\prime}-\mathrm{di}-\underline{\mathrm{n}}-\mathrm{C}_{4} \mathrm{H}_{9}$ & 6.7 \\
3 & $\underline{n}-\mathrm{C}_{4} \mathrm{H}_{9}$ & 6.5 \\
4 & Ferrocene & 5.7 \\
5 & $\mathrm{HgCl}$ & 5.3 \\
6 & $\mathrm{CH}_{2} \mathrm{OH}$ & 4.2 \\
7 & $\mathrm{C}_{6} \mathrm{H}_{5}$ & 18.0 \\
8 & $\mathrm{I}$ & 13.7 \\
\hline
\end{tabular}

A more complete comparison of experiment and theory is shown in Figure 11 where $\log k_{i j}$ experimental is plotted vs $\log \mathrm{k}_{\mathrm{ij}}$ calculated. The latter values were computed assuming the Marcus equation, and using the eight "best" $k_{i} i$ values resulting from the computational procedure. The mean deviation of observed and calculated $k_{i j}$ values is $13 \%$. The fit of experiment to theory is quite satisfactory and should be useful in a predictive sense. The $k_{i i}$ values given in Table 11 do not vary greatly ( a factor of four) for a rather wide range of compounds and it seems reasonable that other ferrocenes not too greatly different from the ones here should 
$66 \mathrm{~b}$

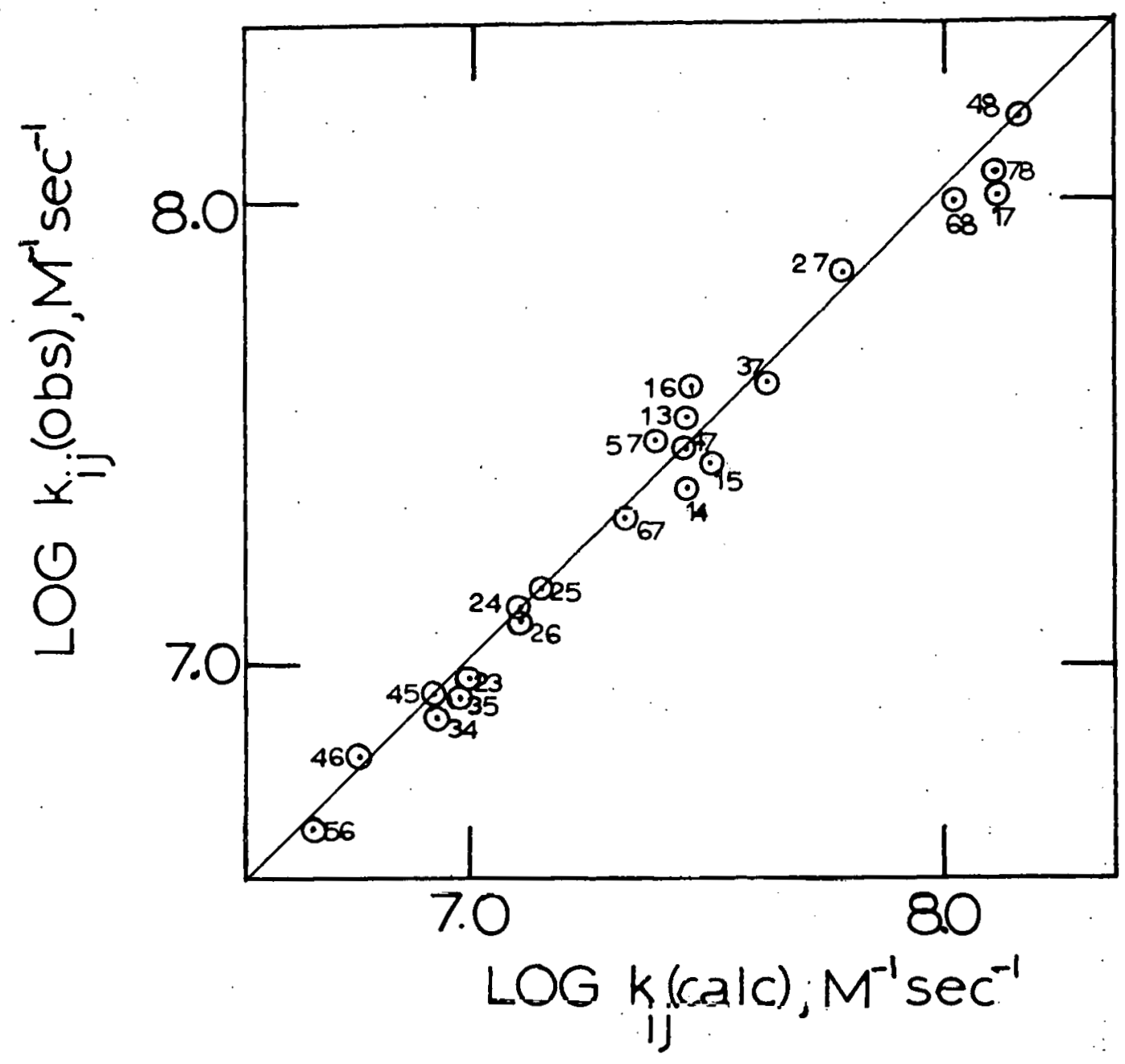

Figure 11. A plot of $\log k_{i j}$ observed vs $\log k_{i j}$ calculated for the ferrocene-ferricenium ion electron transfer reactions, $\mathrm{Eq} .2$. The values of $\mathrm{k}_{i j}$ calculated were determined using $\mathrm{Eq}$. 6, the exchange rates in $\mathrm{Table} 11$, and the equilibrium constants in Table 8 
have similar exchange rates. Consequently, the calculation of related ferrocene-ferricenium ion electron transfer rates would be straightforward. Obvious ly the direct measurement of some of the above calculated exchange rates by isotopic labeling or some other method would be useful in checking the validity of this model and these calculations. However, as mentioned in the introduction, the methods available for electron exchange studies are limited by the fact that no net chemical change occurs for exchange reactions. Stranks. (3) has measured the ferrocene-ferricenium ion exchange rate, Eq. 1 , determining the exchange rate constant, $k_{44}$, to be $1.7 \pm$ $0.4 \times 10^{6} \underline{\mathrm{M}}^{-1} \mathrm{sec}^{-1}$ at $-70^{\circ} \mathrm{C}$ in methanol. While work at $-75^{\circ} \mathrm{C}$ and $-65^{\circ} \mathrm{C}$ was also done in that study, the narrow temperature range covered and the large experimental error associated with the method make quantitative extrapolation of the data to $25^{\circ} \mathrm{C}$ unrealistic. In the same publication Stranks compared several theoretical models to the observed rates. The model that best fit the observed rates was one derived by Marcus $(8 e, f)$ which allows the calculation of the exchange rate provided an estimate of the molecular radius, a, is available. Maximum and minimum values for a of $4.10 \AA$ and $3.54 \AA$ respectively were tried in the calculation since these were felt to 
be the maximum and minimum radius of either ferrocene or ferricenium ion. The calculation using $a=3.54 \AA$ gave results in good agreement with the experimental rate constants measured at $-70^{\circ} \mathrm{C}$. From this model a value of $\sim 3 \times 10^{8} \underline{\mathrm{M}}^{-1} \mathrm{sec}^{-1}$ was calculated for the ferrocene-ferricenium ion exchange rate at $25^{\circ} \mathrm{C}$. Since data obtained in this study at $25^{\circ}$ 1:1 $\mathrm{v} / \mathrm{v}_{2} \mathrm{O}$-n-propanol cannot be directly compared to this value because of the difference in solvent, one experiment (last experiment given in Table 10) has been done in neat $\mathrm{MeOH}$ for the 1,1'-dimethylferrocene-ferricenium ion reaction. By comparing the value $\left(1.2 \times 10^{8} \underline{\mathrm{M}}^{-1} \mathrm{sec}^{-1}\right)$ obtained from this experiment with the average value for this same reaction in $1: 1 \mathrm{v} / \mathrm{v} \mathrm{H}_{2} 0$ - $\underline{n}$-propanol of $0.23 \times 10^{8} \underline{\mathrm{M}}^{-1} \mathrm{sec}^{-1}$ it can be seen the rate increased a factor of five in going from $1: 1 \mathrm{v} / \mathrm{v}$ $\mathrm{H}_{2} \mathrm{O}$-n-propanol to $\mathrm{MeOH}$ solvent. If this same factor is applied to our computed exchange rate we might then predict an exchange rate of $\sim 0.3 \times 10^{8} \underline{\mathrm{M}}^{-1} \mathrm{sec}^{-1}$ in $\mathrm{MeOH}$ at $25^{\circ}$. for the ferrocene-ferricenium ion exchange. While this is somewhat lower than the value of $\sim 3 \times 10^{8} \underline{M}^{-1} \mathrm{sec}^{-1}$ computed by Stranks, the difference may not be meaningful when the large errors associated with Stranks' calculation and our experi- 
ment $^{1}$ and subsequent extrapolation is considered.

An alternate interpretation of the ferrocene-ferricenium ion electron transfer reactions is embodied in the Hammett equation (39), Eq. 29 .

$$
\log k_{i j}=\log k_{i i}+\rho_{i} \sigma_{j}
$$

Where $k_{i j}$ and $k_{i i}$ are as defined earlier, $p_{i}$, a constant, is a function of the reaction but not the substituent, and $\sigma_{j}$, a constant, is a function only of substituent. For example, a plot of $\log k_{4 j}\left(k_{4 j}\right.$ being the rate constant for the reaction of ferrocene with the other substituted ferrocenes) versus $\sigma_{j}$ (Hammett parameter for jth substituent) should yield a slope of $p_{i}$ and an intercept of $k_{44}$. However, since Eq. 29 was originally used to correlate reactions of substituted benzoic acids, the $\sigma$ values available apply to either meta or para

$1_{\text {Only one experiment was carried out in methanol for }}$ several reasons; (a) all $\mathrm{E}^{\prime}$ data were obtained in other solvents, the use of these $\mathrm{E}^{\circ}$ ' values to obtain an equilibrium constant necessary to treat the data obtained in methanol is at best an approximation, (b) the reaction rates were very fast in methanol and hence the error associated with their measurement is greater than the error. for rates measured in 1:1 v/v H2O-n-propanol, (c) the method of preparing ferricenium ion by iron(III) oxidation was not successful in neat methanol, hence ferricenium ion prepared for methanol experiments was prepared by $\mathrm{Cl}_{2}$ oxidation of ferrocene in dilute $\mathrm{H}^{+}$in methanol, the concentration of ferricenium ion prepared in this manner is less precisely known. 
substituted benzoic acids. Use of these values for ferrocene reactions is not justified. Hall and Russell (30) have shown, however, that a linear combination $\left(\sigma_{j}=\left(\sigma_{m}+2 \sigma_{p}\right) / 3\right)$ of the meta and para $\sigma$ values correlated the oxidation potentials of substituted ferrocenes quite we11. (Presumably these $\sigma_{j}$ values should now be usable for any ferrocene reaction since $\sigma_{j}$ is not a function of the reaction). Using the potentials obtained in this study approximate values of $\sigma_{j}$ can be obtained from Hall and Russell's plot of electrode potential vs $\sigma_{j}$. A plot of $\log k_{4 j}$ vs $\sigma_{j}$ is shown in Figure 12. This plot is in reasonable agreement with $\mathrm{Eq} .29$ and yields a $\mathrm{k}_{44}$. value of $5.9 \times 10^{6} \mathrm{M}^{-1} \mathrm{sec}^{-1}$, which compares well with the value of $5.7 \times 10^{6} \underline{M}^{-1} \mathrm{sec}^{-1}$ (Table 11) obtained from the Marcus treatment, and gives $P_{4}$ of +5.0 . Similar plots have been made for the other ferrocenes where sufficient data are available and in general give similar $\rho$ values, (as they should since $\rho$ is a function only of the reaction) and give $k_{i i}$ values close to those found in the Marcus treatment.

As can be seen from the above arguments, the rate of the electron-transfer reactions, Eq. 2, can be understood quite well in terms of only the free energy for reaction. This is to say that substituent effects, other than their electronic 


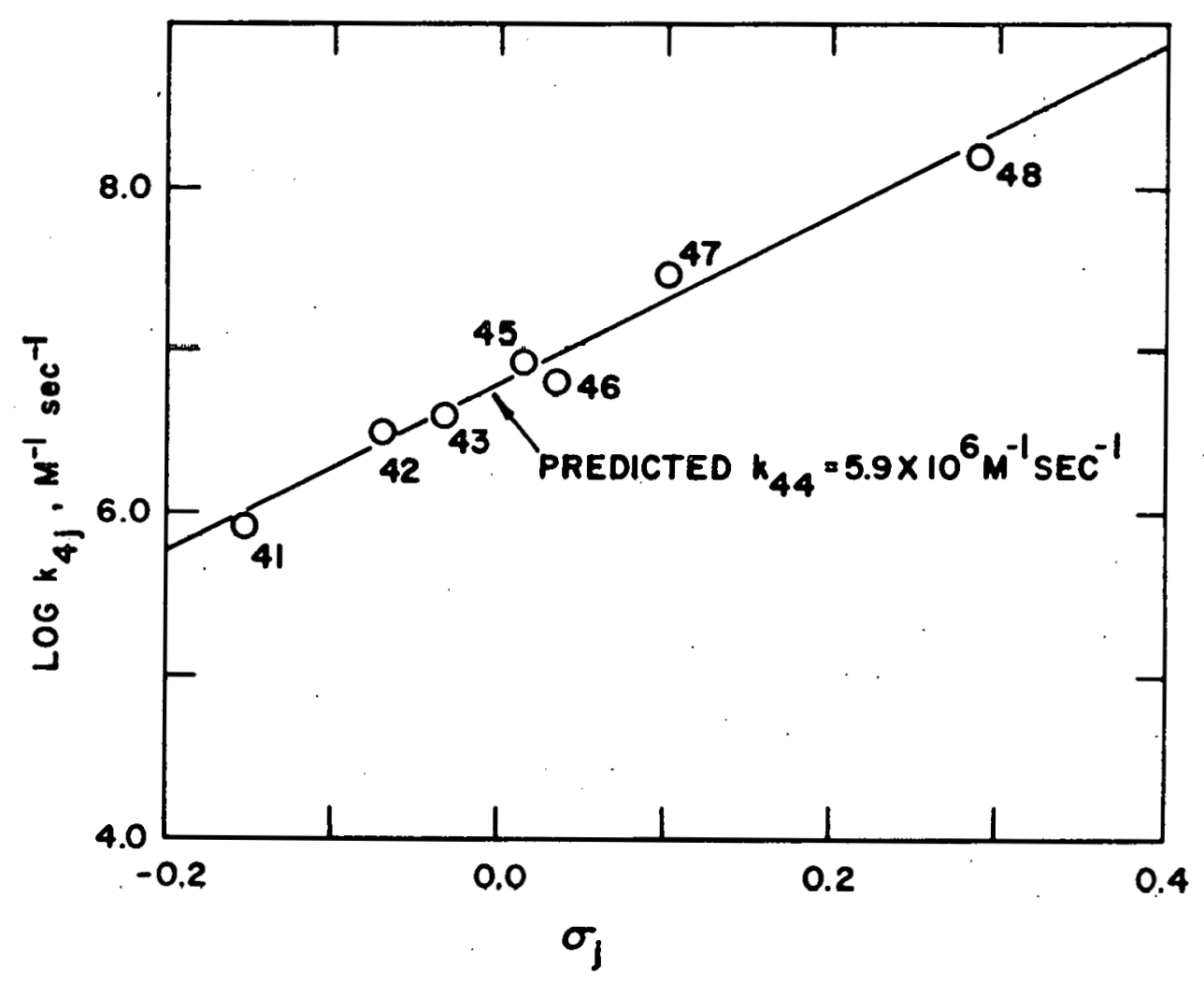

Figure 12. A plot of the log of the observed rate constant for the oxidation of ferrocene by substituted ferricenium ions vs the substituent constant, $\sigma_{j}$. The $a_{j}$ values were obtained by interpolation of data given in reference (30). Values for points 41,42 , and 43 were calculated from the reverse rate constants and equilibrium constants given in Table 8 . 
effects on the ferrocene oxidation potential, are not important for the types of substituents and degree of substitution studied here. There do not appear to be steric requirements depending on the size or geometry of the substituents nor does "bridging" from ferrocene to ferricenium ion via substituents appear to be important in forming the transition state. This is not to say, however, that a more drastic change in the structure of the ferrocene would not produce a noticeable effect. For example, it was of interest to determine if $\pi$-cyclopentadieny $1-\pi-(3)-1,2$-dicarbo11y 1 iron(II) and (III) and bis- $\pi-(3)-1,2-$ dicarbollyl iron(II) and (III) (See Figure 1) would have reaction rates significantly different than those predicted from the ferrocene results. It was felt that one possible detailed mechanism might involve electron transfer through the cyclopentadiene rings of two ferrocenes "sitting-on-top" of one another. If this is the correct mechanism the boron cage in the carbollyl compounds would serve to lengthen the iron-iron distance in the transition state and also block off the ring coordinated to the iron atoms and, as a result, might slow the rate of electron-transfer. From the potentials for the carbollyl compounds (Table 4), if no rate retarding effect were realized, the rate of reaction of 
any of the ferrocenes with either of the carbollyl compounds, or the rate of reaction between the two carbollyl compounds would be predicted to be too fast to observe. As can be seen from data in Table 10 these reactions were too fast to observe in this study. While observing a large rate retardation effect for the carbo11yl compounds might have lent some support to the "sitting-on-top" mechanism the lack of such an effect does not rule out such a mechanism for the ferrocene-ferricenium ion reactions. Studies on a ferrocene with all carbons in the $\pi$-cyclopentadieny 1 rings having substituents on them (such as decamethylferrocene) would also be of interest with regard to this possible mechanism. Such studies have not yet been done. Another plausible geometry of the transition state for these reactions might involve ferrocenes "side-by-side". To elucidate the role of this type of mechanism studies on ferrocenes having substituents which bridge from one cyclopentadiene ring to the other ring on the same ferrocene would be of interest (e.g. 1,1',3,3'-bis (trimethylene) ferrocene), since in compounds of this type the bridging substituent chains might hinder "side-by-side" approach.

A brief solvent and salt dependence was carried out and is given in Table 10. Goals of this study were two fold: 
(a) it has previously been reported (3) that salts in general and chloride ion in particular catalyze the ferrocene-ferricenium ion exchange rate, Eq. 1 , it was of interest to determine if this was also the case in this study; (b) in order to compare the ferrocene-ferricenium ion electron transfer studies with the iron(III)-ferrocene oxidation studies it was necessary to determine the effect of changing medium composition from $\mathrm{H}_{2} \mathrm{O}-\underline{n}$-propanol $(1: 1 \mathrm{v} / \mathrm{v}) \mu=0.050$ maintained with $\mathrm{Ba}\left(\mathrm{C} 10_{4}\right)_{2}$ to $\mathrm{H}_{2} \mathrm{O}-\mathrm{THF}(1: 1 \mathrm{v} / \mathrm{v}) \mu=1.00$ maintained with $\mathrm{LiClO}_{4}$. From the data in Table 10 it can be seen that chloride ion, in concentrations up to $0.50 \mathrm{M}$, did not catalyze the ferrocene-ferricenium ion electron transfer reactions studied here. With regard to salt dependence the last few experiments in Table 10 show the rate constant, $k_{24}$, of the di-n-butylferrocene-ferricenium ion reaction in $\mathrm{H}_{2} \mathrm{O}-\underline{n}$-propanol (1:1 v/v) to be $7.4 \pm 0.5,12.8 \pm 1.4$, and $21 . \pm 1.0 \times 10^{6} \underline{M}^{-1} \mathrm{sec}^{-1}$ in experiments with no added salt $(\mu=0.0007), \mu=0.05$ maintained with $\mathrm{Ba}\left(\mathrm{C}_{4}\right)_{2}$, and $\mu=0.50$ maintained with $\mathrm{LiC} 10_{4}$ respectively. While the rate does increase with increasing salt concentration, the increase is not as large as the effect observed by Stranks where the rate became immeasurably fast at salt concentrations greater than $1 \times 10^{-3} \underline{M}$ (3). 
In going from $\mathrm{H}_{2} \mathrm{O}$-n-propanol $(1: 1 \mathrm{v} / \mathrm{v})$ to $\mathrm{H}_{2} \mathrm{O}$-THF (1:1 $\mathrm{v} / \mathrm{v}$ ) both with $\mu=0.05 \mathrm{Ba}\left(\mathrm{ClO}_{4}\right)_{2}$ the rate decreases from $12.8 \pm 1.4$ to $3.85 \pm 0.2 \times 10^{6} \underline{\mathrm{M}}^{-1} \mathrm{sec}^{-1}$. However, on increasing the ionic strength to $\mu=1.00$ maintained with $\mathrm{LiClO}_{4}$ and $\mathrm{HC} \mathrm{O}_{4}$ in $\mathrm{H}_{2} \mathrm{O}-\mathrm{THF}(1: 1 \mathrm{v} / \mathrm{v})$ the rate increases to $24 . \pm 2.0 \mathrm{x}$ $106 \underline{M}^{-1} \sec ^{-1}$. Hence, the net effect on going from $\mathrm{H}_{2} 0-\underline{n}-$ propanol $(1: 1 \mathrm{v} / \mathrm{v}) \mu=0.05$ maintained with $\mathrm{Ba}\left(\mathrm{ClO}_{4}\right)_{2}$ (the conditions under which the ferrocene-ferricenium ion reactions were observed) to $\mathrm{H}_{2} \mathrm{O}-\mathrm{THF}(1: 1 \mathrm{v} / \mathrm{v}) \mu=1.00$ maintained with $\mathrm{LiClO}_{4}$ and $\mathrm{HClO}_{4}$ (the conditions under which the iron(III)ferrocene reactions were observed) is to increase the electron transfer rates by about a factor of 2 from $12.8 \pm 1.4$ to 24. \pm 2 . $\times 10^{6} \underline{M}^{-1}$ sec $^{-1}$. This result will be used in the discussion of the iron(III)-ferrocene reactions.

\section{Iron(III)-Ferrocene Reactions}

The rates of oxidation of the substituted ferrocenes by iron(III) for seven of the ferrocenes (chloromercuriferrocene decomposes rapidly in acid solution) and one of the carbollyl compounds ( $\pi$-cyclopentadieny $1-\pi-(3)-1,2$-dicarbol1yliron(II)) were measured and found to be a function of their respective equilibrium constants, Figure 13. From Figure 13 it can be seen that the rate of the iron(III) $-\pi$-cyclopentadienyl- $\pi-(3)-$ 
1,2-dicarbollyiron(II) anion reaction falls on the same line with the ferrocene derivatives. In terms of the Marcus crossrelation this kind of behavior would suggest a similar exchange rate for the $\pi$-cyclopentadieny $1-\pi-(3)-1,2-$ dicarbolly iron(II)-iron(III) reaction as for the ferrocene-ferricenium ion exchange rates. The slope of the line shown in Figure 13 is $\simeq 0.44$. It is difficult to compare directly Figure 13 with what is predicted from the Marcus equation since for these reactions the $f_{i}$ values represent a significant and varying contribution to the predicted rate. However, since estimates of the ferrocene-ferricenium ion exchange rates are available (which have been shown not to change greatly, factor of 2, in going to this reaction medium) and since the iron(II)iron(III) exchange rate has been measured in various solvents (40) a direct comparison between observed and predicted rate can be made. Using an iron(II)-iron(III) ${ }^{1}$ exchange rate of $4 \underline{\mathrm{M}}^{-1} \sec ^{-1}$ and multiplying each value in Table 11 by two for the ferrocene-ferricenium ion exchange rates the plot shown

${ }^{1}$ It was shown in reference (40) that the $\mathrm{Fe}$ (II)-Fe(III) exchange rate was in the range of 1 to $8 \mathrm{M}^{-1} \mathrm{sec}^{-1}$ for various mole fractions of methanol, ethanol, or $\underline{n}$-propanol. The value of $8.22 \mathrm{M}^{-1} \mathrm{sec}^{-1}$ was : obtained for $0.50 \mathrm{M}$ aqueous perchloric acid. 


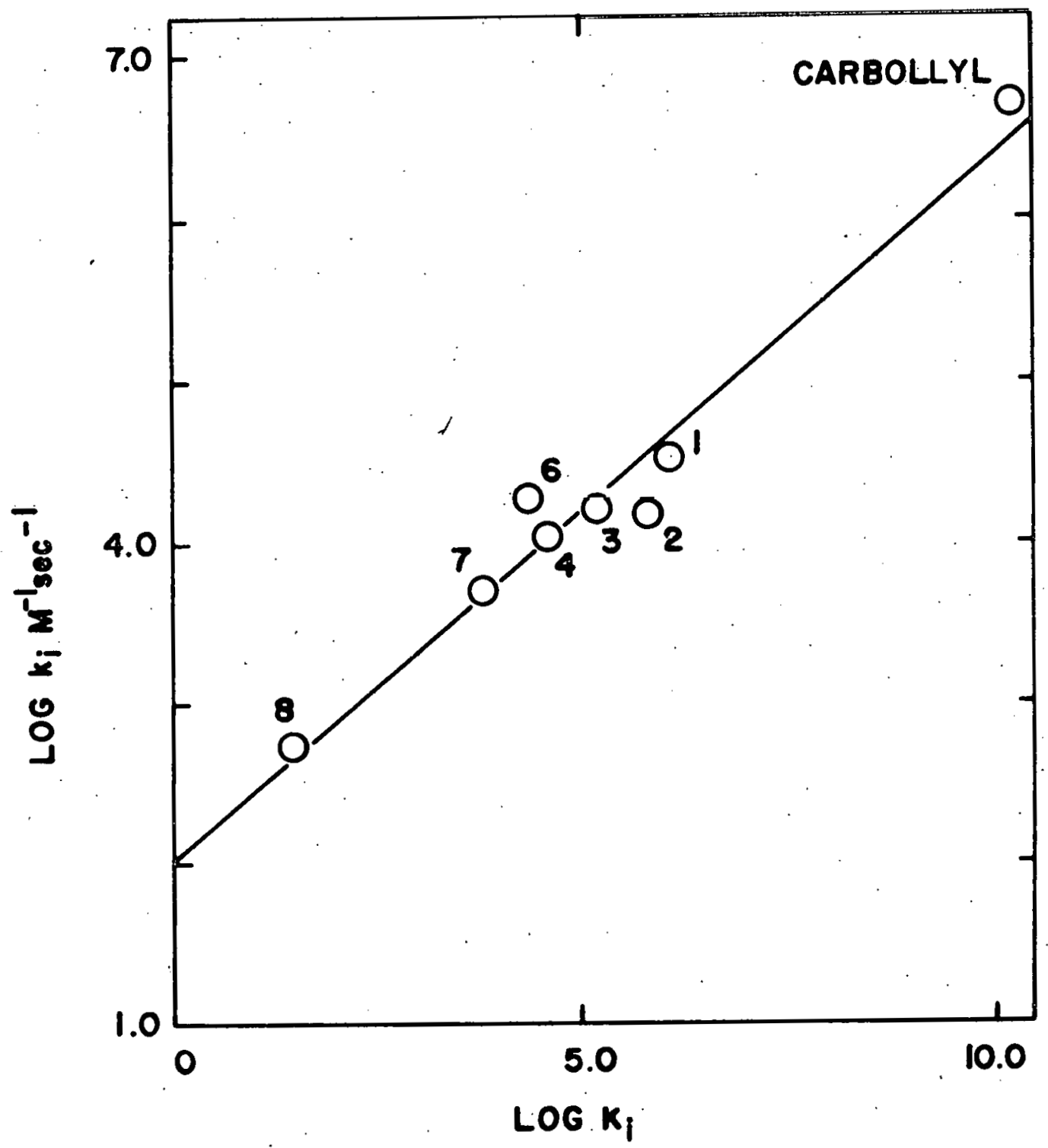

Figure 13. A plot of $\log \mathrm{k}_{\mathbf{i}}, \mathrm{Eq} .4$, vs $\log \mathrm{K}_{i}$, the equilibrium constant for the reaction described by Eq. 4 
in Figure 14 is obtained. As can be seen from Figure 14 the observed rates are in very poor agreement with calculated rates and are from 25-200 times lower than predicted. The lack of agreement of theory and experiment for the iron(III)ferrocene reactions is not particularly surprising. In the derivation of Eq. 6 the assumption is made that the work terms associated with bringing reactants and products together cancel or are negligible, however, it has been pointed out by Marcus ( $8 \mathrm{~b})$ that this assumption is likely to break down when the work terms of the two exchange reactions and the cross-reaction are not quite similar. For example, for an electron transfer reaction between two substituted trisphenanthrolineiron complexes the assumption should be valid because the work terms of the two exchange reactions and the corresponding electron transfer reaction will be very similar. Alternatively if the cross-reaction was between two pairs of aquo ions where only charge is transferred again the work terms should cancel. However, for the reaction between an aquo ion, say iron(III), and trisphenanthrolineiron(II) Marcus argues that there is no reason to expect the work terms of the two exchange reactions and the electron transfer reaction to be equa1. Similarly in the iron(III)-ferrocene reactions 


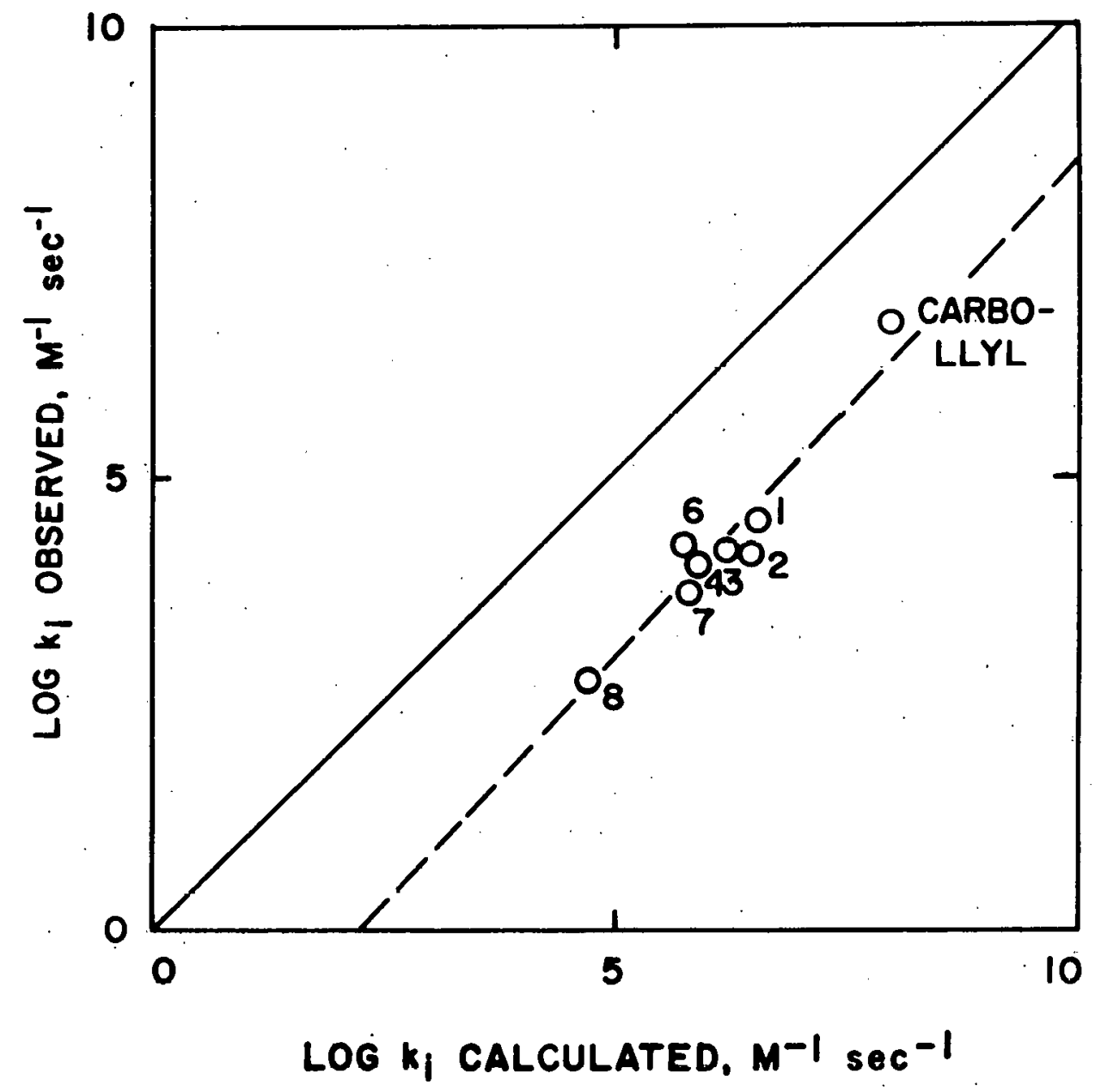

Figure 14. A plot of $\log k_{i}$, Eq. 4, observed vs $\log k_{i}$ calculated. The solid line represents the predicted line from the Marcus equation and the dashed line is a line drawn through the observed points. The $k_{i}$ calculated values were obtained by assuming Eq. 6 and using a value of $4 \mathrm{M}^{-1}$ sec $^{-1}$ for the iron(II)iron(III) exchange and twice the values given in Table 11 for the ferrocene-ferricenium ion exchange rates, $\mathrm{Eq} .3$ 
there is no reason to expect the work terms for hexaaquoiron (II) -(III) exchange and the ferrocene-ferricenium ion exchange to be similar, or to be equal to the cross-reaction work terms.

When the work terms fail to cancel Marcus claims two deductions may be made $(8 \mathrm{~b})$ : (1) the observed rates will be lower than the predicted rates due to an unaccounted for contribution to the free energy of activation from the work terms, (2) if ratios of related reactions $k_{12} / k_{13}$ are considered the work terms should again cancel. In looking at Figure 14 point ( 1 ) is evident. The comparison suggested by point (2) has been attempted and while in principle it should be a useful comparison the large error associated with the experimental rate constants greatly reduces its usefulness (24). Sutin (12) has observed that the experimental electron-transfer rates between substituted trisphenanthrolineiron(III) and iron(II) and between substituted trisphenanthrolineiron (II) complexes and $\mathrm{Ce}(\mathrm{IV}), \mathrm{Mn}(\mathrm{III})$, and $\mathrm{Co}$ (III) are lower than corresponding calculated rates from Eq. 6 . In all but the Co(III)-trisphenanthrolineiron(II) reactions it was suggested that the discrepancy in observed and calculated rates resulted from non-cancellation of work terms as described. 
above, point (1).

Ferrocene-Chromium(VI) Reaction

The chromium(VI)-ferrocene reaction is of particular interest since the mechanisms of chromium(VI)-transition metal complex reactions have been extensively studied (41). The oxidation of ferrocene by chromium(VI) is consistent with a mechanism involving three one-equivalent steps, Eq. 30 .

$$
\begin{aligned}
& \mathrm{Fe}\left(\mathrm{C}_{5} \mathrm{H}_{5}\right)_{2}+\mathrm{Cr}(\mathrm{VI}) \stackrel{\mathrm{k}_{5}}{\rightarrow} \mathrm{Fe}\left(\mathrm{C}_{5} \mathrm{H}_{5}\right)_{2}^{+}+\mathrm{Cr}(\mathrm{V}) \\
& \mathrm{Cr}(\mathrm{V})+\mathrm{Fe}\left(\mathrm{C}_{5} \mathrm{H}_{5}\right)_{2} \stackrel{\mathrm{k}_{4}}{\rightarrow} \mathrm{Fe}\left(\mathrm{C}_{5} \mathrm{H}_{5}\right)_{2}^{+}+\mathrm{Cr}(\mathrm{IV}) \\
& \mathrm{Cr}(\mathrm{IV})+\mathrm{Fe}\left(\mathrm{C}_{5} \mathrm{H}_{5}\right)_{2} \stackrel{\mathrm{k}_{3}}{\rightarrow} \mathrm{Fe}\left(\mathrm{C}_{5} \mathrm{H}_{5}\right)_{2}^{+}+\mathrm{Cr}(\mathrm{III})
\end{aligned}
$$

Mechanisms involving two-equivalent steps are disfavored since oxidation of ferricenium ion results in irreversible decomposition of the metallocene and it is known that the ferrocenechromium(VI) reaction gives the stoichiometric amount of ferricenium ion. Furthermore it is known (42) that the chronopotentiometric oxidation of ferrocene is a one-equivalent reversible oxidation to ferricenium ion. Increasing the voltage to as high as $+1.4 \mathrm{~V}$ versus SCE did not produce another oxidation wave for the ferrocene-ferricenium ion solutions. Hence, it does not seem possible that $\operatorname{Cr}(\mathrm{VI})$ could be involved 
in a two-equivalent oxidation of ferrocene. This is not a surprising result since most chromium(VI) oxidations of transition metal complexes are thought to proceed via the one-equivalent mechanism (41).

The fact that only one transition state, $\left[\mathrm{Fe}\left(\mathrm{C}_{5} \mathrm{H}_{5}\right)_{2}\right.$. $\left.\mathrm{H} \cdot \mathrm{HCrO}_{4}\right]^{\neq}$, is found for this reaction and that $\mathrm{Fe}\left(\mathrm{C}_{5} \mathrm{H}_{5}\right)_{2}^{+}$ion was not found to retard the rate indicate that (if mechanism 30 is the correct mechanism) step $k_{5}$ corresponds to the rate determining step and that $k_{4}$ and $k_{3}$ are rapid. In general for chromium(VI) oxidations where the one equivalent mechanism has been invoked the first step has been found rate determining in substitution inert complexes, such as $\mathrm{Fe}(\mathrm{CN})_{6}^{4-}, \mathrm{Fe}(\mathrm{CN})_{4}(\mathrm{bipy})^{2-}$, $\mathrm{Fe}(\mathrm{CN})_{4}$ (bipy) $2_{2}^{2-}, \mathrm{Fe}(\mathrm{CN})_{2}$ (bipy) ${ }_{2}, \mathrm{Fe}(\mathrm{phen})_{3}^{2+}, \mathrm{Fe}$ (bipy) ${ }_{3}^{2+}$ and the second step has been found rate determining with labile transition metal complexes (41) $\left(\mathrm{Fe}\left(\mathrm{OH}_{2}\right)_{6}^{2+}, \mathrm{VO}_{2}^{+}\right)$. The results of the ferrocene-chromium(VI) reaction are also in agreement with this general point.

The hydrogen ion dependence of the chromium(VI)-ferrocene reaction can be interpreted in several ways: (a) a thirdorder reaction between $\mathrm{H}^{+}, \mathrm{HCrO}_{4}^{-}$and ferrocene, (b) a secondorder reaction between $\mathrm{H}_{2} \mathrm{CrO}_{4}$ and ferrocene, or (c) a secondorder reaction between a protonated ferrocene cation, $\mathrm{Fe}\left(\mathrm{C}_{5} \mathrm{H}_{5}\right)_{2} \cdot \mathrm{H}^{+}$and $\mathrm{HCrO}_{4}^{-}$(in addition to any other mechanism 
which produces the correct composition of the transition state). All of these mechanisms are of course kinetically indistinguishable. A preference for mechanisms (b) and (c) can be expressed since they involve only bimolecular processes while mechanism (a) is a third-order process. A choice between mechanisms (b) and (c) is more difficult since both species $\mathrm{Fe}\left(\mathrm{C}_{5} \mathrm{H}_{5}\right)_{2} \cdot \mathrm{H}^{+}$(43) and $\mathrm{H}_{2} \mathrm{CrO}_{4}$ are known to be present in acidic solution. 


\section{APPENDIX}

Exchange Rate Solution to the Marcus Equation

The Marcus cross-relation is:

$$
k_{i j}=\left(k_{i i} \cdot k_{j j} \cdot k_{i j} \cdot f_{i j}\right)^{\frac{1}{2}}
$$

where

$$
\ln f_{i j}=\left(\ln k_{i j}\right)^{2} / 4 \ln \left(k_{i i} \cdot k_{j j} / z^{2}\right)
$$

Taking the natural logarithm of (1) and rearranging gives:

$$
-\frac{1}{2}\left(\ln k_{i i}\right)^{2}+\ln k_{i i}\left(\ln k_{i j}-\ln k_{j j}-\frac{1}{2} k_{i j}+\ln z\right)+
$$

$\left(\ln k_{j j}-2 \ln z\right)\left(\ln k_{i j}-\frac{1}{2} \ln k_{j j}-\frac{1}{2} \ln k_{i j}\right)-\frac{1}{8}\left(\ln k_{i j}\right)^{2}=0$ Equation $2 \mathrm{~A}$ is of the form $a x^{2}+b x+c=0$, where;

$$
\begin{aligned}
& a=-\frac{1}{2} \\
& b=\left(\ln k_{i j}-\ln k_{j j}-\frac{1}{2} \ln k_{i j}+\ln z\right) \\
& c=\left(\ln k_{j j}-2 \ln z\right)\left(\ln k_{i j}-\frac{1}{2} \ln k_{i j}-\frac{1}{2} \ln k_{i j}\right)-\frac{1}{8}\left(\ln k_{i j}\right)^{2} \\
& x=\ln k_{i i}
\end{aligned}
$$

The solution to this quadratic equation after algebraic rearrangement is:

$$
\begin{gathered}
\ln k_{i i}+\ln k_{j j}=A_{i j} \\
A_{i j}=\left[\left(\ln z-\ln k_{i j}\right)^{2}+\ln k_{i j}\left(\ln z-\ln k_{i j}\right)\right]^{\frac{3}{2}}
\end{gathered}
$$


Given 3 equations of the form of Eq. $3 \mathrm{~A}$,

$$
\begin{aligned}
& \ln k_{11}+\ln k_{22}=A_{12} \\
& \text { In } k_{11}+\ln k_{33}=A_{13} \\
& \text { ln } k_{22}+\ln k_{33}=A_{23}
\end{aligned}
$$

the following solutions for $k_{11}, k_{22}$, and $k_{33}$ are obtained:

$$
\begin{aligned}
& k_{11}=\exp \left[\left(A_{12}+A_{13}-A_{23}\right) / 2\right] \\
& k_{22}=\exp \left[\left(A_{12}+A_{23}-A_{13}\right) / 2\right] \\
& k_{33}=\exp \left[\left(A_{13}+A_{23}-A_{12} / 2\right]\right.
\end{aligned}
$$

For more than three related equations the solutions are over-determined and are best obtained by a computer fit of Eq. 3A. A program to do this has been written ${ }^{1}$ and is 1isted here.

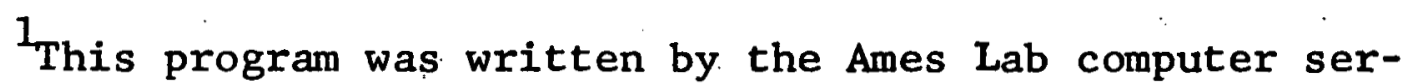
vice group, Iowa State University, Ames, Iowa. 


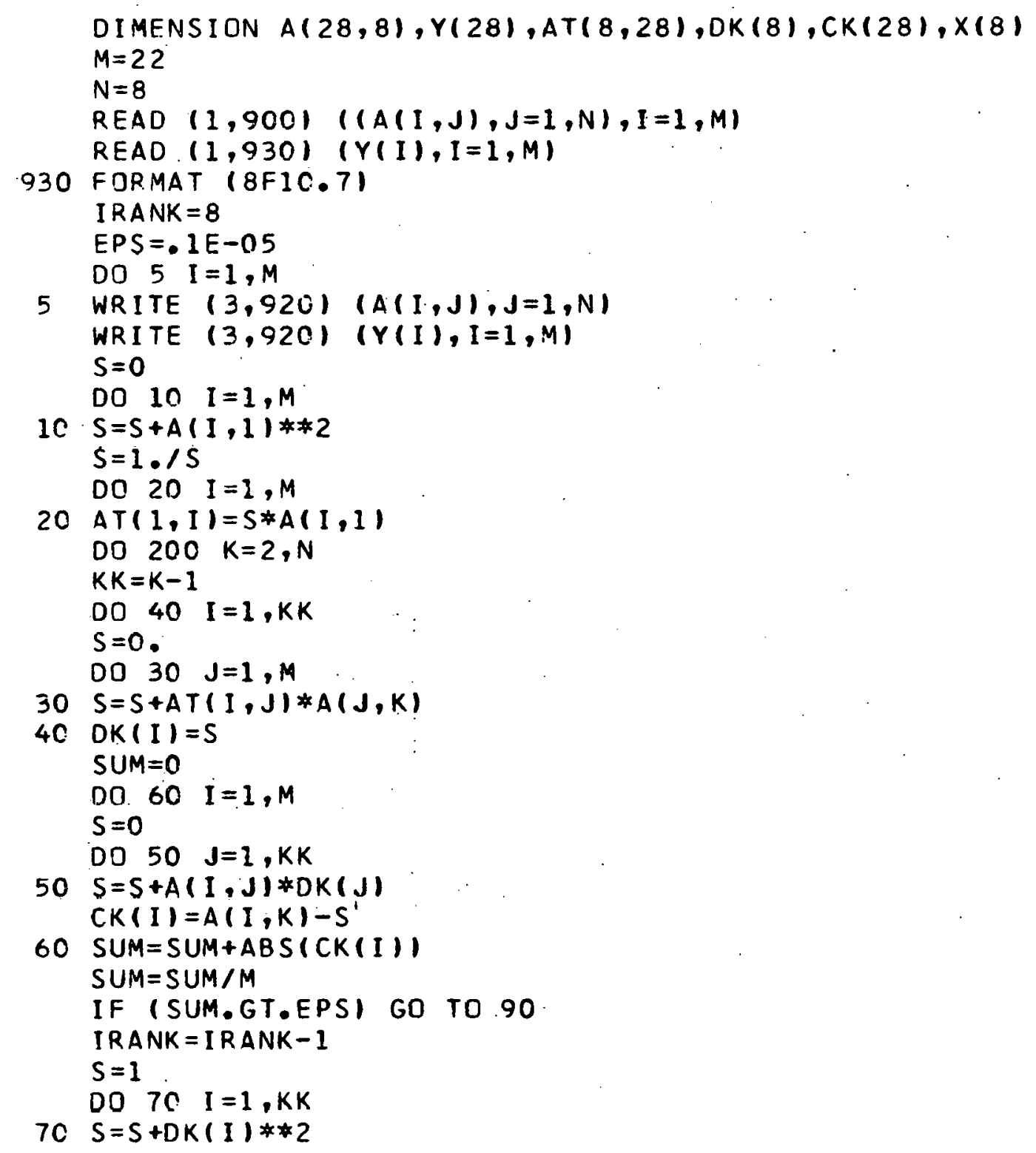




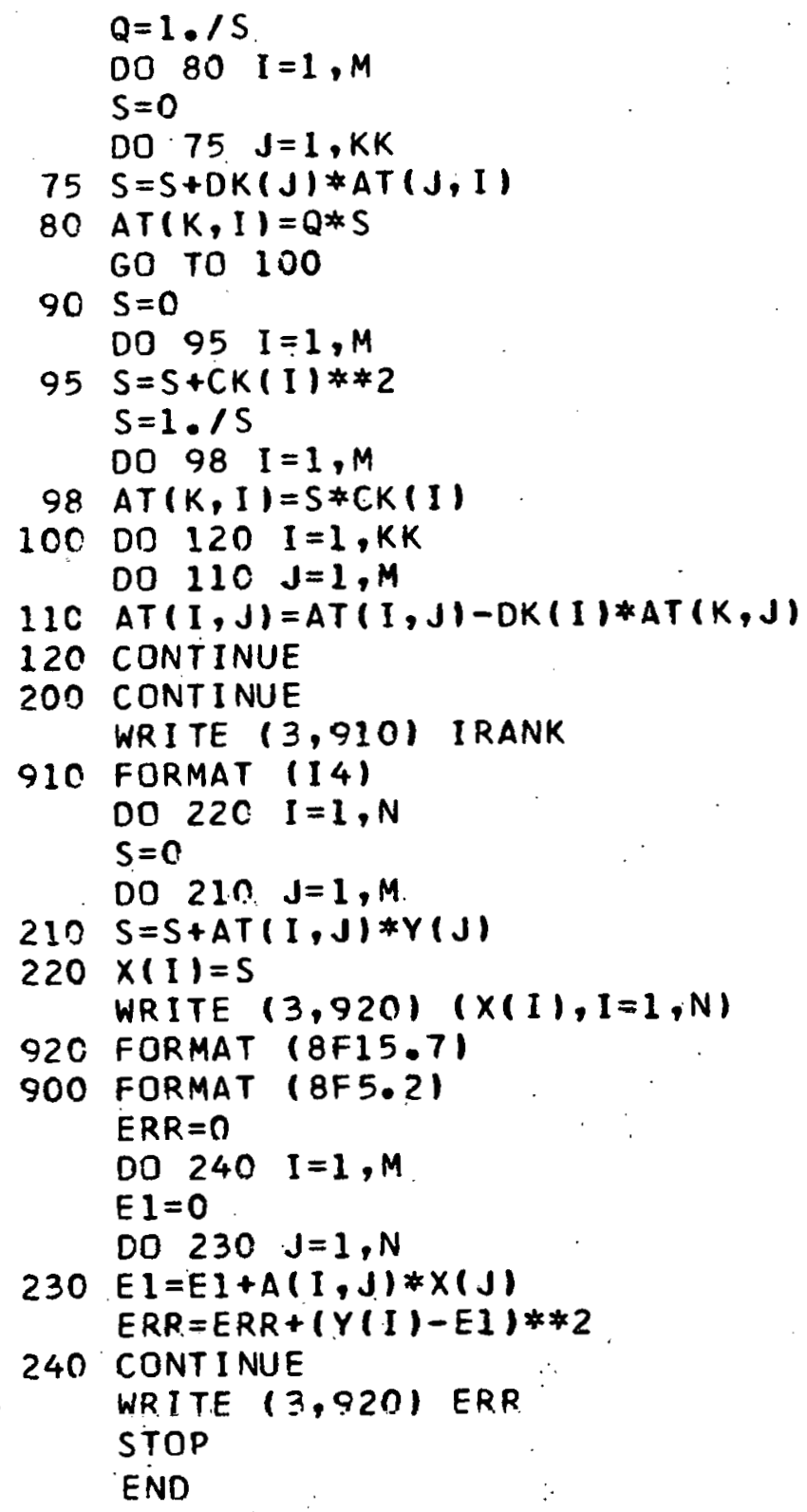


For this program $\underline{M}$ is the number of equations like Eq. $3 A$ to be fit and $\underline{N}$ is the highest value of $i$ and $j$.

A data deck consists of $\underline{M}$ cards block loaded in $\underline{N} 5.2$ format. Each card contains the coefficient either 1 or 0 for the $\underline{N} i$ and $j$ in the $\underline{N}$ columns. These $\underline{M}$ cards are followed by the $\underline{M} A_{i j}$ values loaded in $8 F 10.7$ format.

For example, for $M=22$, and $N=8$ if the first equation like Eq. $3 \mathrm{~A}$ is: $\ln \mathrm{k}_{11}+\ln \mathrm{k}_{22}=10.0$ the first card in the data deck would contain a 1 in columns one and six and a decimal in columns two and seven. Card 23 would have 1,0 , and a decimal in columns one, two, and three respectively. If the $22 n d$ equation is: $\ln \mathrm{k}_{55}+\ln \mathrm{k}_{88}=30.0$; then the $22 \mathrm{nd}$ card in the data deck would contain a 1 in columns 21 and 36 and a decimal in columns 22 and 37 . The last value on the last card would then contain 30.0 in $8 \mathrm{~F} 10.7$ format. 


\section{BIBLIOGRAPHY}

1. G. Lang, Masters Thesis, Washington University, Saint Louis, Missouri, 1956.

2. M. Dietrich, Ph.D. Thesis, Washington University, Saint Louis, Missouri, 1962.

3. D. R. Stranks, Disc. Faraday Soc., 29, 73 (1960).

4. A. V. Savitsky and Y. K. Syrkin, Dok1. Akad. Nauk SSSR, 120, 119 (1958).

5. F. R. Duke and W. W. Lawrence, Iowa State J. Sci., $\underline{38}$ (3), 299 (1964).

6. F. R. Duke and N. C. Peterson, J. Phys. Chem., 67, 531 (1963).

7. W. L. Reynolds and R. W. Lumry, Mechanisms of Electron Transfer, Ronald Press, New York, 1966.

8. (a) R. A. Marcus, Disc. Faraday Soc., 29, 21 (1960);

(b) J. Phys. Chem., 67, 853 (1963);

(c) Ann. Rev. Phys. Chem., 15, 155 (1964);

(d) J. Chem. Phys., 43, 679 (1965);

(e) ibid., 24, 966 (1956);

(f) ibid., $\underline{26}, 867$ (1957);

(g) N. Sutin, Accounts Chem. Res., 1, 225 (1968).

9. G. Dulz and N. Sutin, Inorg. Chem., 2, 917 (1963).

10. M. H. Ford-Smith and N. Sutin, J. Amer. Chem. Soc., 83, 1830 (1961).

11. H. Diebler and N. Sutin, J. Phys. Chem., 68, 174 (1964).

12. R. J. Campion, N. Purdie, and N. Sutin, Inorg. Chem., $\underline{3}$, 1091 (1964).

13. M. F. Hawthorne, D. C. Young, T. D. Andrews, D. V. Howe, R. L. Pilling, A. D. Pitts, M. Reintjes, L. F. Warren, Jr., and P. A. Wegner, J. Amer. Chem. Soc., 90, 879 (1968). 
14. J. C. D. Brand and W. Snedden, Trans. Faraday Soc., 53, 894 (1957).

15. P. H. Harju and N. C. Peterson, North Dakota Acad. Sci., XI (1957).

16. T. D. Smith, J. Inorg. Nuc1. Chem., 14, 290 (1960).

17. V. Weinmayr, J. Amer. Chem: Soc., 77, 3012 (1955).

18. (a) H. Shechter and J. F. Helling, J. Org. Chem., 26, 1034 (1961);

(b) M. Rosenbilum, Chemistry of Iron Group Metallocenes, Interscience, New York, Part I, 1965, pp. 33, 40,

19. R. Reinschneider and D. Helm, Z. Naturforsch, 146, 811814 (1959).

20: L. T. Reynolds and G. Wilkinson, J. Inorg. Nuc1. Chem., 9, 86 (1959).

21. E. L. DeYoung, J. Org. Chem., 26, 1312 (1961).

22. K. Sch $\log 1$, A. Mohar, and M. Peterlik, Monatsch. Chem., 92, 921 (1961).

23. A. N. Nesmeyanov and N. A. Vol'kenan, Dok1. Akad. Nauk SSSR, 107, 262 (1956).

24. A. N. Nesmeyanov, E. G. Peravalova, R. V. Golovnya, and O. A. Nesmeyanova, Dokl. Akad. Nauk SSSR, 97, 459 (1954).

25. J. K. Lindsay and C. R. Hauser, J. Org. Chem., 22, 355 (1957).

26. P. L. Pauson, J. Amer. Chem. Soc., 76, 2187 (1954).

27. A. N. Nesmeyanov; E. G. Perevalora, and O. A. Nesmeyanova, Dok1. Akad. Nauk SSSR, 100, 1099 (1955).

28. (a) M. Rosenblum; R. W. Santer, and W. G. Howells, J. Amer. Chem. Soc., 85, 1450 (1963);

(b) R. Prinz, Mo1. Phys., 19, 603 (1970). 
29. (a) T.. Kuwana, D. E. Bublitz, and G. L. K. Hoh, J. Amer. Chem. Soc., 82, 5811 (1960);

(b) Chem. Ind., 635 (1959).

30. D. W. Ha1l and C. D. Russell, J. Amer. Chem. Soc., 89, 2316 (1967).

31. (a) M. F. Hawthorne, D. C. Young, and P. Wegner, J. Amer. Chem. Soc., 87, 1818 (1965).

(b) M. F. Hawthorne and R. L. Pilling, ibid., 7, 3987 (1965).

32. W. C. Pierce, E. L. Haenisch, and D. T. Sawyer, Quantitative Analysis, Wiley, New York, 1958, p. 315.

33. J. G. Mason, M. Rosenblum, J. Amer. Chem. Soc., 74, 6149 (1960).

34. J. A. Page and G. Wilkinson, J. Amcr. Chem. Soc., 74, 6149 (1952).

35. D. W. Kemp and E. L. King, J. Amer. Chem. Soc., $\underline{89}, 3433$ (1967).

36. A. A. Frost and R. G. Pearson, Kinetics and Mechanisms, Wiley, New York, 1961, pp. 187,8.

37. (a) G. P. Haight, Jr., D. C. Henderson, and N. H. Coburn, Inorg. Chem., $\underline{3}, 1777$ (1964);

(b) J. Y. Tong, ibid., $\underline{3}, 1804$ (1964).

38. J. R. Pladziewicz and J. H. Espenson, Inorg. Chem., 10, 634 (1971).

39. R. Livingston, in Techniques of Organic Chemistry, S. L. Friess, E. S: Lewis, and A. Weissberger, Ed., Interscience, New York, 1961, Vol. 8, Part I, p. 45.

40. R. A. Horne, Ph.D. Thesis, Columbia University, New York, New York, 1955.

41. J. H. Espenson, Accounts Chem. Res., 3 , 347 (1970). 


\section{$90 \mathrm{~b}$}

42. T. K. Kuwana, D. E. Bublitz, and G. Hoh, J. Amer. Chem. Soc., 82,5811 (1960).

43. T. J. Curphey, J. O. Santer, M. Rosenblum, and J. H. Richards, J. Amer. Chem. Soc., 82, 5249 (1960). 